\title{
UNIVERSIDADE DE SÃO PAULO ESCOLA DE ENFERMAGEM DE RIBEIRÃO PRETO
}

\author{
ANA MARIA DA SILVEIRA RODRIGUES
}

Avaliação do acesso ao diagnóstico e tratamento de tuberculose na perspectiva dos indivíduos coinfectados ou não pelo HIV, São José do Rio Preto-SP 


\section{ANA MARIA DA SILVEIRA RODRIGUES}

Avaliação do acesso ao diagnóstico e tratamento de tuberculose na perspectiva dos indivíduos coinfectados ou não pelo HIV, São José do Rio Preto-SP

Dissertação apresentada à Escola de Enfermagem de Ribeirão Preto da Universidade de São Paulo para obtenção do título de Mestre junto ao Programa de Pós-Graduação em Enfermagem Fundamental.

Linha de pesquisa: "Doenças Infecciosas: problemática e estratégias de enfrentamento”..

Orientadora: Profa. Dra. Elucir Gir

\section{Ribeirão Preto}


Autorizo a reprodução e divulgação total ou parcial deste trabalho, por qualquer meio convencional ou eletrônico, para fins de estudo e pesquisa, desde que citada a fonte.

Rodrigues, Ana Maria da Silveira

Avaliação do acesso ao diagnóstico e tratamento de tuberculose na perspectiva dos indivíduos coinfectados ou não pelo HIV, São José do Rio Preto-SP / Ana Maria da Silveira Rodrigues

Ribeirão Preto, 2009

$93 \mathrm{f.}$

Dissertação (Mestrado) - Programa de Pós-Gradação em Enfermagem Fundamental - Escola de Enfermagem de Ribeirão Preto da Universidade de São Paulo - USP

Linha de Pesquisa: "Doenças Infecciosas: problemática e estratégias de enfrentamento"

Orientadora: Profa. Dra. Elucir Gir

1. Tuberculose; 2. HIV; 3. Acesso aos Serviços de Saúde. 
Nome: RODRIGUES, Ana Maria da Silveira

Título: Avaliação do acesso ao diagnóstico e tratamento de tuberculose na perspectiva dos indivíduos coinfectados ou não pelo HIV, São José do Rio Preto-SP.

Dissertação apresentada à Escola de Enfermagem de Ribeirão Preto da Universidade de São Paulo para obtenção do título de Mestre junto ao Programa de Pós-Graduação em Enfermagem Fundamental.

Aprovado em:

\section{Banca Examinadora}

Prof. Dr. Instituição:

Julgamento: Assinatura:

Prof. Dr. Instituição:

Julgamento: Assinatura:

Prof. Dr. Instituição:

Julgamento: Assinatura: 
Aos meus pais,

\section{Alonso da Silveira e Maria Ferreira de Oliveira}

(in memorian)

Toda minha gratidão pelo exemplo de perseverança, pela preocupação e empenho com a formação pessoal da filha, oferecendo aquilo que acreditava ser sabido e duradouro, sem medir sacrifícios para tal. Trago sempre comigo seus ensinamentos, dentro do meu coração.

Saudades...

Ao meu filho Pedro Augusto, quem eu amo acima de todas as coisas, grande presente de Deus e meu maior projeto de vida. Mesmo sem entender a minha ausência na realização desse trabalho, sempre me recompensou com alegria e muito amor.

Ao meu esposo Elson, pelo amor que nos une, companheiro de todas as horas, que acreditou e compartilhou a realização desse trabalho. 
À Profa. Dra. Elucir Gir, minha orientadora, pela confiança em mim depositada, paciência, amizade, por estar sempre pronta para compartilhar comigo seus conhecimentos e por abrir as portas para me receber com carinho e respeito. Sinceros agradecimentos e obrigada pelo apoio na realização desta dissertação.

À Profa. Dra. Lúcia Maria Scatena pela imensa contribuição e ensinamentos nas análises estatísticas desse trabalho. A sua contribuição torna mais proveitosa nossa jornada.

À Profa. Dra. Silvia Helena Figueiredo Vendramini, por acreditar na minha capacidade, por estar ao meu lado nesta dissertação. Saiba que tenho por você o maior respeito e admiração, não só por seus conhecimentos, mas principalmente pela humildade e sabedoria com que você os compartilha. Que Deus a ilumine sempre. 
A Deus, pela vida, pela serenidade, pelo equilíbrio, pela sabedoria, por me permitir que mais um objetivo na minha vida fosse alcançado. Nele busquei forças nos momentos mais difíceis.

Aos meus familiares, que foram companheiros nos momentos tristes e alegres de minha vida, pelo apoio, incentivo, por acompanhar minha trajetória, por compartilhar a vida, sempre muito presentes.

À Profa. Dra. Tereza Cristina Scatena Villa, pelo acolhimento, pelas sugestões no inicio da pesquisa, pela acessibilidade ao banco de dados do grupo GEOTB.

À Profa. Dra. Claudia Bernardi Cesarino, amiga e comadre de todas as horas, por ter compartilhado todos os momentos dessa trajetória, sempre com palavras enaltecedoras, seu apoio e incentivo foram de grande valia.

Aos docentes e funcionários, colegas do Curso de Graduação em Enfermagem da Faculdade de Medicina de São José do Rio Preto/SP pelo apoio e contribuições durante a trajetória da minha vida profissional.

As Professoras Lúcia, Ligia, Roseli amigas e companheiras de departamento, pelo apoio, incentivo, troca de experiências e os momentos de compartilhar a vida.

As minhas colegas de pós-graduação: Carla; Maria Amélia; Marília; Elisangela; Maria Eugênia; Daniela Bezerra; Ariane e Eliana Cavalari, pessoas especiais, foi muito bom compartilhar com vocês.

\section{À Escola de Enfermagem de Ribeirão Preto da Universidade de São Paulo - EERP/USP, que me acolheu e permitiu a conquista deste título.}

A bibliotecária Rosangela pela correção bibliográfica.

$\checkmark \quad$ E a todos que colaboraram direta ou indiretamente para a realização deste trabalho e que, por ventura, seus nomes não foram citados.

\section{Obrigada!}


RODRIGUES, A. M. S. Avaliação do acesso ao diagnóstico e o tratamento de tuberculose na perspectiva dos indivíduos coinfectados ou não pelo HIV, São José do Rio Preto-SP. 2009. 93 f. Dissertação (Mestrado) - Programa de Pós-Gradação em Enfermagem Fundamental - Escola de Enfermagem de Ribeirão Preto da Universidade de São Paulo USP, 2009.

Objetivos: O objetivo deste estudo foi avaliar o acesso ao diagnóstico e ao tratamento de doentes com Tuberculose e coinfectados pelo HIV, no município de São José do Rio PretoSP. Materiais e Métodos: Trata-se de uma pesquisa avaliativa, de abordagem quantitativa que utilizou o modelo de estudo transversal. Foram entrevistados 106 doentes no período de junho de 2006 a julho de 2007, que estavam em tratamento nas Unidades de Saúde que desenvolvem o Programa de Controle da Tuberculose (PCT) do município. Utilizou-se o instrumento "Primary Care Assessment Tool," adaptado para atenção à tuberculose. Para análise dos dados foram usadas técnicas de estatística descritiva como análise de freqüência, média, desvio-padrão, intervalo de confiança, teste $t$ de Student e teste de Mann-Whitney Resultados: Dos 106 doentes entrevistados, 11 foram excluídos por não terem sido submetidos ao teste de anti HIV Desta forma 95 doentes participaram deste estudo, sendo que 76,8\% apresentavam TB e não-coinfecção pelo HIV e 23,2\% apresentavam TB e coinfecção pelo HIV. A maioria (66,3\%) era do sexo masculino, 69,5\% possuia ensino fundamental, $50,5 \%$ declarou residir em casa própria e $98,9 \%$ possuia casa de alvenaria. A partir dos dados observados houve diferenças estatisticamente significativas quanto as variáveis acesso ao diagnóstico cujos doentes com TB e coinfectados quase nunca ou às vezes procuram o posto de saúde mais próximo da residência e os doentes com TB quase sempre procuram o posto de saúde mais próximo da residência. Como também, houve diferenças estatisticamente significativas no acesso ao tratamento sendo que, o profissional da saúde visita mais vezes os doentes acometidos pela coinfecção quando comparados com os doentes que não apresentam a coinfecção e os doentes coinfectados quase nunca realizam o tratamento da doença em um posto de saúde perto da residência. Considerações finais: Os resultados do estudo apontam para a necessidade de maior integração e comunicação entre o PCT e o DST/Aids, fator este, considerado como facilitador tanto no acesso dos doentes ao diagnóstico quanto ao tratamento da doença.

Palavras-chave: Tuberculose, HIV, Acesso ao Serviço de Saúde. 
RODRIGUES, A. M. S. Assessment of The Access to Tuberculosis Diagnose and Treatment from the Individuals Co-infected or Not with HIV in São José do Rio Preto, SP. 2009. 93 p. Master Thesis - Fundamental Nursing Post-Graduation Program - Univesity of São Paulo at Ribeirão Preto College of Nursing - USP, 2009.

Objetives: The aims of this study were to characterize the patients with Tuberculosis and coinfected with AIDS as to their sociodemographic aspects (gender, schooling, place of living and type of residence); to analyze the access to the diagnose and treatment of these patients; to identify the disagreements among groups of patients with TB and those co-infected with TB/AIDS regarding the access to diagnose and treatment and in this way to evaluate the access to diagnose and treatment of persons with Tuberculosis and co-infected with HIV living in São José do Rio Preto, São Paulo State. Material and Methods: This is an evaluative research with a quantitative approach using a cross-sectional study model developed at the Health Units developing the Tuberculosis Control Program (TCP) in São José do Rio Preto. The patients received medical attention from June 2006 to June 2007. Techniques of descriptive analysis were used to analyze the data, such as frequency analysis, mean (average), standard deviation, and confidence interval. Results: Of the 106 patients interviewed 11 were excluded because they have not done the anti-HIV test. Therefore, the study population was composed of 95 patients. Of these, $76.8 \%$ presented TB and not coinfection with HIV, and $23.2 \%$ presented both TB and co-infection with HIV. The majority (66.3\%) was male, 69.5\% have Elementary Education, 50.5\% reported to be homeowners, and $98.9 \%$ live in a brick-made house. From these results, we can imply that there were statistically significant differences as to the variables access to diagnose of those patients with TB and those co-infected who hardly ever or sometimes seek for the nearest Health Unit, and the patients with TB who most of the time seeks for the nearest Health Unit. There have been also statistically significant differences as to the access to treatment once the health professional visits more times the patients with co-infection in comparison to the patients who did not present co-infection and those co-infected. The co-infected patients hardly ever receive treatment at the nearest Health Unit. Final Comments: The study results point out to the necessity of a greater integration and communication between both programs TCP and sexually transmitted disease - aids (STD/AIDS). This factor is considered as a facilitator to both the access of patients to diagnose and treatment of the disease.

Key Words: Tuberculosis, HIV, Access to Health Services 
RODRIGUES, A. M. S. Evaluación del acceso al diagnóstico y al tratamiento de tuberculosis en la perspectiva de los individuos coinfectados o no por el VIH, São José do Rio Preto-SP. 2009. 93 f. Disertación (Maestría) - Programa de Posgrado en Enfermería Fundamental - Escuela de Enfermería de Ribeirão Preto de la Universidad de São Paulo USP, 2009.

Objetivos: El objetivo de este estudio ha sido evaluar el acceso al diagnóstico y al tratamiento de enfermos con Tuberculosis y coinfectados por el VIH, en la ciudad de São José do Rio Preto- SP. Materiales y Métodos: Dicha investigación es evaluativa, de abordaje cuantitativo que ha utilizado el modelo de estudio transversal. Se han entrevistado 106 enfermos entre junio de 2006 y julio de 2007, que eran tratados en las Unidades de Salud que desarrollan el Programa de Control de la Tuberculosis (PCT) de la ciudad. Se ha utilizado el instrumento "Primary Care Assessment Tool," adaptado para la atención a la tuberculosis. Para análisis de los datos se han utilizado técnicas de estadística descriptiva como análisis de frecuencia, promedio, desvío-patrón, intervalo de confianza, prueba $t$ de Student y prueba de MannWhitney. Resultados: De los 106 enfermos entrevistados, se excluyeron 11 por no haber sido sometidos a la prueba de anti VIH. Así, han participado de este estudio 95 enfermos, de los cuales el 76,8\% presentaba TB y no-coinfección por VIH y el 23,2\% presentaban TB y coinfección por VIH. La mayoría (el 66,3\%) era del sexo masculino, el 69,5\% poseía enseñanza fundamental, el 50,5\% declaró residir en vivienda propia y el 98,9\% poseía casa de albañilería. A partir de los datos observados hubo diferencias estadísticamente significativas en cuanto a las variables acceso al diagnóstico cuyos enfermos con TB y coinfectados casi nunca o a veces buscan la unidad de salud más cercana a la residencia y los enfermos con TB casi siempre buscan la unidad de salud más cercana a la residencia. De la misma manera, hubo diferencias estadísticamente significativas en el acceso al tratamiento ya que el profesional de la salud visita más veces a los enfermos aquejados por la coinfección cuando comparados a los enfermos que no presentan la coinfección y los enfermos coinfectados casi nunca realizan el tratamiento de la enfermedad en una unidad de salud cerca de la residencia. Consideraciones finales: Los resultados del estudio señalan la necesidad de mayor integración y comunicación entre el PCT y el DST/Sida. Dicho factor es considerado como fomentador tanto en el acceso de los enfermos al diagnóstico, como al tratamiento de la enfermedad.

Palabras-Clave: Tuberculosis, VIH, Acceso al Servicio de Salud. 
Figura 1. Média, desvio-padrão e intervalos de confiança (95\%), dos escores das variáveis que compõem o acesso ao diagnóstico por indivíduos com Tuberculose.

Figura 2. Média, desvio-padrão e intervalos de confiança (95\%),dos escores das variáveis que compõem o acesso ao diagnóstico por indivíduos coinfectados com tuberculose e HIV

Figura 3. Média, desvio-padrão e intervalos de confiança (95\%), dos escores das varáveis que compõem o acesso ao tratamento por indivíduos com tuberculose.

Figura 4. Média, desvio-padrão e intervalos de confiança (95\%), dos escores das variáveis que compõem o acesso ao tratamento por indivíduos coinfectados por tuberculose e HIV..... 
Tabela 1. Caracterização sócio-demográfica dos indivíduos com tuberculose (TB) e coinfectados tuberculose - vírus da imunodeficiência humana (TB-HIV). São José do Rio Preto-SP, 2006-2007

Tabela 2. Distribuição percentual associativa da coinfecção (TB/HIV) em relação ao sexo São José do Rio Preto-SP, 2007.

Tabela 3. Distribuição percentual associativa da coinfecção em relação ao local onde os doentes analisados vivem São José do Rio Preto-SP, 2007.

Tabela 4. Estatísticas descritivas referentes ao acesso ao diagnóstico dos doentes avaliados no período de 2006-2007

Tabela 5. Estatísticas descritivas referentes ao acesso ao tratamento dos pacientes avaliados, São José do Rio Preto,2006-2007. 


\begin{tabular}{|c|c|}
\hline AIDS & - Síndrome da Imunodeficiência Adquirida \\
\hline APS & - Atenção Primaria a Saúde \\
\hline AR & - Ambulatórios de Referência \\
\hline CAPS & - Centro de Atenção Psicossocial \\
\hline $\mathrm{CNPq}$ & - Conselho Nacional de Desenvolvimento Científico e Tecnológico \\
\hline CTA & - Centro de Testagem e Aconselhamento \\
\hline DOTS & - Directly Observed Treatment Short-Course \\
\hline DST & - Doença Sexualmente Transmissível \\
\hline GEOTB & - Grupo de Estudo Epidemiológico-Operacional em TB \\
\hline HIV & - Vírus da Imunodeficiência Humana \\
\hline NGA-60 & - Núcleo de Gestão Ambulatorial \\
\hline NOA & - Normas Operacionais de Assistência \\
\hline NOB & - Normas Operacionais Básica/96 \\
\hline OMS & - Organização Mundial da Saúde \\
\hline ONG & - Organização não Governamental \\
\hline PCAT & - Primary Care Assessment Tool \\
\hline PCT & - Programa de Controle da TB \\
\hline PNCT & - Programa Nacional de Controle da TB \\
\hline REDE TB & - Rede Brasileira de Pesquisa em Tuberculose \\
\hline SAE & - Serviço de Assistência Especializada \\
\hline SINAM & - Sistema Nacional de Atendimento Médico \\
\hline SUS & - Sistema Único de Saúde \\
\hline TB & - Tuberculose \\
\hline TB Web & - Sistema de Controle de Pacientes com Tuberculose, on line \\
\hline UBS & - Unidades Básicas de Saúde \\
\hline UBSF & - Unidade Básica de Saúde da Família \\
\hline
\end{tabular}




\section{SUMÁRIO}

1. INTRODUÇÃ

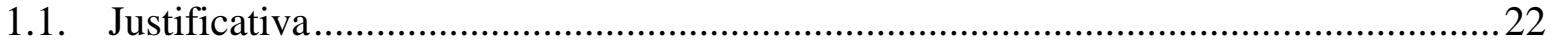

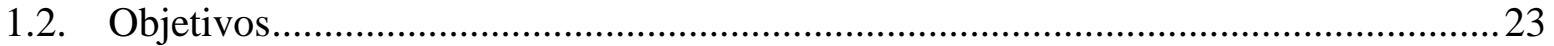

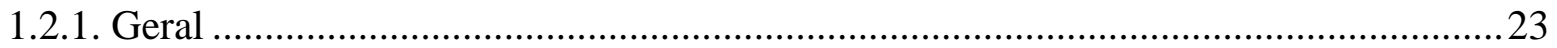

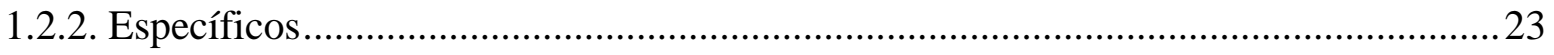

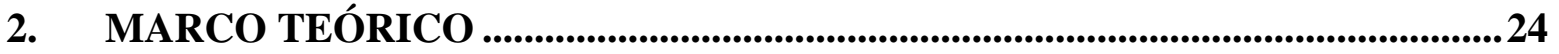

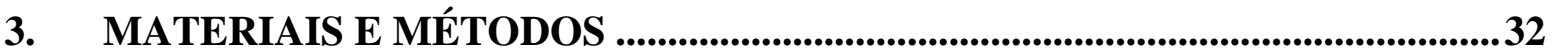

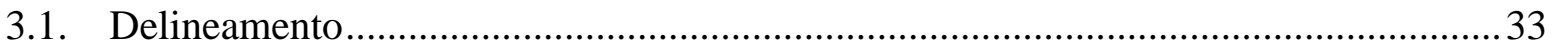

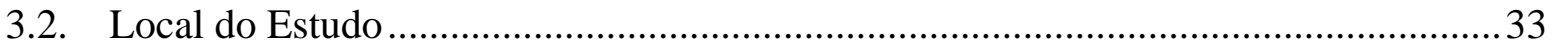

3.3. Políticas Públicas de Saúde em TB no município de São José do Rio Preto ...............33

3.3.1. Processo de Descentralização do Programa de TB .....................................................35

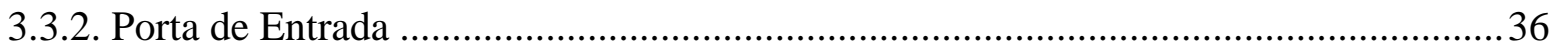

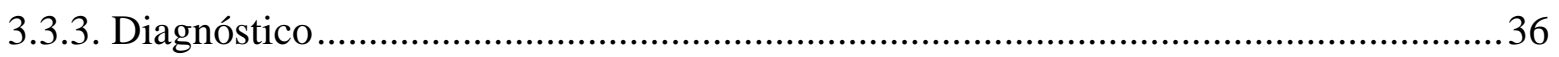

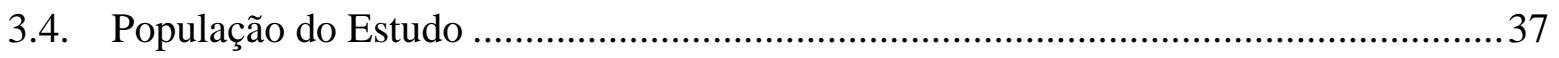

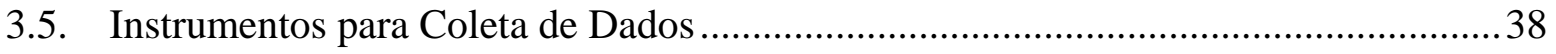

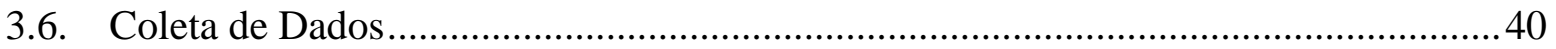

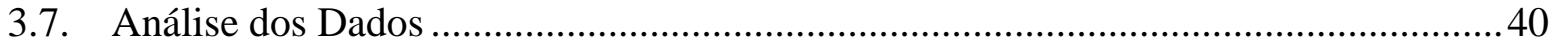

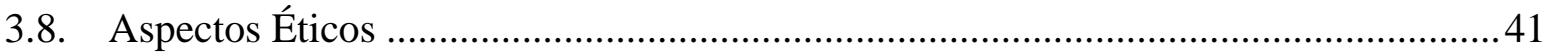

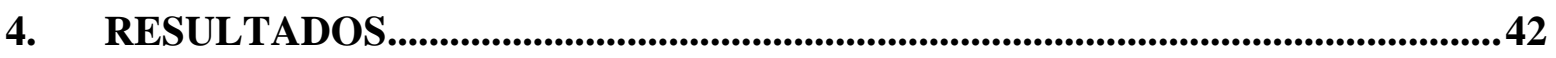

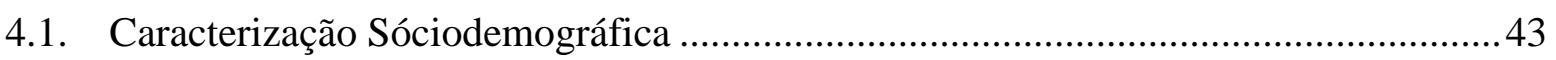

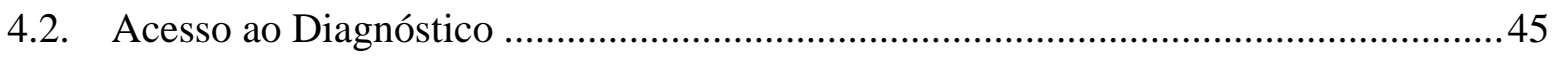

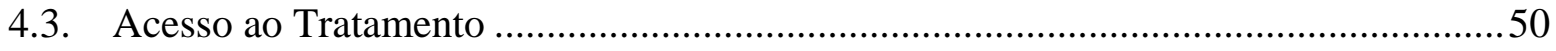

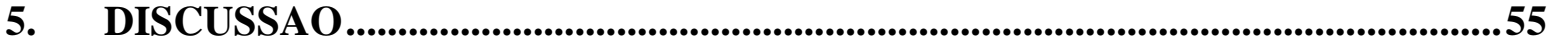

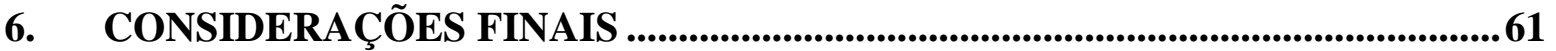

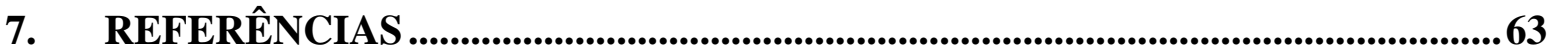

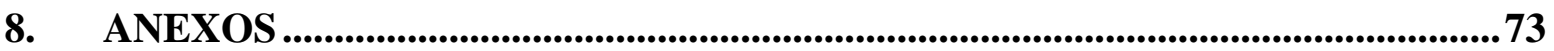

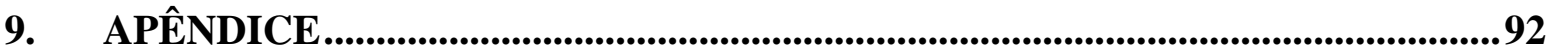




\section{APRESENTAÇÃO}

O presente estudo faz parte do Projeto Integrado de Pesquisa: CNPq Edital Doenças Negligenciadas, processo 410547/2006-9, intitulado “Avaliação das dimensões organizacionais e de desempenho dos serviços de atenção básica no controle da tuberculose (TB) em centros urbanos de diferentes regiões do Brasil”, resultado da colaboração de pesquisadores da Área Epidemiológica e Operacional da Rede Brasileira de Pesquisa em Tuberculose - REDE TB, da Escola de Enfermagem e Faculdade de Medicina de Ribeirão Preto da Universidade de São Paulo, Faculdade de Medicina de São José do Rio Preto (FAMERP), Universidade Federal do Rio de Janeiro, Universidade Estadual da Paraíba, Universidade Federal da Paraíba e Universidade Estadual de Feira de Santana. Tem como propósito buscar apoio para avançar no estudo da temática Atenção à TB em sistemas de saúde, objeto do Grupo de Estudo Epidemiológico-Operacional em TB (GEOTB/CNPq).

Esta pesquisa teve como fundamento avaliar os elementos estruturais de um sistema de saúde com base na Atenção Primária à Saúde, denominada, no Brasil, como Atenção Básica, elegendo os atributos ou dimensões essenciais: acesso, elenco de serviços, vínculo ou longitudinalidade, coordenação da atenção, enfoque familiar, orientação na comunidade e formação profissional para avaliar o desempenho dos Serviços de Saúde na atenção à TB utilizando os instrumentos componentes do Primary Care Assessment Tool (PCAT) (BRASIL, 2006), formulados e validados para avaliação rápida das características organizacionais e de desempenho dos serviços de Atenção Básica e adequado para as ações do Programa de Controle da TB (PCT) (VILLA e RUFFINO-NETTO, 2009). 


\section{INTRODUÇÃO}

Ao longo da história milenar das doenças sexualmente transmissíveis (DST), o estigma e o preconceito sempre se fizeram presentes, a ponto de se constituírem numa interferência negativa nas questões do seu enfrentamento (REIS; GIR; 2002)

A tuberculose (TB) é uma doença negligenciada e vêm sendo considerada ao longo da história da humanidade um grave problema de saúde pública, atingindo cidadãos socialmente vulneráveis, destacando-se pela sua magnitude, principalmente pelo aumento de sua incidência (RUFFINO-NETTO, 2002). Apesar da descoberta de drogas eficazes para o seu tratamento e programas de controle eficientes a doença, contudo mantém características que tornam inviáveis, atualmente, a sua eliminação.

A TB ainda é uma das principais causas de morte no mundo inteiro. Segundo estimativas da Organização Mundial da Saúde (OMS), o Brasil apresentou 92 mil novos casos de TB no ano de 2007, ocupando o $14^{\circ}$ lugar entre os 22 países com a mais alta carga de TB notificada no mundo. A taxa de coinfecção TB e Vírus da Imunodeficiência Humana (HIV foi de 14 por 100.000 habitantes e a taxa de mortalidade por todas as formas de TB foi de 4 por 100.000 habitantes no mesmo ano, sendo que a taxa de mortalidade por TB/HIV foi 1 por 100.000. Em 2006, a taxa de sucesso do Directly Observed Treatment Short-Course (DOTS) foi de $72 \%$ sendo, 33\% de cura e 39\% completado (WORLD HEALTH ORGANIZATION, 2009).

O município de São José do Rio Preto apresentou em 2006, um coeficiente de TB de todas as formas, de 39,25/100.000 habitantes, sendo que em 2007 este coeficiente aumentou para 43,02. No mesmo período de taxa de óbito foi de 14,6 e 11,0\% respectivamente; e o abandono foi de 5,1\% em 2006 e 4\% em 2007 (SÃO JOSÉ DO RIO PRETO, 2008)

Os fatores que colaboram para esta atual situação são pobreza, educação precária, habitação ruim/inexistente, desnutrição, alcoolismo, sub-financiamento de programas da saúde pública, epidemia da aids, multirresistência às drogas, além do envelhecimento da população e os grandes movimentos migratórios (RUFFINO-NETTO, 2002). Agravam ainda este quadro, a organização e qualidade do serviço de saúde, que compromete o acesso aos serviços de saúde, a falha na distribuição de drogas antituberculosas e a falta de pessoal 
treinado para o diagnóstico, notificação e o acompanhamento do paciente com TB (ALVES; SANTANA; CUNHA; 2000).

Entretanto, apesar do aumento dos números de detecção de casos, o Brasil encontra-se longe de alcançar as metas propostas pela OMS, isso porque, em uma série histórica, observou-se queda considerável de 50\% nessas taxas, haja vista que em 1998 era de $80 \%$ e em 2006 não ultrapassou $40 \%$ evidenciando desta forma, que muitos casos de TB não descobertos continuam infectando outras pessoas (DYE; WATT; BLEED, 2002; WHO, 2005).

Nas últimas décadas, o controle da TB foi fortemente negligenciado. As políticas públicas na área da saúde foram direcionadas para outros campos de atuação e, consequentemente, as ações de combate à TB foram relegadas a segundo plano, por ser considerada como um problema sob controle (RUFINO-NETTO, 2002). Outra autora Lucca (2008), ressalta que o esperado da área de saúde é que os serviços estejam acessíveis, estruturados e organizados, para facilitar o atendimento para aqueles que demandam os serviços, como também para aqueles que não buscam os serviços de saúde, a fim de diagnosticar, tratar e curar os doentes de TB, bem como prevenir novos casos da doença e proteger populações vulneráveis à TB e suas formas multirresistentes. Segundo a OMS os atuais desafios mundiais para o controle da TB são: impacto do HIV na TB, multidroga resistência no tratamento de TB, debilidades dos sistemas de saúde não utilização de trabalhadores comunitários, médicos privados não comprometidos, serviços de atenção primária com resposta insuficiente e sistema prisional desligados do DOTS (ORGANIZAÇÃO PANAMERICANA DE LA SAÚDE, 2004).

A TB pulmonar configura-se como uma doença de fácil diagnóstico, entretanto muitos países em desenvolvimento enfrentam grandes desafios para seu controle, verificados pelo aumento no número de internações (WORLD HEALTH ORGANIZATION, 2005). Outros autores afirmam que o diagnóstico da TB ainda é tardio no Brasil, e este fato dificulta a notificação e controle da doença (SELIG, et al., 2004; CAVALCANTI et al., 2006; JAMAL; MOHERDAUI, 2007; HANE et al, 2007), o que contribui para o aumento do risco de transmissão da doença, principalmente em ambientes urbanos, além de diminuir a chance de cura do doente de TB (LEUNG; LEUNG; TAM, 2007).

Em populações com educação precária e baixa renda, o diagnóstico tardio de TB está relacionado às dificuldades de acesso aos serviços de saúde (MUNIZ et al.,2005; JARAMILHO, 1999; SANCHEZ, 2007), e isso pode estar relacionado ao doente, bem como à 
organização dos serviços de saúde, que por sua vez contribuem para o aumento na demora para realização deste diagnóstico (OLIVEIRA et al., 2009).

Por ser uma doença crônica, seus sintomas são confundidos com os de outras doenças, aumentando, assim, o tempo de exposição, dificultando a confirmação diagnóstica quando a pesquisa direta do bacilo em secreção respiratória é negativa, dependendo, então, de cultura em meio específico, que pode demorar até 60 dias. (FRANCO, 2003).

Tendo em vista a progressão da doença, é imprescindível que atenção especial seja dada à sua disseminação, pois a mesma demonstra uma grande habilidade em ressurgir, mesmo depois de um longo período de estabilidade (BERTAZONE; GIR, 2000).

Segundo as Normas Operacionais de Assistência a Saúde (NOAS) 01/02, a TB consiste em uma doença que deve ser diagnosticada e tratada na atenção básica (BRASIL, 2005). Entretanto, os profissionais de saúde não têm dado merecido olhar a essa doença. Seu diagnóstico é simples, rápido, barato e a baciloscopia de escarro é o método prioritário para a realização do diagnóstico de TB, e pode ser solicitada por qualquer profissional de saúde.

Apesar disso, muitos locais ainda apresentam dificuldades para a realização rápida do diagnóstico da doença, seja por não priorizarem o método da baciloscopia ou em virtude das deficiências no acesso ao diagnóstico da TB nos serviços de saúde (LEUNG; LEUNG; TAM, 2007).

O município de São José do Rio Preto-SP é considerado pelo Ministério da Saúde como prioritário no controle da doença e apresenta em torno de $80 \%$ de descoberta de casos pelos serviços hospitalares, principalmente os de referência terciária e quaternária (VENDRAMINI, 2005).

O Programa Nacional de Controle da TB (PNCT) vem desenvolvendo estratégias em relação à descentralização das ações de prevenção, vigilância e controle, sendo a atenção primária a principal porta de acesso (BRASIL, 2004). Entretanto, algumas ações permanecem centralizadas nos PCT dos municípios que geralmente são desenvolvidos em Ambulatórios de Referência (AR). Por isso, como uma nova estratégia de atenção básica, o Ministério da Saúde criou a Estratégia da Saúde da Família, que tem como finalidade assistir a saúde da comunidade no âmbito familiar prevenindo doenças (BODSTEIN, 2002).

A obtenção do sucesso terapêutico ultrapassa a dimensão biológica da doença e eficácia farmacológica, existindo diversos obstáculos que por dificultarem a acessibilidade ao cuidado em saúde durante o tratamento da TB, trazem conseqüências como o aumento dos índices de mortalidade, incidência da doença e multidrogarresistência, configurando-se como um dos aspectos mais desafiadores na atenção à TB (SÁ et al, 2007, VILLA et al, 2008). 
É comum no início do tratamento o doente apresentar efeitos colaterais em decorrência da terapia medicamentosa como: epigastralgia, artralgia entre outros. Nesse sentido, as consultas de urgência são de vital importância frente à possibilidade de interrupção medicamentosa no período crítico do tratamento em que há elevado risco de transmissibilidade do bacilo. Verifica-se, portanto, agilidade do serviço na atenção a esse evento, o que tem contribuído para a acessibilidade do doente ao tratamento (BRASIL, 2002).

Essas situações podem desmotivar o doente a dar continuidade ao tratamento e, portanto, gerar abandono (JAISWAL et al., 2003). Os diversos obstáculos financeiros durante a obtenção de cuidado podem aumentar os riscos de não adesão ao tratamento da TB mesmo quando é oferecido gratuitamente (WORLD HEALTH ORGANIZATION, 2005).

A rigidez na rotina de atendimento por parte dos serviços de saúde agrava as dificuldades econômicas e sociais vivenciadas pelo doente de TB, o que pode influenciar no abandono ao tratamento (SAGBAKKEN et al., 2008).

A infecção pelo HIV é um dos mais importantes fatores de risco para o adoecimento por TB, em função das alterações imunológicas que a mesma determina, criando assim condições favoráveis para a ativação da infecção tuberculosa e desenvolvimento da doença (CASTELO FILHO, 2004).

A coinfecção TB/HIV afeta principalmente os países pobres, nos quais o HIV está alimentando a epidemia da TB, em razão dos baixos níveis de instrução da população, falta de acesso aos serviços gratuitos de saúde e, aos preservativos (PONCE et al., 2006).

Um total de 12\% de casos de TB notificados no Brasil em 2006 estava associado com a infecção pelo HIV (WORLD HEALTH ORGANIZATION, 2008). Em 2007, essa taxa aumentou para 14\% no país (WORLD HEALTH ORGANIZATION, 2009), e em 2005, no Estado de São Paulo era de 13\% (SECRETARIA DO ESTADO DA SAÚDE DE SÃO PAULO, 2006).

No período de 1984 a julho de 2008, foram notificados 3487 casos de aids em adultos residentes em São José do Rio Preto, (1126 mulheres e 2361 homens), sendo que 1670 $(47,89)$ estão vivos, 1783 (51,13\%) já morreram e 34 ignorados (0,98\%) (SÃO JOSÉ DO RIO PRETO, 2008?).

A sorologia anti-HIV em pacientes com TB é importante, dada a alta prevalência da coinfecção por Mycobacterium Tuberculosis e HIV e por não ser conclusiva a identificação dos coinfectados baseadas apenas na história clínica (CHEADE et al., 2009).

As populações com menor renda e escolaridade também estão mais expostas à aids, bem como grupos estigmatizados e excluídos tais como detentos, profissionais do sexo e 
usuários de drogas, sendo que o risco de contrair HIV nessa população é oito a 12 vezes maior do que para a população em geral (BRASIL, 2007). Sabe-se também que a epidemia no Brasil tem aproximadamente $60 \%$ dos casos notificados associados a alguma forma de contato sexual desprotegido (DOURADO et al, 2006).

Dados preliminares indicam que índices de mortalidade em pacientes soropositivos para o HIV com TB são maiores do que em pacientes apenas soropositivos sem TB. A infecção pelo HIV é hoje importante fator de risco para desenvolvimento da TB, se não a mais grave, a mais característica em termos de morbidade, não apenas pela interação patológica, mas por uma combinação de fatores que favorecem a evolução da doença em ambas as condições.

A associação entre TB e infecção pelo HIV afeta a mortalidade de duas formas: a TB traz uma importante letalidade para as pessoas infectadas pelo HIV, e o HIV atua como causa indireta do aumento da incidência da TB e consequente mortalidade entre pessoas com sorologia negativa para o HIV, pelo aumento do reservatório de Mycobacterium tuberculosis (OLIVEIRA, et al, 2004).

Em regiões de elevada prevalência da coinfecção HIV/TB, o paciente com TB infectado pelo HIV não aderente ao tratamento, torna possível o aumento da resistência às drogas anti TB e o aumento no risco da transmissão de Mycobacterium. tuberculosis e de HIV para os seus comunicantes.

Em virtude disso, em regiões nas quais a prevalência da infecção pelo HIV é elevada, o seu diagnóstico é imprescindível, bem como o tratamento precoce, afim de que se obtenha diminuição no abandono desse tratamento e também a minimização desse impacto negativo (LUCCA, 2008).

Vários fatores têm sido associados à adesão ao tratamento, entre eles os psicossociais, relacionados com a pessoa, seu perfil socioeconômico, sua escolaridade e suas crenças. As crenças e percepções parecem influenciar diretamente no comportamento e nas atitudes dos seres humanos (NEVES; GIR, 2007).

O diagnóstico de pacientes coinfectados HIV/TB é realizado por meio da prova tuberculínica na avaliação inicial do HIV positivo, independente do seu estado clínico ou laboratorial (contagem de células CD4 e carga viral), devendo ser repetido anualmente nos indivíduos não reatores, e nos reatores que iniciam tratamento com antirretroviral, seis meses após o início da terapêutica, dada a possibilidade de reconstituição imunológica e restauração da resposta tuberculínica (LUCCA, 2008).

O acesso universal ao tratamento com antirretroviral introduzido no país em 1996 tem causado impacto sobre a mortalidade e aumento da sobrevida nesses pacientes, que passou de 
seis meses para aproximadamente cinco anos. A ocorrência de infecções oportunistas decresceu de $60 \%$ a $80 \%$. Mais de 90.000 óbitos e 633.200 internações foram evitados, representando economia de mais de 1,8 milhões de dólares no período de 1997 a 2003 (VITÓRIA, 2006).

Nenhuma doença exigiu tanto envolvimento de organizações governamentais e não governamentais, mobilizando a sociedade sob diversos aspectos. Conquistas diversas foram obtidas, em termos científicos, tecnológicos e humanísticos. Mas o sentimento de impotência profissional ficou marcado, principalmente nos primeiros anos, quando os pacientes eram diagnosticados e com brevidade morriam, pois não se dispunha de alternativas terapêuticas. Os profissionais de saúde conscientizam-se da necessidade do trabalho multi, inter e até transdiciplinar (GIR; VAICHULONIS; OLIVEIRA, 2005).

O impacto negativo de uma doença sobre a outra dificulta o alcance das metas estabelecidas para o controle da TB no Brasil, havendo a necessidade de implementação de ações de controle da coinfecção TB/HIV nas áreas assistenciais, vigilância epidemiológica e programática (JAMAL; MOHERDAUI, 2007).

Desde 2006, as metas globais do Plano Stop TB são interromper a incidência de TB e reduzir para 50\% as taxas de prevalência e mortalidade até 2015 relativas aos níveis apresentados em 1990 (WORLD HEALTH ORGANIZATION, 2009).

A estratégia Stop TB estabeleceu várias intervenções que deveriam ser implantadas para atingir as metas do milênio, entre elas, adotar uma alta qualidade na expansão DOTS e intensificação; direcionamento dos casos de TB/HIV e Droga Multirresistente - TB (MDRTB) no atendimento às reais necessidades das populações pobres e vulneráveis com esses diagnósticos; contribuir para o sistema-saúde no fortalecimento do cuidado básico da saúde; engajar todos cuidadores de saúde; auxiliar pessoas com TB e comunidades por meio de parcerias, e capacitar e promover pesquisa (WORLD HEALTH ORGANIZATION, 2009).

Em 1998, São José do Rio Preto-SP foi selecionado como município prioritário para o controle da TB em razão da elevada coinfecção TB/HIV, que apresentou taxa de 35\% em 1998 e 51\% em 2004. A implantação do Tratamento Supervisionado foi direcionada, em 1998, para os doentes coinfectados TB/HIV.

Apesar dos avanços científicos, a infecção pelo HIV ainda é incurável e são alarmantes os números atuais da epidemia tornando-se de grande importância o desenvolvimento da pesquisa, para que os conhecimentos gerados sejam divulgados e aplicados no ensino e na assistência, contribuindo desta forma, para um ensino de melhor qualidade e uma assistência 
mais humanizada e integral, visando melhor também, a qualidade de vida dos portadores de HIV/aids ( REIS; GIR, 2002).

\subsection{Justificativa}

Durante minha atuação como docente na área hospitalar, observei alta ocorrência de casos de TB, principalmente em doentes infectados pelo HIV, e no estágio avançado da doença as dificuldades de se fazer um diagnóstico precoce de ambas as enfermidades.

Após minha inserção no GEOTB, tive um despertar para a problemática da TB diagnosticada tardiamente, em âmbito hospitalar, em detrimento do diagnóstico precoce na Atenção Básica, considerada porta de entrada para o sistema de saúde, responsável por essa ação prioritária.

Considerando os elementos estruturais da Atenção Básica, além da situação epidemiológica preocupante da TB, da aids e da coinfecção destas duas enfermidades, que contribuíram para a escolha do município de São José do Rio Preto como prioritário no controle da TB, justifica-se esta investigação.

Este estudo abordou um dos objetivos do projeto-mãe que é avaliar o acesso ao diagnóstico e tratamento em pessoas com Tuberculose e coinfectados com HIV, como uma das ações de controle na Atenção Básica, nos serviços de saúde do município de São José do Rio - SP. 


\subsection{Objetivos}

\subsubsection{Geral}

- Avaliar o acesso ao diagnóstico e ao tratamento das pessoas com Tuberculose e coinfectadas pelo HIV, no município de São José do Rio Preto-SP.

\subsubsection{Específicos}

- Caracterizar doentes de Tuberculose e coinfectados pelo HIV, quanto aos aspectos sociodemográficos (sexo, escolaridade, local onde vive, e tipo de moradia).

- Analisar o acesso ao diagnóstico dos doentes de Tuberculose e dos coinfectados pelo HIV.

- Analisar o acesso ao tratamento dos doentes de Tuberculose e dos coinfectados pelo HIV

- Identificar discrepâncias dos grupos de doentes com TB e dos doentes coinfectados TB/HIV em relação ao acesso ao diagnóstico e tratamento. 


\section{MARCO TEÓRICO}

O quadro teórico que subsidia a discussão deste estudo tem como foco central o acesso como dimensão essencial da Atenção Primária à Saúde no controle da TB.

No ano de 1978, a Conferência Internacional sobre Cuidados Primários de Saúde, reunida em Alma Ata, promovida pela Organização Mundial de Saúde/ Fundo das Nações Unidas para Infância, na Rússia, representou um marco de influência nos debates sobre o rumo das políticas de saúde no mundo, reafirmando a saúde como direito humano fundamental (ORGANIZAÇÃO MUNDIAL DE SAÚDE, 1979). Nessa conferência ficou decidido entre os governos participantes que a meta principal deles seria fazer com que todos os cidadãos do mundo atingissem um alto nível de saúde no ano 2000 o que permitiria levar vida social e economicamente produtiva, hoje conhecida como "Saúde para Todos no ano 2000”. Assim, desencadeou-se uma série de atividades que tiveram um grande impacto sobre o pensamento a respeito da atenção primária á saúde (STARFIELD, 2002).

Após a conferência, a atenção primária à saúde foi definida como:

Atenção essencial à saúde baseada em tecnologia e métodos práticos, cientificamente comprovados e socialmente aceitáveis, tornados universalmente acessíveis a indivíduos e famílias na comunidade por meio aceitáveis para eles e a um custo que tanto a comunidade como o país possa arcar em cada estágio de seu desenvolvimento, um espírito de autoconfiança e autodeterminação. É parte integral do sistema de saúde do país, do qual é função central, sendo o enfoque principal do desenvolvimento social e econômico global da comunidade. É o primeiro nível de contato dos indivíduos, da família e da comunidade com o sistema nacional de saúde, levando à atenção à saúde o mais próximo possível do local onde as pessoas vivem e trabalham, constituindo o primeiro elemento de um processo de atenção continuada à saúde. (WORLD HEALTH ORGANIZATION, 1978 apud STARFIELD, 2002).

Ficou especificada na conferência, que os elementos fundamentais da atenção primária á saúde eram educação em saúde; saneamento ambiental, especialmente de águas e alimentos; programas de saúde materno-infantis, inclusive imunizações e planejamento familiar; 
prevenções de doenças endêmicas locais; tratamento adequado de doença e lesões comuns, fornecimento de medicamentos essências; promoção de boa nutrição e medicina tradicional.

Um dos indicadores mais potentes para medir a qualidade da Atenção Primária a Saúde (APS) é o percentual de internações hospitalares por condições sensíveis à atenção ambulatorial, o indicador de morbidade hospitalar (MENDES, 2002).

A hospitalização pode ser usada para documentar barreiras potenciais à atenção ambulatorial, para avaliar o desempenho da APS e identificar possíveis deficiências na qualidade da assistência em pontos de atenção primária. A demora em receber uma assistência efetiva na atenção primária á saúde pode resultar em admissões hospitalares desnecessárias, por muitas condições comuns (BILLINGS; ANDERSON; NEWMAN, 1996).

Dentre as diversas correntes interpretativas, a que mantém consonância com os conceitos de Atenção Primária à Saúde, é definida por Mendes (2002) como estratégia de organização do sistema de saúde a partir de uma forma singular de apropriar, recombinar, reorganizar e reordenar todos os recursos do sistema para satisfazer necessidades, demandas e representações da população, o que implica a articulação da Atenção Primária à Saúde dentro de um sistema integrado de serviços de saúde, com alguns componentes estruturantes no processo de organização dos serviços de saúde. Assim, com esta definição pode-se dizer que ela contempla os elementos da definição de atenção primária elaborada por Starfield (2002), que estão em conformidade com o conceito da Atenção Primária à Saúde proposta em Alma Ata.

Ainda assinalar que as diversas configurações do sistema de serviço em saúde podem ser agregadas, basicamente, em duas opções: sistemas fragmentados, fortemente hegemônios, ou sistemas integrados de serviços de saúde. No primeiro sistema, os diversos serviços se configuram em conjunto de pontos isolados de atenção à saúde, frequentemente representados como uma estrutura piramidal, expressando sua organização hierárquica, por níveis de atenção, fundamentados por um conceito equivocado de complexidade. Nos sistemas integrados, por sua vez, não há hierarquia entre os diferentes pontos de atenção à saúde, mas conformação de uma rede horizontal de pontos de atenção à saúde de diferentes densidades tecnológicas (MENDES, 2002)

Os autores Mendes (2002) e Starfield (2002) enfatizam que uma atenção primária á saúde de qualidade deve seguir, em sua totalidade, seus princípios ordenadores: primeiro contato, a longitudinalidade, a integralidade, a coordenação, a focalização na família e a orientação comunitária. O primeiro contato é a porta de entrada e implica a acessibilidade e o uso de serviços para cada novo problema. A longitudinalidade a existência de uma fonte 
regular de cuidados e seu uso ao longo do tempo. A integralidade implica na prestação de serviços pela equipe de saúde ajustados as necessidades da população descrita. A coordenação contempla a facilidade em acessar os demais níveis de atenção e a integração com os serviços de outros setores sociais. $\mathrm{O}$ enfoque familiar considera o individuo em seu contexto familiar e o conhecimento integral de seus problemas de saúde. A orientação para a comunidade diz respeito ao conhecimento das prestadoras sobre as necessidades dos usuários e a participação na comunidade.

Uma APS de qualidade é um requisito bastante enfatizado atualmente em vários países. Esse movimento ganhou força a partir das evidências de que os sistemas nacionais de saúde que priorizam as ações primárias como eixos organizados das práticas sanitárias alcançam melhores indicadores de saúde, menores custos e maior satisfação dos usuários. (MENDES, 2004).

Muitos países incorporam a terminologia atenção primária á saúde, e no Brasil, a terminologia utilizada para indicar atenção primária á saúde é denominada de atenção básica. O Ministério da Saúde em 1999 define atenção básica como sendo, conjunto de ações, de caracteres individuais ou coletivos, desenvolvidos no primeiro nível de atenção dos sistemas de saúde, voltada para promoção de saúde, prevenção dos agravos, tratamento e reabilitação. (BRASIL, 1999). Em 2006, esse conceito tornou amplo para:

Um conjunto de ações de saúde, no âmbito individual e coletivo, que abrangem a promoção e a proteção de saúde, a prevenção de agravos, o diagnóstico, o tratamento, a reabilitação e a manutenção de saúde. É desenvolvida por meio do exercício de práticas gerenciais e sanitárias democráticas e participativas, sob forma de trabalho em equipe, dirigida as populações de territórios bem delimitados, pelas quais assume a responsabilidade sanitária, utiliza tecnologias de elevada complexidade e baixa densidades, que devem resolver os problemas de saúde de maior freqüência e relevância em seu território. É o contato preferencial dos usuários com os Sistemas de Serviços. Orienta-se pelos princípios da universalidade, da acessibilidade e da coordenação do cuidado, do vinculo e continuidade, de integralidade e na inserção sócio-cultural e busca a promoção de sua saúde, a prevenção e tratamento de doenças e a redução de danos ou sofrimentos que possam comprometer suas possibilidades de viver de modo saudável. (BRASIL, 2006).

A reorganização da Atenção Básica, terminologia utilizada pelo Ministério da Saúde no Brasil, ocorre a partir da descentralização do Sistema Único Saúde (SUS), tendo a transferência de responsabilidade para os municípios como estratégia de mudança do modelo 
assistencial. Os municípios, então, passam a responder pela gestão da atenção básica com o propósito de privilegiar este nível de atenção como porta de entrada dos serviços de saúde, enfatizando um modelo centrado nas ações preventivas e de promoção à saúde (BODSTEIN, 2002).

As dimensões essenciais como características necessárias da organização da atenção básica em saúde são: porta de entrada, acesso, vínculo, elenco de serviços, coordenação, enfoque familiar, orientação para a comunidade e formação profissional (STARFIELD, 2002).

Um dos agravantes para o controle da TB é a dificuldade de acesso aos serviços de saúde enfrentada pelas populações menos favorecidas, alvo principal da TB, apesar dos avanços do SUS relacionados à oferta e cobertura dos serviços de saúde (MAGALHÃES; BURLANDY; SENNA, 2007).

Acesso é um conceito complexo, muitas vezes empregado de forma imprecisa, e pouco clara na sua relação com o uso dos serviços de saúde, é um conceito que varia entre autores e que muda ao longo de tempo e de acordo com o contexto (TRAVASSOS; MARTINS 2004)

Alguns autores empregam o termo acessibilidade no sentido de caráter ou qualidade do que é acessível (DONABEDIAN, 1973). Enquanto outros autores preferem o termo acesso no sentido de ingressar, entrar nos serviços (HOUAISS; VILLAR, 2001). Donabedian (2003) utiliza os dois termos para indicar o grau de facilidade com que as pessoas obtêm cuidados de saúde.

O acesso compreende a localização da unidade de saúde mais próxima com horários pré-programados para atendimento, o grau de tolerância para consultas não agendadas e o quanto à população percebe a conveniência destes aspectos do acesso (STARFIELD, 2002).

Para alguns autores, o acesso é um conceito multidimensional, em que cada dimensão expressa um conjunto de características de oferta que atua aumentando ou dificultando a capacidade das pessoas utilizarem serviços de saúde (STARFIELD 2002; TRAVASSOS; CASTRO 2008).

O acesso depende da estrutura disponível que inclui facilidades para utilização dos serviços, tais como sua distribuição geográfica, localização, planta física, amenidades, tempo de espera, disponibilidade de equipamentos. A tecnologia empregada deve ser adequada, não necessariamente de alta densidade, mas associada a equipes multiproqualificadas, a uma efetiva organização da assistência, como ênfase no enfoque domiciliar e comunitário. Deve ainda ser capaz de identificar as necessidades de saúde e dar resposta apropriada. Como parte 
da estrutura organizacional, inclui-se ainda a existência de registros, de informação e de um sistema de marcação de consultas (CAMPOS, 2005).

Outros autores Thiede e McIntye (2008), apresentam três dimensões que também constituem como barreira de acesso: disponibilidade, capacidade de pagar e aceitabilidade. Informação é um elemento essencial pertencente as três dimensões e que possibilita às pessoas fazerem suas escolhas.

Os termos acessos e acessibilidade são usados de forma intercalada e, geralmente, ambígua. Acesso é a forma como as pessoas percebem a acessibilidade e a acessibilidade refere-se a características da oferta (STARFIELD, 2002)

A acessibilidade que possibilita às pessoas chegarem aos serviços não é uma característica apenas da atenção primária, uma vez que todos os níveis de atenção devem estar acessíveis. Entretanto, os requisitos específicos para acessibilidade diferem na atenção primária, porque esta é a porta de entrada dos serviços de sistema de saúde (STARFIELD, 2002)

Enquanto caráter ou qualidade de que é acessível, a acessibilidade difere do conceito acesso, compreendida como “entrada, ato de ingressar” (TRAVASSOS; MARTINS, 2004). A acessibilidade implica na prestação contínua e organizada de serviços a que todos os indivíduos tenham fácil acesso cultural, funcional, geográfico e financeiro (ORGANIZAÇÃO MUNDIAL de SAÚDE, 1979).

A acessibilidade é classificada sociocultural, organizacional, geográfica e econômica e considerada como um dos principais atributos da atenção básica, sendo compreendida como ausência ou presença de barreiras financeiras, organizacionais e/ou estruturais que dificultam a obtenção do cuidado (FEKETE, 1997; STARFIELD, 2002).

A acessibilidade sociocultural refere-se à busca de assistência à saúde como: percepção sobre o corpo e a doença, crenças relativas à saúde, tolerância à dor e credibilidade nos serviços de saúde. Os estigmas e mitos em relação à doença podem afetar a relação profissional-paciente, dificultando o cuidado.

Já, acessibilidade organizacional representa os obstáculos que se originam nos diferentes modos de organização dos recursos de assistência à saúde. Esses obstáculos podem estar na entrada ou no interior da unidade. Os obstáculos na entrada são: demora em conseguir consultas médicas, flexibilidade do horário de atendimento entre outros, já os obstáculos no interior são as características que interferem com a assistência dentro da unidade (tempo de espera). Os obstáculos relativos à organização dos serviços podem ser encontrados no contato 
inicial com estabelecimento de saúde (porta de entrada) e ao longo de todo o processo de cuidado.

A acessibilidade geográfica reflete a distância média entre a população e os recursos. Não se mede apenas pela distância, já que uma determinada região pode representar características físicas que impedem ou dificultem o acesso da população. Deve ser medida em função do tempo que, pelos meios habituais de transporte, se consome para obter assistência à saúde e pela avaliação dos motivos que levam a população a procurar determinado serviço de saúde em determinado local.

A acessibilidade econômica representa o gasto em saúde da família em razão da oferta insuficiente de ações e serviços. Esse gasto está relacionado com o consumo de tempo, energia e recursos financeiros para busca e obtenção da assistência à saúde, os prejuízos, por perda de dias de trabalho, as possíveis perdas decorrentes de afastamento por doenças, o custo do tratamento e outros. Essa acessibilidade se refere às ações de suporte oferecidas pelo serviço de saúde, como a entrega de vale-transporte e cestas básicas ao doente em tratamento.

Toda definição de um sistema de assistência à saúde deve levar em consideração as dimensões da acessibilidade, a fim de que os avanços teóricos, relativos à organização setorial, transformem-se em práticas no interior dos serviços (FEKETE, 1997).

No Brasil, com a definição do SUS que estabelece como princípios a universalidade, a equidade, a integralidade, a regionalização e hierarquização, e como a descentralização da gestão administrativa, novas estratégias vêm sendo implantadas na promoção de saúde, prevenção de doenças, tratamento e reabilitação. A municipalização das ações e serviços exige cada vez mais o emprego de métodos de avaliação para subsidiar a redefinição de diretrizes e estratégias para efetivação do atual serviço de saúde (OLIVEIRA, 2008).

Nesse sentido, o programa saúde da família assume caráter estratégico para viabilizar a reorganização do sistema de serviço, seguindo os princípios da atenção básica de saúde. O programa saúde da família surgiu em 1994 com o propósito de ampliar o acesso da população aos serviços básicos de saúde, numa conjuntura neoliberal que põe em risco a universalidade do sistema de saúde brasileiro. Por outro lado, assume diretrizes consoantes com o SUS, ou seja, integralidade, resolutividade e intersetorialidade das ações, trabalho em equipe, vínculo de corresponsabilidade às famílias assistidas e estímulo à participação social, e se propõe como estratégia para organização da rede básica de serviços de saúde, com repercussões para o sistema de saúde. Entre programa de saúde pública e a estratégia de mudança, a saúde da família segue os dilemas do SUS, ou seja, de pretender-se universal e igualitário, numa 
realidade neoliberal e com pouca cidadania organizada para exigir oportunidades de vida (PIRES; GÖTTEMS, 2009).

Mesmo frente ao significativo processo de implantação e expansão do programa saúde da família no Brasil, ainda é nítido a hegemonia do modelo tradicional de assistência à saúde (MENDES, 2004).

O modelo tradicional é manifestado por meio das unidades básicas de saúde que atende a demanda por atenção médica e exercita algumas funções programativas. Nas grandes e médias cidades, predomina o trabalho médico realizado por clínicos, gineco-obstetras e pediatras; já nas pequenas cidades predominam os médicos generalistas, com ou sem especialização. A maioria das unidades básicas de saúde atua como uma extensa base populacional, médicos múltiplos e a falta de vínculo, o que reforça o predomínio da atenção voltada às condições agudas e na lógica de atenção por demanda espontânea (MENDES, 2004).

A universalidade e a garantia de acesso por meio dos cuidados primários de saúde são preconizadas em vários países do mundo como forma de se alcançar maior equidade e satisfação das expectativas dos usuários. Todo cidadão deve ter o direito à saúde e acesso a qualquer tipo de serviço de que necessita, seja de caráter estatal quanto privado, contratado ou convencionado (CAMPOS, 2005). 
3. MATERIAIS E MÉTODOS 


\section{MATERIAIS E MÉTODOS}

\subsection{Delineamento}

Trata-se de uma pesquisa avaliativa, de abordagem quantitativa que utilizou o modelo de estudo transversal.

\subsection{Local de Estudo}

O presente estudo foi desenvolvido nas Unidades de Saúde que desenvolvem o Programa de Controle da Tuberculose (PCT) do município de São José do Rio Preto-SP, entre junho de 2006 a julho de 2007.

São José do Rio Preto situa-se na região Noroeste do Estado de São Paulo, a aproximadamente $500 \mathrm{~km}$ da capital, caracterizando-se como pólo regional, sede da $8^{\text {a }}$ Região Administrativa, com 96 municípios. O município possui grande porte e é centro de referência na prestação de serviços de saúde, contando com área de influência que atende 101 municípios do Departamento Regional de Saúde XV (DRS XV) e de outros Estados de Minas Gerais, Goiás, Mato Grosso e Mato Grosso do Sul. O município também ocupa a sétima posição no ranking nacional em relação à eficiência de políticas públicas nos municípios, relacionada à melhoria nas condições de saúde, educação e renda (SÃO JOSÉ DO RIO PRETO, 2008).

\subsection{Políticas Públicas de Saúde em TB no município de São José do Rio Preto}

O município de São José do Rio Preto é prioritário para o controle da TB no Estado de São Paulo, possui área geograficamente delimitada com equipes do programa saúde da família e programa agente comunitário de saúde e unidades básicas de saúde, com alta taxa de 
incidência de TB e TB/HIV, sendo que o DOTS foi implantado em 1998, inicialmente para os doentes coinfectados TB/HIV (SANTOS, et al., 2009). Apresenta razoável organização dos serviços de atenção básica e desenvolvimento de ações de controle da TB em atenção básica com parceria entre academias, serviços de saúde (gestores/ equipes de PCT/ Vigilância Epidemiológica, e sociedade civil e organizada (ONG, HIV-aids, Conselho Local de Saúde).

O município está habilitado em gestão plena do sistema pela Norma Operacional Básica (NOB/96). A Secretaria Municipal de Saúde e Higiene é a responsável pela estruturação da atenção básica no município, buscando cumprir os princípios do SUS. A rede de atenção básica à saúde do município é composta por: 10 unidades básicas de saúde; 04 policlínicas que contam com equipes de agentes comunitários de saúde e estão em fase de transição para a estratégia de saúde da família; 09 unidades de saúde da família, perfazendo um total de 23 unidades.

No nível secundário de atenção conta com um Ambulatório Regional de Especialidades (NGA-60), um Serviço de Assistência Especializada (SAE) ao doente de aids, um hospital dia, três Centros de Atenção Psicossocial (CAPS) infantil, dois CAPS adulto, um Ambulatório de Saúde Mental e um Núcleo Municipal de Reabilitação. O nível terciário conta com três hospitais conveniados ao SUS e três privados, um hospital psiquiátrico e um hospital de longa permanência.

O PCT está localizado nas dependências do Ambulatório de Especialidades - Núcleo de Gestão Ambulatorial-60 (NGA-60) que presta assistência aos doentes de nível de referência para micro região e município. Conta com equipe multidisciplinar composta por um médico infectologista, que realiza atendimento aos doentes, um coordenador para o programa, uma enfermeira que faz consulta de enfermagem e as orientações sobre o tratamento, duas auxiliares de enfermagem sendo uma atende os doentes no NGA e a outra realiza o tratamento supervisionado durante a semana, uma assistente social e um digitador para alimentar o banco de dados do Sistema Nacional de Atendimento Médico (SINAM) e do Sistema de Controle de Pacientes com TB (TBWeb).

Em 2001 iniciou-se um período de reestruturação e reorganização do sistema de saúde, o município foi dividido em pólos I, II, III, IV e V, cada um dos quais localizados nas zonas norte, sul, leste e oeste e cada um possui uma média de três a quatro Unidades Básicas de Saúde (UBS), e a Unidade Básica de Saúde da Família (UBSF) localizam-se na periferia da cidade. Portanto, houve definição da área de abrangência de cada serviço e expressivos investimentos na reformulação e expansão da Vigilância Epidemiológica, com informatização 
dos sistemas de saúde, o que garantiu que todas as fichas de notificação compulsória fossem colocadas no banco de dados do SINAM.

Em 2007, o município assinou o Pacto de Saúde pela Vida e, assim, as ações de descentralização foram efetuadas, sendo que, $87 \%$ das unidades de saúde realizavam o tratamento supervisionado e, 36\% além do tratamento supervisionado já realizavam diagnósticos, consulta médica e acompanhamento ao doente. (SÃO JOSÉ DO RIO PRETO, 2008?).

\subsubsection{Processo de Descentralização do Programa de TB}

Em 2002, deu-se início ao processo de descentralização do tratamento supervisionado para as Unidades Básicas de Saúde e Unidades Básicas de Saúde das famílias, introduzindo novas possibilidades de intervenção no processo de trabalho, uma parceria visando à expansão das ações do PCT. De forma gradativa, as ações de diagnóstico e tratamento também foram descentralizadas para as UBS/UBSF, porém observa-se resistência dos profissionais da Atenção Básica em assumir estas ações. .

Com o projeto de descentralização, a Agente de Saúde da equipe central - Ambulatório de Referência-NGA-60 continua realizando as visitas e tratamento supervisionado aos doentes em tratamento no NGA e também supervisiona o tratamento supervisionado e/ou tratamento que foi descentralizado para as unidades básicas de saúde e unidades básicas de saúde da família; conversa com a equipe da unidade, levanta problemas e se necessário, junto com o responsável naquela unidade faz visita ao doente. Quando percebe que está havendo problemas ou possibilidade de abandono do tratamento, discute com a equipe o retorno do doente para tratamento no NGA. Nas unidades básicas de saúde, nas quais a estratégia de Saúde da Família não está implantada o tratamento supervisionado é realizado principalmente na unidade (falta viatura e pessoal).

Outro serviço de referência o SAE - que atende ao doente de aids e os coinfectados TB/HIV, também é referência para o atendimento de acidente ocupacional com material biológico de risco de toda rede municipal: hospital clínica médico, odontológicas, laboratórios, farmácias e pessoas que participam no resgate. A unidade não possui área de abrangência, pois atende todo o município de São José do Rio Preto. É composta por sete médicos (três infectologistas, dois clínicos, um ginecologista e um pediátrico), três 
enfermeiras (uma gerente), um técnico, dois auxiliares de enfermagem, um auxiliar de laboratório, um farmacêutico, um auxiliar de farmácia, uma educadora de saúde, dois motoristas (ambulância e viatura), dois agentes de saúde, um auxiliar de serviços gerais.

O SAE tem viatura própria para a realização do tratamento supervisionado o que facilita o andamento operacional. Possui uma média de dez doentes coinfectados TB/HIV. O cliente procura o serviço por telefone ou pessoalmente, encaminhado ou não por outro serviço. Nesse momento é agendada consulta médica de acordo com disponibilidade de horário da agenda médica ou quando necessário atendimento de encaixe, em função da necessidade clínica. O cliente deve ser residente no município e estar munido de documento pessoal e exame antiHIV para abertura de prontuário. Na ausência de exame, este é solicitado imediatamente para que na primeira consulta o paciente esteja com o resultado ou realizada testagem rápida para HIV.

\subsubsection{Porta de Entrada}

Os sintomáticos respiratórios procuram primeiramente as unidades básicas de saúde ou unidades básicas de saúde da família, mas apresentam dificuldade no diagnóstico. Na maioria das vezes o usuário entra no programa encaminhado principalmente pelos hospitais e unidade de pronto atendimento e pronto socorro municipal. Deve-se salientar que a atenção básica realiza a busca ativa de TB, de forma incipiente.

Desde julho de 2007, o município não realiza atendimento aos doentes das penitenciárias, apenas realiza notificações “on-line”, via internet pela TBWeb, pois de acordo com Secretária de Saúde do Estado de São Paulo, o sistema penitenciário recebe incentivos financeiros para atender os detentos.

\subsubsection{Diagnóstico}

Demanda Espontânea: os usuários procuram as unidades básicas de saúde ou prioritamente o pronto atendimento por apresentarem algum sintoma respiratório, como a tosse. Todas as unidades de saúde que fazem o atendimento 24 horas também estão 
preparadas para solicitar exames de baciloscopia ou Raio X. Os exames de escarro são enviados ao Instituto Adolfo Lutz e, normalmente, ficam prontos no prazo de 24 horas. O Raio X é realizado no NGA-60 ou serviço conveniado. Nos hospitais e clinicas particulares os exames são realizados pelos laboratórios e serviços de Raio X próprios.

Quando do diagnóstico positivo pela atenção básica é oferecido ao doente a oportunidade de realizar o tratamento e o tratamento supervisionado na unidade de saúde mais próxima do domicílio, se a mesma já possui equipe treinada pela coordenação do PCT para tal. Se o doente preferir, ou se a unidade não está capacitada, o doente é acompanhado pela equipe do ambulatório de referência (NGA-60) ou pelo SAE. O acompanhamento do tratamento supervisionado é realizado principalmente pelas unidades básicas de saúde na própria unidade ou nas unidades básicas de saúde da família, nas quais é realizado prioritariamente pelo agente comunitário de saúde da equipe no domicílio do doente, se ele assim desejar.

Em todas as situações a auxiliar de enfermagem, a enfermeira e assistente social da equipe do NGA-60 realizam o tratamento supervisionado no domicílio do doente ou o tratamento supervisionado de atenção básica quando solicitado. São realizadas visitas periódicas nas unidades e quando necessário também no domicílio - a equipe do ambulatório de referência tem sido cuidadosa com o processo de descentralização.

Hospitais de onde são encaminhados casos já com diagnóstico definido ou sugestivo para tratamento. O próprio hospital faz a notificação do caso e encaminha o doente, principalmente para o NGA-60 ou SAE. Na maior parte desses casos, há coinfecção pelo vírus HIV e passam a ser seguido pelo nível secundário e receber o tratamento supervisionado.

A TB infantil é notificada e acompanhada pela equipe de pneumologia pediátrica do hospital de ensino da cidade.

\subsection{População do Estudo}

A população do estudo foi constituída por 106 doentes de Tuberculose, em tratamento nas unidades de saúde que desenvolvem o PCT, no período de junho de 2006 a julho de 2007. Destes 106 doentes, foram selecionados os que realizaram teste de sorologia anti HIV, incluindo aqueles com resultado negativo. 
Os critérios de inclusão adotados foram:

- $\quad$ Ter idade igual ou maior de 18 anos;

- $\quad$ Ter diagnóstico confirmado de TB;

- Residir em São José do Rio Preto no momento do diagnóstico

- Ter sido diagnosticado e cadastrado para realizar o tratamento no período de junho de 2006 a julho de 2007 no município de São José do Rio Preto-SP;

- $\quad$ Ter realizado sorologia anti HIV;

- $\quad$ Concordar em participar da pesquisa

\subsection{Instrumentos para Coleta dos Dados}

Para a coleta dos dados utilizou-se como instrumento o questionário Primary Care Assessment Tool (PCAT) elaborado por Starfield (2002). Este instrumento foi adaptado e validado para o Brasil por Almeida e Makinko (2006) por meio de sua aplicação no município de Petrópolis/RJ. Posteriormente foi adaptado para a atenção à TB por Villa e Ruffino-Netto (2009).

O instrumento contém perguntas específicas sobre cada dimensão essencial da atenção básica e foi adequado para avaliar a atenção à TB. Destaca-se que o questionário inclui perguntas sobre o perfil do doente, informações clinico epidemiológica e estado atual de saúde.

Esse instrumento foi utilizado na pesquisa do projeto multicêntrico para “Avaliação das dimensões organizacionais e de desempenho dos serviços de atenção básica no controle da TB em centros urbanos de diferentes regiões do Brasil.” Inclui 89 questões sobre as oito dimensões essenciais da atenção básica: acesso; porta de entrada; vínculo; elenco de serviços; coordenação; enfoque familiar; orientação para a comunidade e formação profissional. (ANEXO I).

Neste estudo, são apresentados os resultados referentes às dimensões acesso ao diagnóstico e acesso ao tratamento, sendo que foram consideradas 19 questões do instrumento para avaliar as referidas dimensões.

“Acesso ao diagnóstico" usando nove questões que correspondem a: o profissional de saúde pergunta se quando começou a adoecer, quantas vezes precisou procurar o 
posto/centro/unidade de saúde para conseguir atendimento; teve dificuldade para deslocar até o posto/centro/unidade de saúde; teve dificuldades para pedir informação por telefone no posto/centro/unidade de saúde; teve dificuldades para marcar consulta por telefone posto/centro/unidade de saúde; teve que deixar de trabalhar ou perder seu dia de trabalho ou compromisso para consultar no posto/centro/unidade de saúde; precisou utilizar algum tipo de transporte motorizado para ir até o posto/centro/unidade saúde; gastou dinheiro com o transporte para ir até o posto/centro/unidade de saúde; conseguiu consulta no posto/centro/unidade de saúde para descobrir a doença no prazo de 24hs; procurou o posto/centro/unidade de saúde mais perto da sua casa. .

Na dimensão “Acesso ao tratamento”, foram consideradas as dez questões do instrumento que os profissionais de saúde utilizam-se para avaliar a referida dimensão, ou seja, se o doente passar mal por causa da medicação ou da TB, consegue uma consulta médica no prazo de 24hs; consegue pedir informações por telefone no posto/centro/unidade de saúde; consegue marcar consultas por telefone no posto/centro/unidade de saúde; quando vai consultar seu problema de TB, tem que deixar de trabalhar ou perder seu dia de trabalho ou compromisso; quando vai consultar precisa utilizar algum tipo de transporte motorizado; quando vai consultar paga pelo transporte; durante seu tratamento faltou medicamentos para TB; demora mais de 60 minutos para ser atendido quando vai consultar; o profissional que acompanha seu tratamento de TB costuma visitá-lo em sua moradia; faz tratamento na unidade de saúde mais perto de sua casa.

O entrevistado respondeu cada pergunta do questionário segundo uma escala de possibilidade pré-estabelecida, tipo Likert, à qual foi atribuído um valor entre zero e cinco. $\mathrm{O}$ valor zero foi atribuído para resposta "não sei” ou “não se aplica” e os valores de um a cinco registraram o grau de relação de preferência (ou concordância) com as afirmações

Para cada questão foi determinado um escore médio que corresponde somatória dos escores (categorias) das respostas dos doentes, dividido pelo total de doentes entrevistados. Este escore médio que foi classificado como: não satisfatórios (valores próximos entre um e dois); regular (próximo a três) e satisfatório (próximo a quatro e cinco).

Em relação às informações gerais e sociodemográficas sobre o doente de $T B$, o entrevistado respondeu cada pergunta do questionário segundo escalas variadas de respostas. 


\subsection{Coleta de Dados}

Inicialmente, foram levantados por meio da TBWeb todos os doentes com TB e coinfetados pelo HIV no período do estudo. Esse momento visou à elaboração de uma listagem dos doentes, contendo iniciais do nome e número de identificação.

Para proceder à coleta de dados foram utilizados roteiros explicativos sobre a escala de respostas do questionário, direcionadas aos usuários. Foi realizado o treinamento de entrevistadores para a aplicação do instrumento.

Para arquivar as respostas obtidas nos questionários foi criado um banco de dados e as informações foram disponibilizadas em planilhas eletrônicas do software Statístic 8.0 da StatSoft.

\subsection{Análise dos Dados}

Para análise dos dados foram usadas técnicas de estatística descritiva como análise de freqüência, média, desvio-padrão e intervalo de confiança. Os escores médios das variáveis foram analisados individualmente e comparados entre dois grupos diferentes: doentes com TB e coinfectados pelo HIV e outro grupo de doentes de TB e não coinfectados pelo HIV. Foram realizados testes de hipóteses quanto à semelhança ou diferença desses indicadores utilizando o teste $t$ de Student e o teste de Mann-Whitney, quando as pressuposições exigidas pelo teste $t$ foram comprometidas. A suposição de igualdade de variância (homocedasticidade) requerida pelo teste $t$ foi verificada utilizando o teste de Levene.

Com o objetivo de verificar a associação entre as variáveis "sexo” e "local onde vive” e com o fato dos pacientes serem ou não-infectados pelo HIV, foram construídas tabelas de freqüências para a aplicação do teste do qui-quadrado para proporções.

O nível de significância estatística adotada em todos os testes foi de cinco por cento de significância. 


\subsection{Aspectos Éticos}

O projeto da pesquisa foi avaliado e aprovado (protocolo número 0762/2007) pelo Comitê de Ética em Pesquisa da Escola de Enfermagem de Ribeirão Preto - Universidade de São Paulo, atendendo as orientações contidas na resolução 196/96 CNS (ANEXOII).

Cada entrevistado leu e assinou o Termo de Consentimento Livre e Esclarecido (TCLE), em duas vias, assegurando a livre participação na pesquisa, sendo que uma cópia ficou com o entrevistado e a outra com o entrevistador. (APENDICÊ). Foi-lhes garantida à confidencialidade e sigilo das informações. Aos seis sujeitos sem escolaridade foram usadas as digitais para autorização. 
4. RESULTADOS 


\section{RESULTADOS}

Os resultados foram apresentados de acordo com os dados de caracterização da amostra, o acesso ao diagnóstico e ao tratamento.

\subsection{Caracterização Sóciodemográfica}

Dos 106 doentes entrevistados, 73 (68,8\%) não apresentavam coinfecção pelo HIV; 22 (20,7\%) apresentaram coinfecção pelo HIV e 11 (10,5\%) deles não foram submetidos ao teste de anti HIV.

Os doentes que não foram submetidos ao teste anti-HIV foram excluídos da análise. Desta forma, 95 doentes participaram deste estudo sendo que: 73 (76,8\%) apresentavam TB e não-coinfecção pelo HIV e 22 (23,2\%) apresentavam TB e coinfecção pelo HIV.

Com referência ao sexo os resultados mostraram que, 63 (66,3\%) eram do sexo masculino e 32 (33,7\%) do sexo feminino. Quanto à escolaridade verificou-se que 66 (69,5\%) dos pacientes possuíam ensino fundamental .

Quanto ao local onde vivem os pacientes, 48 pacientes (50,5\%) declararam residir em casa própria; 26 (27,4\%) em moradia alugada; 15 (15,8\%) em casa proveniente de algum tipo de empréstimo e 6 (6,3\%) informaram não possuir residência.

A análise da variável tipo de moradia foi dividida em quatro níveis sendo eles: alvenaria, madeira, material reciclável, entre outros. A maioria dos pacientes (98,9\%) possuía casa de alvenaria, não havendo casos de moradias feitas de material reciclável ou outros, somente um paciente $(1,1 \%)$ residia em casa de madeira e nenhum residia em moradia feita de material reciclável.

A tabela 1 mostra os resultados percentuais das variáveis de caracterização da amostra. 
Tabela 1 - Caracterização sociodemográfica dos indivíduos com tuberculose (TB) e coinfectados tuberculose - vírus da imunodeficiência humana (TB-HIV). São José do Rio Preto-SP, 2006-2007.

\begin{tabular}{|c|c|c|c|c|}
\hline \multirow[t]{2}{*}{ Características } & \multicolumn{2}{|c|}{ TB* } & \multicolumn{2}{|c|}{ TB/HIV** } \\
\hline & $\mathrm{N}=73$ & $76,8 \%$ & $\mathrm{~N}=22$ & $23,2 \%$ \\
\hline \multicolumn{5}{|l|}{ Sexo } \\
\hline Masculino & 47 & 64,4 & 16 & 72,7 \\
\hline Feminino & 26 & 35,6 & 6 & 27,3 \\
\hline \multicolumn{5}{|l|}{ Escolaridade } \\
\hline Sem escolaridade & 5 & 6,9 & 1 & 4,5 \\
\hline Ensino fundamental & 49 & 67,1 & 17 & 77,3 \\
\hline Ensino médio & 16 & 21,9 & 3 & 13,6 \\
\hline Ensino superior & 3 & 4,1 & 1 & 4,6 \\
\hline \multicolumn{5}{|l|}{ Local onde vive } \\
\hline Casa própria & 39 & 53,4 & 9 & 40,9 \\
\hline Casa alugada & 18 & 24,7 & 8 & 36,4 \\
\hline Empréstimo & 11 & 15,1 & 4 & 18,2 \\
\hline Sem moradia & 5 & 6,8 & 1 & 4,5 \\
\hline \multicolumn{5}{|l|}{ Tipo de moradia } \\
\hline Alvenaria & 72 & 98,6 & 22 & 100,0 \\
\hline Madeira & 1 & 1,4 & 0 & 0,0 \\
\hline
\end{tabular}

* TB= tuberculose; **TB/HIV= tuberculose/vírus da imunodeficiência humana.

No que se refere à análise da associação entre as variáveis 'sexo' e 'local onde vive' com o fato de os pacientes serem ou não coinfectados pelo HIV não foram encontradas indícios estatisticamente significativos que comprovassem associação, tabela 2. Observa-se certo equilíbrio percentual de doentes do sexo feminino e masculino, ou seja, independentemente do sexo, a maioria dos doentes não apresenta a coinfecção pelo HIV $(\mathrm{p}=0,468)$. 
Tabela 2 - Distribuição percentual associativa da coinfecção (TB/HIV) em relação ao sexo São José do Rio Preto-SP, 2007.

\begin{tabular}{cccc}
\hline \multirow{2}{*}{ TB/HIV } & \multicolumn{2}{c}{ Sexo } & \multirow{2}{*}{ Valor P } \\
\cline { 2 - 3 } & Masculino & Feminino & \\
\hline Negativo & $47(74,6 \%)$ & $26(81,2 \%)$ & 0,468 \\
Positivo & $16(25,4 \%)$ & $6(18,8 \%)$ & \\
Total & $\mathbf{6 3 ( 1 0 0 , 0 \% )}$ & $\mathbf{3 2}(\mathbf{1 0 0 , 0 \% )}$ & \\
\hline
\end{tabular}

A partir dos dados da Tabela 3 é possível evidenciar que não houve associação entre a coinfecção dos doentes e o local onde os mesmos vivem $(p=0,970)$, sendo que o fato de o doente residir em casa própria, alugada, proveniente de empréstimo ou não ter moradia não influenciou diretamente no fato do doente de TB ser coinfectado pelo HIV.

Tabela 3 - Distribuição percentual associativa da coinfecção em relação ao local onde os doentes analisados vivem São José do Rio Preto-SP, 2007

\begin{tabular}{cccccc}
\hline \multirow{2}{*}{ TB/HIV } & \multicolumn{4}{c}{ Local onde vive } & \multirow{2}{*}{ Valor P } \\
\cline { 2 - 5 } & Casa própria & Casa alugada & Empréstimo & Não possui & \\
\hline Negativo & $37(77,1 \%)$ & $20(76,9 \%)$ & $11(73,3 \%)$ & $5(83,3 \%)$ & 0,970 \\
Positivo & $11(22,9 \%)$ & $6(23,1 \%)$ & $4(26,7 \%)$ & $1(16,7 \%)$ & \\
\hline Total & $\mathbf{4 8 ( 1 0 0 , 0 \% )}$ & $\mathbf{2 6 ( 1 0 0 , 0 \% )}$ & $\mathbf{1 5 ( 1 0 0 , 0 \% )}$ & $\mathbf{6 ( 1 0 0 , 0 \% )}$ & \\
\hline
\end{tabular}

\subsection{Acesso ao Diagnóstico}

Os resultados a seguir mostram o acesso ao diagnóstico dos doentes com TB e que apresentam ou não-coinfecção pelo HIV.

Os resultados dessa análise são suportados pelo teste $t$ para amostras independentes e estão evidenciados nas Figuras 1 (doentes de TB) e na Figura 2 (coinfectados pelo HIV) e na Tabela 4. 


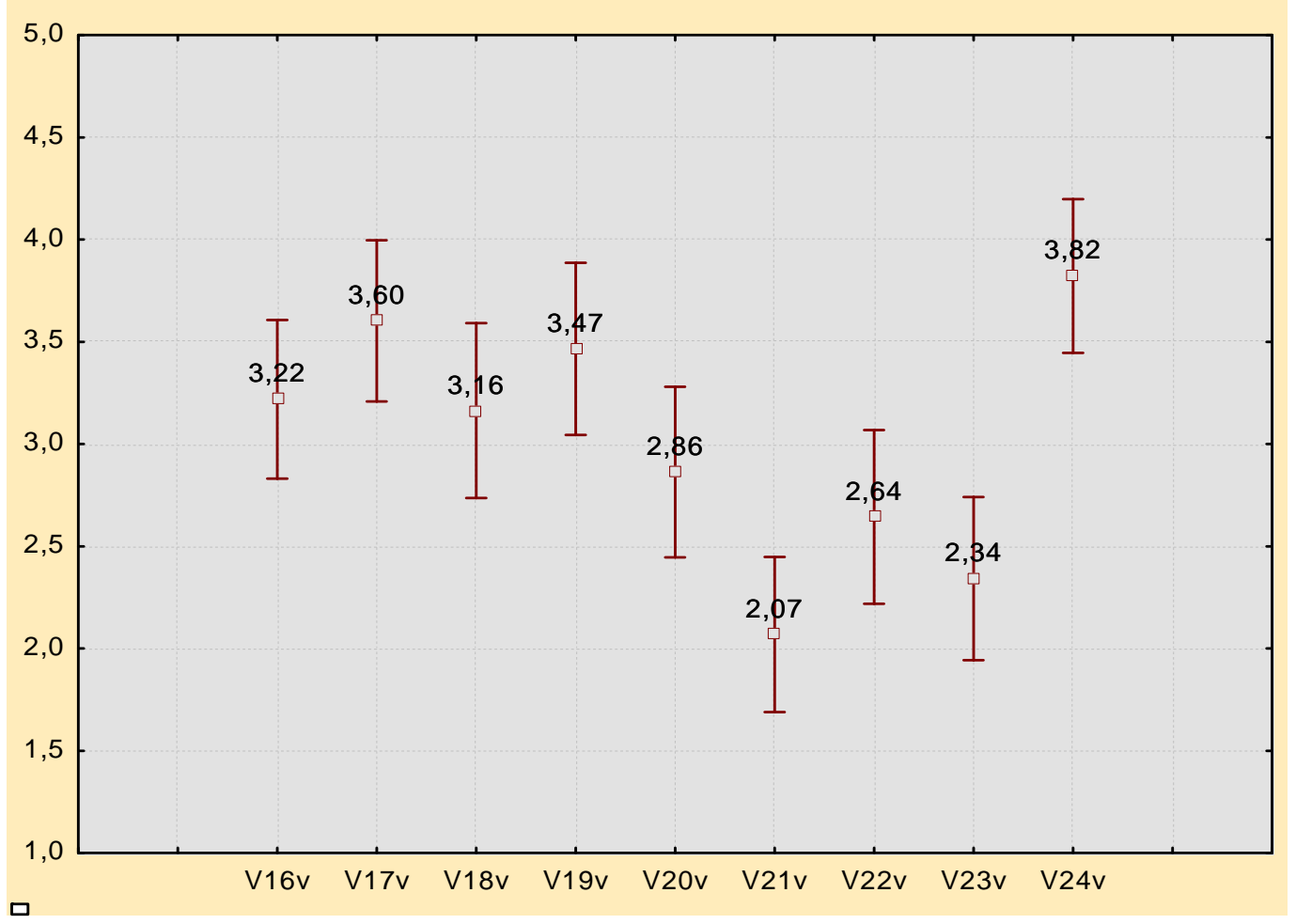

\begin{tabular}{|c|c|c|c|c|}
\hline Variáveis & $\mathbf{n}$ & Média & $\begin{array}{l}\text { Desvio- } \\
\text { padrão }\end{array}$ & $\begin{array}{c}\text { Intervalo de Confiança } \\
(95 \%)\end{array}$ \\
\hline V16 & 73 & 3,22 & 1,66 & $2,83-3,61$ \\
\hline V17 & 73 & 3,60 & 1,69 & $3,21-4,00$ \\
\hline V18 & 73 & 3,16 & 1,83 & $2,74-3,59$ \\
\hline V19 & 73 & 3,47 & 1,80 & $3,04-3,89$ \\
\hline V20 & 73 & 2,86 & 1,79 & $2,45-3,28$ \\
\hline V21 & 73 & 2,07 & 1,63 & $1,69-2,45$ \\
\hline V22 & 73 & 2,64 & 1,82 & $2,22-3,07$ \\
\hline V23 & 73 & 2,34 & 1,71 & $1,94-2,74$ \\
\hline V24 & 73 & 3,82 & 1,61 & $3,45-4,20$ \\
\hline Variável & \multicolumn{4}{|c|}{ Descrição } \\
\hline V16 & \multicolumn{4}{|c|}{$\mathrm{N}^{\circ}$ de vezes que procurou posto de saúde para conseguir atendimento } \\
\hline V17 & \multicolumn{4}{|c|}{ Dificuldade de se deslocar ao posto de saúde } \\
\hline V18 & \multicolumn{4}{|c|}{ Dificuldade de obter informações por telefone no posto de saúde } \\
\hline V19 & \multicolumn{4}{|c|}{ Dificuldades de marcar consulta por telefone no posto de saúde } \\
\hline V20 & \multicolumn{4}{|c|}{ Frequência de faltas no trabalho para se consultar no posto de saúde } \\
\hline V21 & \multicolumn{4}{|c|}{ Necessidade de utilizar transporte motorizado para ir até o posto de saúde } \\
\hline V22 & \multicolumn{4}{|c|}{ Necessidade de gastar dinheiro para se deslocar até o posto de saúde } \\
\hline V23 & \multicolumn{4}{|c|}{ Obtendo a consulta, o diagnóstico da doença foi feito em 24 horas } \\
\hline V24 & \multicolumn{4}{|c|}{ Procura ao posto de saúde mais próximo da moradia do paciente } \\
\hline
\end{tabular}

Figura 1 - Média, desvio-padrão e intervalos de confiança (95\%), dos escores das variáveis que compõem o acesso ao diagnóstico por indivíduos com Tuberculose. 


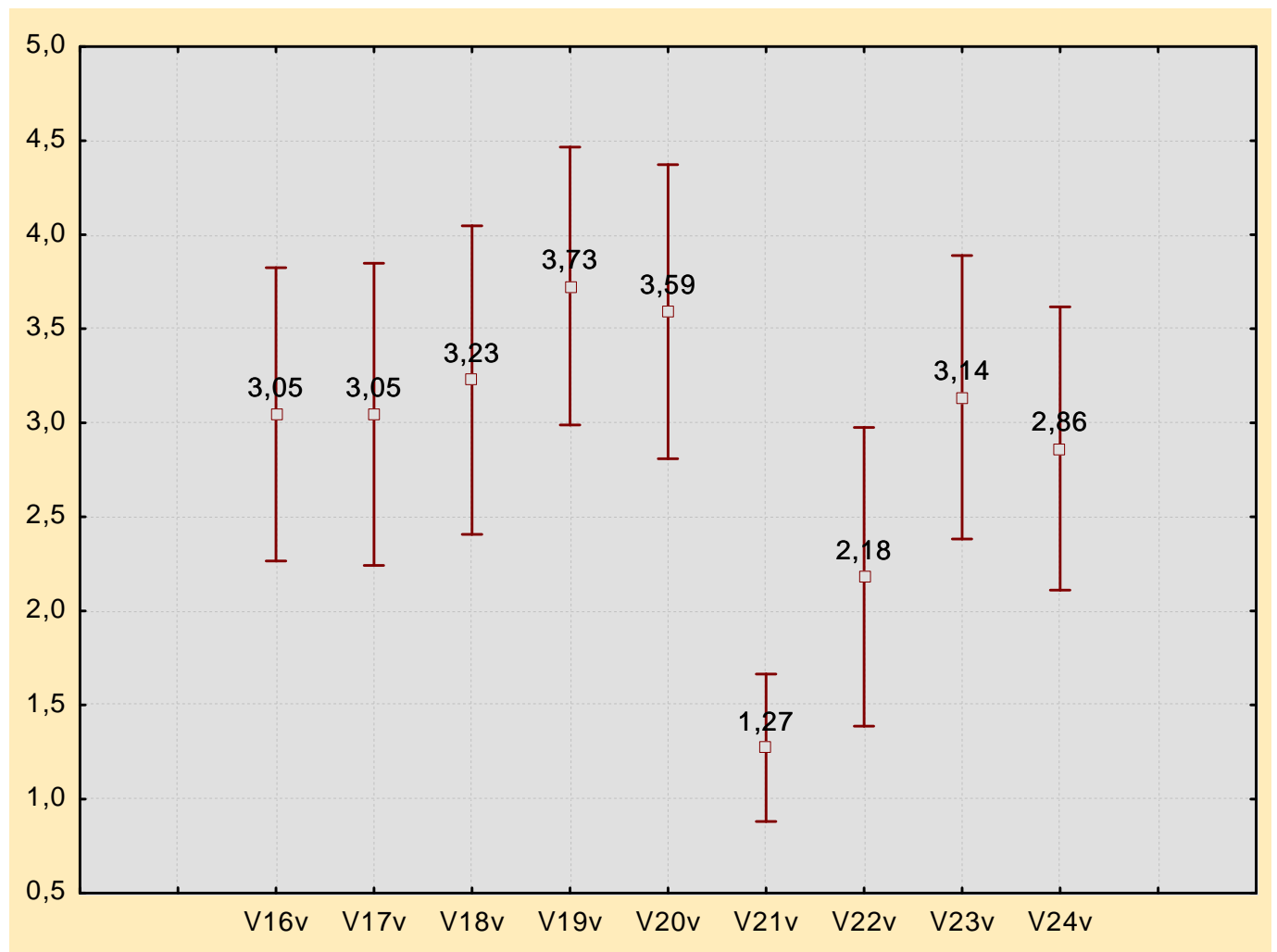

\begin{tabular}{|c|c|c|c|c|}
\hline Variáveis & $\mathbf{n}$ & Média & $\begin{array}{l}\text { Desvio- } \\
\text { padrão }\end{array}$ & $\begin{array}{c}\text { Intervalo de Confiança } \\
(95 \%)\end{array}$ \\
\hline V16 & 22 & 3,05 & 1,76 & $2,27-3,83$ \\
\hline V17 & 22 & 3,05 & 1,81 & $2,24-3,85$ \\
\hline V18 & 22 & 3,23 & 1,85 & $2,41-4,05$ \\
\hline V19 & 22 & 3,73 & 1,67 & $2,99-4,47$ \\
\hline V20 & 22 & 3,59 & 1,76 & $2,81-4,37$ \\
\hline V21 & 22 & 1,27 & 0,88 & $0,88-1,66$ \\
\hline V22 & 22 & 2,18 & 1,79 & $1,39-2,98$ \\
\hline V23 & 22 & 3,14 & 1,70 & $2,38-3,89$ \\
\hline V24 & 22 & 2,86 & 1,70 & $2,11-3,62$ \\
\hline Variável & \multicolumn{4}{|c|}{ Descrição } \\
\hline V16 & \multicolumn{4}{|c|}{$\mathrm{N}^{\circ}$ de vezes que procurou posto de saúde para } \\
\hline V17 & \multicolumn{4}{|c|}{ Dificuldade de se deslocar ao posto de saúde } \\
\hline V18 & \multicolumn{4}{|c|}{ Dificuldade de obter informações por telefone no posto de saúde } \\
\hline V19 & \multicolumn{4}{|c|}{ Dificuldades de marcar consulta por telefone no posto de saúde } \\
\hline V20 & \multicolumn{4}{|c|}{ Frequência de faltas no trabalho para se consultar no posto de saúde } \\
\hline V21 & \multicolumn{4}{|c|}{ Necessidade de utilizar transporte motorizado para ir até o posto de saúde } \\
\hline V22 & \multicolumn{4}{|c|}{ Necessidade de gastar dinheiro para se deslocar até o posto de saúde } \\
\hline V23 & \multicolumn{4}{|c|}{ Obtendo a consulta, o diagnóstico da doença foi feito em 24 horas } \\
\hline V24 & \multicolumn{4}{|c|}{ Procura ao posto de saúde mais próximo da moradia do paciente } \\
\hline
\end{tabular}

Figura 2 - Média, desvio-padrão e intervalos de confiança (95\%),dos escores das variáveis que compõem o acesso ao diagnóstico por indivíduos coinfectados com tuberculose e HIV 
Tabela 4 - Estatísticas descritivas referentes ao acesso ao diagnóstico dos doentes avaliados no período de 2006-2007.

\begin{tabular}{|c|c|c|c|c|c|c|c|}
\hline \multicolumn{8}{|c|}{ Acesso ao diagnóstico } \\
\hline \multirow{2}{*}{ Variáveis } & \multicolumn{3}{|c|}{ Negativo para HIV } & \multicolumn{3}{|c|}{ Positivo para HIV } & \multirow{2}{*}{ Valor $\mathbf{P}$} \\
\hline & $\mathbf{n}$ & $\bar{x} \pm s$ & IC (95\%) & $\mathbf{n}$ & $\bar{x} \pm s$ & IC (95\%) & \\
\hline V16 & 73 & $3,22 \pm 1,66$ & $(2,83 ; 3,61)$ & 22 & $3,05 \pm 1,76$ & $(2,27 ; 3,83)$ & 0,672 \\
\hline V17 & 73 & $3,60 \pm 1,69$ & $(3,21 ; 4,00)$ & 22 & $3,05 \pm 1,81$ & $(2,24 ; 3,85)$ & 0,185 \\
\hline V18 & 73 & $3,16 \pm 1,83$ & $(2,74 ; 3,59)$ & 22 & $3,23 \pm 1,85$ & $(2,41 ; 4,05)$ & 0,888 \\
\hline V19 & 73 & $3,47 \pm 1,80$ & $(3,04 ; 3,89)$ & 22 & $3,73 \pm 1,67$ & $(2,99 ; 4,47)$ & 0,545 \\
\hline V20 & 73 & $2,86 \pm 1,79$ & $(2,45 ; 3,28)$ & 22 & $3,59 \pm 1,76$ & $(2,81 ; 4,37)$ & 0,096 \\
\hline V21 & 73 & $2,07 \pm 1,63$ & $(1,69 ; 2,45)$ & 22 & $1,27 \pm 0,88$ & $(0,88 ; 1,66)$ & $0,046^{1}$ \\
\hline V22 & 73 & $2,64 \pm 1,82$ & $(2,22 ; 3,07)$ & 22 & $2,18 \pm 1,79$ & $(1,39 ; 2,98)$ & 0,297 \\
\hline V23 & 73 & $2,34 \pm 1,71$ & $(1,94 ; 2,74)$ & 22 & $3,14 \pm 1,70$ & $(2,38 ; 3,89)$ & 0,058 \\
\hline V24 & 73 & $3,82 \pm 1,61$ & $(3,45 ; 4,20)$ & 22 & $2,86 \pm 1,70$ & $(2,11 ; 3,62)$ & 0,017 \\
\hline
\end{tabular}

${ }^{1}$ Valor P referente ao teste de Mann-Whitney.

A partir dos resultados observados nas Figuras 1 e 2 e na Tabela 4, pressupõe que há diferenças estatisticamente significativas quando as médias e os intervalos de confiança da variável V24 ( $\mathrm{p}=0,017)$ são comparados quanto ao diagnóstico de doentes com TB e coinfectados pelo HIV. O valor P calculado é inferior ao nível de significância adotado, pressupondo diferenças significativas em relação à procura de um posto de saúde perto da moradia dos doentes avaliados.

Ao comparar o diagnóstico de doentes com TB e coinfectado pelo HIV constata-se que para essa a variável (V24), que as médias são distantes e os intervalos de confiança abrangem valores divergentes entre os diagnósticos. Observa-se que para a V24, o valor mínimo do intervalo de confiança para os doentes com TB igual a 3,45, ao passo que para os doentes coinfectados, o valor máximo do intervalo de confiança é de 3,62. Isso pressupõe a existência de diferenças estatisticamente significativas entre as variáveis analisadas, confirmando o valor P calculado. 
Analisando os valores médios da variável V24, verifica-se que, para V24, os doentes com TB e coinfectados quase nunca ou às vezes procuram o posto de saúde mais próximo da residência sendo o escore médio classificado entre não satisfatório e regular. Os doentes com TB quase sempre procuram o posto de saúde mais próximo da residência, sendo o escore médio classificado como satisfatório.

Um teste de igualdade de variâncias foi realizado para verificar a possibilidade de haver discrepâncias nas variâncias dos dados referentes aos grupos analisados em relação às variáveis que compõem o acesso ao diagnóstico. Assim, utilizou-se o teste de Levene que, por sua vez, consistiu em verificar se a variância do grupo de doentes com TB é igual à variância do grupo de doentes com TB e coinfectados. Nos casos em que ocorreu discrepância nos resultados das variâncias entre os grupos, utilizou-se a análise não-paramétrica.

A aplicação do teste de Levene resultou em discrepâncias nas variâncias dos grupos analisados referentes à V21, visto que o valor P do teste foi menor que 0,05. Assim, o teste de Mann-Whitney foi utilizado somente para embasar as pressuposições estatísticas referentes à V21. Aplicando o teste não-paramétrico aos resultados referentes à V21, o valor P resultou em 0,046, pressupondo a existência de diferenças estatisticamente significativas para os grupos de doentes com TB e doentes com TB e coinfectados em relação à necessidade de utilizar algum transporte motorizado para se dirigir a um posto de saúde. Constata-se que os doentes não coinfectados pelo HIV quase sempre necessitaram utilizar algum transporte motorizado para se dirigir a algum estabelecimento de saúde, ao passo que os doentes coinfectados pelo HIV sempre necessitaram utilizar meio de transporte. Os escores médios desta variável foram classificados como não satisfatórios para os dois grupos de doentes não coinfectados pelo HIV e doentes coinfectados pelo HIV

Com relação aos escores médios das variáveis dos doentes não coinfectados pelo HIV observou-se que as variáveis: teve que deixar de trabalhar ou perder seu dia de trabalho ou compromisso para consultar na unidade de saúde; precisou utilizar algum tipo de transporte motorizado para ir até a unidade saúde; gastou dinheiro com o transporte para ir até a unidade de saúde e conseguiu consulta na unidade de saúde para descobrir a doença no prazo de 24hs obtiveram escores médios não satisfatórios. Foram considerados de regulares a satisfatórios os escores médios das variáveis: o profissional de saúde pergunta se quando começou a adoecer, quantas vezes precisou procurar a unidade de saúde para conseguir atendimento; teve dificuldade para deslocar até a unidade de saúde; teve dificuldades para pedir informação por telefone na unidade de saúde; teve dificuldades para marcar consulta por telefone na unidade de saúde e procurou a unidade de saúde mais perto da sua casa. 
Para os doentes coinfectados pelo HIV, os escores médios das variáveis foram semelhantes aos escores dos doentes não coinfectados exceto para os escores já mencionados como: procurou a unidade de saúde mais perto da sua casa e precisou utilizar algum tipo de transporte motorizado para ir até a unidade saúde. Observou-se também que a variável “conseguiu consulta na unidade de saúde para descobrir a doença no prazo de 24hs” obteve escore classificado como regular para os doentes coinfectados pelo HIV e não satisfatório para os doentes não coinfectados pelo HIV mesmo não apresentando diferenças estatísticas (P $=0,058$ ), o que pode ser explicado pela proximidade do valor de $\mathrm{P}$ ao nível de significância estatística adotado $(\mathrm{P}=0,05)$ para o teste.

\subsection{Acesso ao Tratamento}

O acesso ao tratamento pelos doentes está vinculado às ocorrências que tiveram em relação ao atendimento do posto de saúde. Fatores como falta de medicamentos, tempo de consulta e tempo de espera para a consulta foram avaliados, dentre outros. Os resultados dessa análise são suportados pelo teste $t$ para amostras independentes e estão evidenciados na Tabela 5 e na Figura 3 (doentes de TB) e na Figura 4 (coinfectados pelo HIV). 


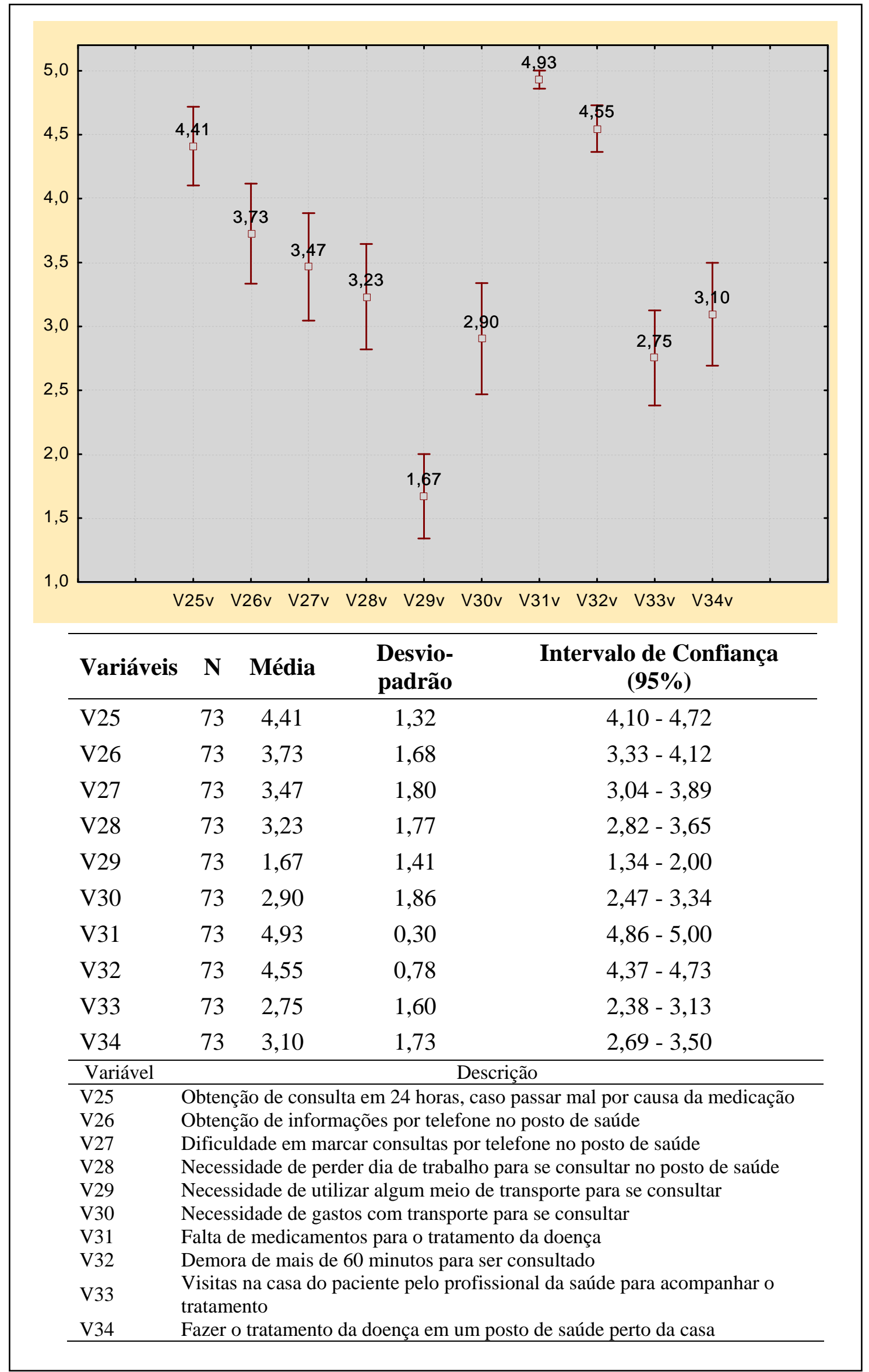

Figura 3 - Média desvio-padrão e intervalos de confiança (95\%), dos escores das varáveis que compõem o acesso ao tratamento por indivíduos com tuberculose. 


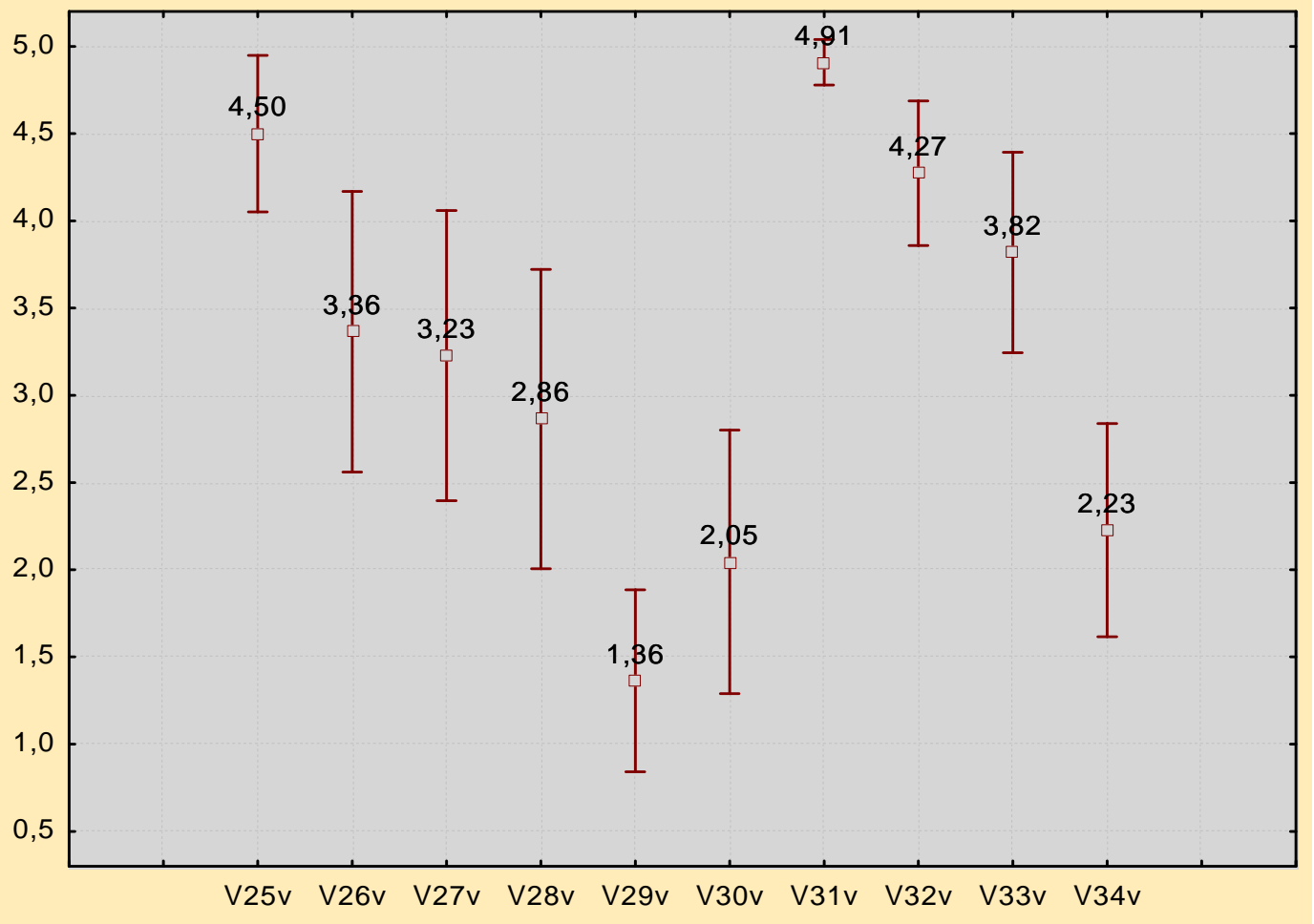

\begin{tabular}{|c|c|c|c|c|}
\hline Variáveis & $\mathbf{n}$ & Média & $\begin{array}{l}\text { Desvio- } \\
\text { padrão }\end{array}$ & $\begin{array}{c}\text { Intervalo de Confiança } \\
(95 \%)\end{array}$ \\
\hline V25 & 22 & 4,50 & 1,01 & $4,05-4,95$ \\
\hline V26 & 22 & 3,36 & 1,81 & $2,56-4,17$ \\
\hline V27 & 22 & 3,23 & 1,88 & $2,40-4,06$ \\
\hline V28 & 22 & 2,86 & 1,93 & $2,01-3,72$ \\
\hline V29 & 22 & 1,36 & 1,18 & $0,84-1,89$ \\
\hline V30 & 22 & 2,05 & 1,70 & $1,29-2,80$ \\
\hline V31 & 22 & 4,91 & 0,29 & $4,78-5,04$ \\
\hline V32 & 22 & 4,27 & 0,94 & $3,86-4,69$ \\
\hline V33 & 22 & 3,82 & 1,30 & $3,24-4,39$ \\
\hline V34 & 22 & 2,23 & 1,38 & $1,62-2,84$ \\
\hline Variável & \multicolumn{4}{|c|}{ Descrição } \\
\hline V25 & \multirow{2}{*}{\multicolumn{4}{|c|}{ Obtenção de consulta em 24 horas, caso passar mal por causa da medicaçã }} \\
\hline V26 & & & & \\
\hline V27 & \multicolumn{4}{|c|}{ Dificuldade em marcar consultas por telefone no posto de saúde } \\
\hline V28 & \multicolumn{4}{|c|}{ Necessidade de perder dia de trabalho para se consultar no posto de saúde } \\
\hline V29 & \multicolumn{4}{|c|}{ Necessidade de utilizar algum meio de transporte para se consultar } \\
\hline V30 & \multicolumn{4}{|c|}{ Necessidade de gastos com transporte para se consultar } \\
\hline V31 & \multicolumn{4}{|c|}{ Falta de medicamentos para o tratamento da doença } \\
\hline V32 & \multicolumn{4}{|c|}{ Demora de mais de 60 minutos para ser consultado } \\
\hline V33 & \multicolumn{4}{|c|}{$\begin{array}{l}\text { Visitas na casa do paciente pelo profissional da saúde para acompanhar o } \\
\text { tratamento }\end{array}$} \\
\hline V34 & \multicolumn{4}{|c|}{ Fazer o tratamento da doença em um posto de saúde perto da casa } \\
\hline
\end{tabular}

Figura 4 - Média, desvio-padrão e intervalos de confiança (95\%), dos escores das variáveis que compõem o acesso ao tratamento por indivíduos coinfectados por tuberculose e HIV. 
Tabela 5 - Estatísticas descritivas referentes ao acesso ao tratamento dos pacientes avaliados, São José do Rio Preto, 2006-2007.

\begin{tabular}{|c|c|c|c|c|c|c|c|}
\hline \multicolumn{8}{|c|}{ Acesso ao tratamento } \\
\hline \multirow{2}{*}{ Variáveis } & \multicolumn{3}{|c|}{ Negativo para HIV } & \multicolumn{3}{|c|}{ Positivo para HIV } & \multirow{2}{*}{ Valor $\mathbf{F}$} \\
\hline & $\mathbf{n}$ & $\bar{x} \pm s$ & IC (95\%) & $\mathbf{n}$ & $\bar{x} \pm s$ & IC (95\%) & \\
\hline V25 & 73 & $4,41 \pm 1,32$ & $(4,10 ; 4,72)$ & 22 & $4,50 \pm 1,01$ & $(4,05 ; 4,95)$ & 0,771 \\
\hline V26 & 73 & $3,73 \pm 1,68$ & $(3,33 ; 4,12)$ & 22 & $3,36 \pm 1,81$ & $(2,56 ; 4,17)$ & 0,385 \\
\hline V27 & 73 & $3,47 \pm 1,80$ & $(3,04 ; 3,89)$ & 22 & $3,23 \pm 1,88$ & $(2,40 ; 4,06)$ & 0,591 \\
\hline V28 & 73 & $3,23 \pm 1,77$ & $(2,82 ; 3,65)$ & 22 & $2,86 \pm 1,93$ & $(2,01 ; 3,72)$ & 0,403 \\
\hline V29 & 73 & $1,67 \pm 1,41$ & $(1,34 ; 2,00)$ & 22 & $1,36 \pm 1,18$ & $(0,84 ; 1,89)$ & 0,356 \\
\hline V30 & 73 & $2,90 \pm 1,86$ & $(2,47 ; 3,34)$ & 22 & $2,05 \pm 1,70$ & $(1,29 ; 2,80)$ & 0,056 \\
\hline V31 & 73 & $4,93 \pm 0,30$ & $(4,86 ; 5,00)$ & 22 & $4,91 \pm 0,29$ & $(4,78 ; 5,04)$ & 0,760 \\
\hline V32 & 73 & $4,55 \pm 0,78$ & $(4,37 ; 4,73)$ & 22 & $4,27 \pm 0,94$ & $(3,86 ; 4,69)$ & 0,170 \\
\hline V33 & 73 & $2,75 \pm 1,60$ & $(2,38 ; 3,13)$ & 22 & $3,82 \pm 1,30$ & $(3,24 ; 4,39)$ & 0,005 \\
\hline V34 & 73 & $3,10 \pm 1,73$ & $(2,69 ; 3,50)$ & 22 & $2,23 \pm 1,38$ & $(1,62 ; 2,84)$ & 0,033 \\
\hline
\end{tabular}

De acordo com os resultados obtidos nas figuras 3 e 4 e na Tabela 5, pressupõe-se a existência de diferenças estatisticamente significativas para as variáveis V33 ( $p=0,005)$ e V34 ( $\mathrm{p}=0$, 033) quando estatísticas calculadas são comparados entre os grupos de doentes com TB e doentes coinfectados. Observa-se que para a variável V33, o valor máximo do IC $(3,13)$ para o grupo não coinfectado é menor que o valor mínimo do IC $(3,24)$ para o grupo coinfectado, ou seja, os intervalos de confiança localizam-se em faixas de valores divergentes, confirmando o valor P calculado. Para a variável V34, o valor máximo do IC $(2,84)$ para o grupo coinfectados é aproximado do valor mínimo do IC $(2,69)$ para o grupo nãocoinfectados. Tal fato também reafirma o valor $\mathrm{P}$ calculado. Além disso, comparando as médias calculadas dessas variáveis em relação à existência da coinfecção pelo HIV, observase à discrepância das mesmas. Para V33, a média calculada para os doentes de TB é de 2,75; ao passo que para os doentes coinfectados é de 3,82. Para a V34, a média dos doentes de TB é de 3,10; no entanto, para os doentes coinfectados, a média é de 2,23. A discrepância entre as 
médias dos grupos também é um fator relevante para pressupor a existência de diferenças significativas.

Os valores $\mathrm{P}$ calculados referem-se às variáveis que indicam o acompanhamento do profissional da saúde ao tratamento dado na residência do paciente (V33) e à possibilidade de realizar o tratamento em um posto de saúde próximo à residência do doente (V34). De acordo com os valores médios calculados, para V33, o profissional da saúde visita mais vezes os doentes acometidos pela coinfecção quando comparados com os doentes que não apresentam a coinfecção. Em contrapartida, para V34, os doentes coinfectados quase nunca realizam o tratamento da doença em um posto de saúde perto da residência. 


\section{DISCUSSÃO}

Quanto à caracterização sociodemográfica dos doentes de TB e coinfectados pelo HIV, destaca-se a predominância de indivíduos do sexo masculino, 64,4\% doentes de TB e 72,7\% coinfectados pelo HIV.

Esses dados corroboram resultados de outros estudos, que analisaram a variável sexo com associação entre TB e HIV e encontraram grande predomínio do sexo masculino, confirmando sua maior vulnerabilidade e prevalência para a coinfecção por Mycobacterium tuberculosis e HIV (CARVALHO et al., 2006; CHEADE et al., 2009).

Considerando o nível de escolaridade os resultados indicam que o ensino fundamental prevaleceu tanto para os doentes de TB quanto para os coinfectados pelo HIV. Outros estudos apontam a mesma realidade, ficando evidente que a baixa escolaridade pode refletir-se em suas possibilidades profissionais, restringindo-os às condições desfavoráveis de vida e emprego, mantendo seu estado de pobreza, com isso dificultando a autopromoção de saúde (CORTEZI, M.D.; SILVA, M.V.; 2006; CHEADE et al., 2009).

Em relação à moradia, a maioria dos doentes residia em casa própria e com estrutura de alvenaria. Estes dados foram consoantes com outra pesquisa (ARCÊNCIO, 2008).

\section{Acesso ao Diagnóstico}

No presente estudo é possível verificar que os doentes coinfectados vivenciaram maiores dificuldades em relação ao acesso ao diagnóstico nas questões: número de vezes que procuraram o posto de saúde para conseguir atendimento, dificuldade de se deslocar ao posto de saúde, necessidade de utilizar transporte motorizado, necessidade de gastar dinheiro para se deslocar até o posto de saúde e na utilização do posto de saúde mais próximo da moradia do paciente que os doentes não coinfectados.

De acordo com os resultados analisados, constatou-se a real necessidade dos doentes de coinfectados em utilizar transporte motorizado para se dirigir a um posto de saúde e, além disso, são eles que não procuraram de forma mais frequente o posto de saúde que se 
localizava mais perto da residência. Tal fato pressupõe que os pacientes coinfectados pelo HIV direcionaram-se de forma freqüente para estabelecimentos que, porventura, possuíssem maior estrutura com relação à facilidade de se obter um diagnóstico preciso e rápido, negativando a ação de postos de saúde que, por sua vez, cedem lugar aos hospitais como alternativa para o diagnóstico. Além disso, como conseqüência desse fato, constatou-se o aumento dos gastos com transporte pelos doentes coinfectados pelo HIV, já que os postos de saúde mais próximos da moradia do paciente são menos utilizados pelos coinfectados.

Conforme Gazetta et al., (2003) verifica-se que a população de São José do Rio PretoSP caracteriza-se por um hábito cultural vinculado à procura de serviços de caráter emergencial, ou seja, optam por direcionar o paciente à emergência mesmo com o desconhecimento da gravidade da doença que acomete o paciente. Este hábito está diretamente correlacionado com o modelo empregado na saúde em nível municipal - modelo caracterizado pelo direcionamento de pacientes a um serviço de referência quaternária (hospital universitário), sendo este o principal local de recebimento de casos desse tipo.

Outra pesquisa desenvolvida no município de São José do Rio Preto-SP mostrou a dificuldade de acesso aos serviços de saúde (VENDRAMINI et al., 2005). Foi apontado o fato de o paciente ter que recorrer às unidades de saúde várias vezes até conseguir chegar ao diagnóstico e iniciar o tratamento (GAZETTA et al., 2007).

Conforme verificado por Dimitrova et al., (2006), há grande incidência de faltas no trabalho para que os pacientes consigam consultas objetivando diagnósticos precisos. Em muitos casos, horários incompatíveis e a demora no atendimento são causas de abandono de tratamento pelo fato de haver reincidência de faltas no trabalho, pois os pacientes apresentam certo receio de perder o respectivo emprego. Tal fato foi possível de ser verificado no estudo comparativo entre os doentes TB e os coinfectados pelo HIV, visto que os doentes coinfectado apresentaram maior incidência de faltas no trabalho.

Outra pesquisa desenvolvida no município de Petrópolis que avaliou a dimensão "acesso aos sistemas serviços na atenção básica”, identificou como barreira no acesso, o horário de atendimento, das unidades somente até as 18 horas (MACINKO; ALMEIDA; OLIVEIRA, 2003).

Em estudo realizado no Estado de São Paulo, os autores classificaram o acesso aos serviços de saúde de insuficientes e enfatizaram que esta dimensão está inserida em um dos pilares mais estruturantes e complexos da atenção básica nos sistemas de saúde (IBAÑEZ et al., 2006). 
Estudos científicos abordam o caráter educacional como uma das fontes da falta de informação por parte dos pacientes quando se relaciona TB com HIV (CARVALHO et al., 2006). Muitos deles desconhecem o fato da infecção pelo HIV otimizar a probabilidade de se contrair TB, visto a debilitação do sistema imunológico do paciente (SOUZA, 2006).

Estudos com a utilização de instrumentos de medição consagrados embasam a estatística dos dados e, com isso, são de extrema importância para direcionar os órgãos competentes a orientar os serviços de saúde para otimizar o acesso ao diagnóstico e ao tratamento dos pacientes acometidos por TB e coinfectados (CHEADE et al., 2009).

Um fator que contribui para a cura da coinfecção é o diagnóstico e tratamento precoce do HIV. O programa de DST/aids do município vem conseguindo ampliar o acesso à testagem e aconselhamento por meio de ações como a implantação de testagem rápida no Centro de Testagem e Aconselhamento (CTA), a partir de dezembro de 2006, expansão dos campos da Unidade Itinerante em bairros distantes (loteamentos irregulares e outros) e campos de prevenção dirigidos a populações específicas, além de empresas e escolas. O programa "Fique Sabendo” também foi ampliado e atualmente todas as unidades de saúde da rede básica do município estão capacitadas e realizam testagem e aconselhamento. Assim, tem-se conseguido diagnosticar os casos de coinfecção mais cedo e tratar precocemente a doença (SANTOS et al.,2009).

De acordo com os resultados, as barreiras econômicas e organizacionais são as que afetam de forma mais direta a negligência quanto ao diagnóstico das doenças.

O fato de os indivíduos infectados não terem acesso aos serviços de saúde contribui para que muitos casos não sejam diagnosticados (MUNIZ et al., 2005).

\section{Acesso ao Tratamento}

Com referência ao acesso ao tratamento, analisando as variáveis que compõem o presente estudo, verificou-se que na maioria delas os escores mais altos foram verificados entre os pacientes acometidos somente por $\mathrm{TB}$, exceto em duas dessas variáveis. Os coinfectados apresentaram maiores escores quando se tratava de se obter uma consulta em menos de 24 horas no caso em que os pacientes se sintam mal e quando o profissional da saúde direciona-se à casa do paciente para acompanhar o tratamento. Caso o paciente se sinta 
mal e quando o profissional da saúde direciona-se à casa do paciente para acompanhar o tratamento

Ao se sentirem doentes as pessoas tendem a procurar por atendimento em serviços de emergência 24 horas, fora de seu horário de trabalho. Esses serviços, pela própria lógica de funcionamento devem ter o mais fácil acesso com relação aos demais, proporcionando rapidez no atendimento (FEKETE, 2001).

Uma variável que atesta as análises realizadas anteriormente está vinculada à procura por um posto de saúde que se localize perto da residência dos pacientes que sofrem somente de TB. Tal fato foi possível também de ser verificado no acesso ao diagnóstico.

O fato de apenas os indivíduos com TB realizarem o tratamento perto da residência pode estar relacionado a aspectos de organização interna das unidades de saúde e não aos geográficos, visto que os pacientes sempre necessitaram utilizar algum meio de transporte para se consultar. Também pode estar relacionada com a compatibilidade do horário de atendimento da unidade, com a disponibilidade de horário e tempo de alguns doentes, qualidade no acolhimento desse doente, estigma da doença e inclusive a questão do vínculo entre os profissionais de saúde e doentes coinfectados pelo HIV (FIGUEIREDO, 2008).

Em ambos os casos de pacientes analisados, constatou-se escores médios satisfatórios para a falta de medicamentos e no tempo de espera de mais de 60 minutos para ser consultado.

Nesse contexto, a falta de uma política organizacional adequada contesta o que se verifica atualmente na saúde em nível nacional. Porém, o que se visualiza nem sempre está correlacionado com a falta de campanhas que prezem por informação ou pela importância de se realizar os exames necessários para se obter o diagnóstico e, por conseguinte, o tratamento de forma mais rápida, mas também se correlaciona com o estigma dos pacientes quanto ao diagnóstico e aos exames referentes ao diagnóstico dessas doenças.

As doenças TB e HIV são historicamente estigmatizadas e o impacto negativo gera consequências drásticas de abandono do tratamento e elevadas taxas de mortalidade (SANTOS, et al. 2009).

Estudos científicos abordam que as barreiras muitas vezes são impostas pelos próprios pacientes. Conforme Lima et al. (1997); Garcia et al. (2000) e Carvalho et al. (2006) o teste de determinação de HIV é considerado discriminatório pelos pacientes e, nesses casos, ele pode optar por não realizá-lo. Esse fato agrava a dinâmica de portadores de TB, pois se verifica que, conforme estudo de Carvalho et al. (2006), cerca de 70 de 165 pacientes de TB (42,4\%) apresentaram coinfecção por HIV, contrastando o que se verifica em outros estudos que, de 
maneira geral, abordam índices em torno de 9\% a 18\%. Assim, quando o paciente de TB recusa-se a realizar o exame de determinação de HIV, o diagnóstico se torna inviável.

Além disso, outro fato importante de ser ressaltado refere-se à condição social dos pacientes acometidos por essas doenças. Todas as variáveis estudadas no acesso ao tratamento podem ser dificultadas por essa condição. Verifica-se que a maioria dos pacientes vivendo em condições desfavoráveis de vida e emprego são os que encontram maiores dificuldades em relação ao acesso ao diagnóstico e ao tratamento (CHEADE et al., 2009).

Nesse contexto, todos os resultados obtidos neste presente estudo estão passíveis de serem influenciados pelas condições sociais dos respondentes, mesmo que não haja pressuposições em nível estatístico que reiterem tal fato.

O que pode ser analisado de forma mais crítica é o fato de todos os pacientes encontrarem dificuldades em relação ao acesso ao tratamento independentemente de serem acometidos somente por TB ou serem coinfectados pelo HIV. Em alguns casos, os pacientes coinfectados pelo HIV apresentam maior facilidade como obter uma consulta em menos de 24 horas caso o paciente se sinta mal e, além disso, recebem profissionais da saúde em suas casas de forma mais frequente para acompanhamento do tratamento. Doentes de TB nem sempre apresentam esses serviços de forma adequada - sendo a questão da gravidade da doença como pressuposição para a ocorrência desse fato.

A falta de recursos humanos na atenção básica de saúde pode resultar em sobrecarga de funções entre os profissionais de saúde e comprometer a capacidade resolutiva dos serviços, o processo de interação com os doentes de TB, bem como o vínculo e a adesão ao processo terapêutico (MONROE et al., 2008). A sobrecarga faz com que os profissionais de saúde visitem mais vezes os doentes coinfectados pelo HIV e também em razão do estado depressor e debilitado dos doentes coinfectados.

Embora os medicamentos para TB estejam disponíveis no serviço público de saúde, ainda representa um custo econômico para o doente de TB em função da necessidade de deslocamento até o serviço de saúde, bem como da perda do turno de trabalho para ser consultado (FIGUEIREDO et al., 2009). 
6. CONSIDERAÇÕES FINAIS 


\section{CONSIDERAÇÕES FINAIS}

A TB e a coinfecção pelo HIV se apresentaram em indivíduos do sexo masculino, predominantemente com ensino fundamental incompleto, que residem em moradia própria e de alvenaria.

Os doentes, muitas vezes, se deparam com barreiras relacionada à organização dos serviços de saúde, em virtude da grande demanda de consultas nos estabelecimentos de saúde, como também pela procura por atendimento especializado, o que constitui uma barreira cultural importante em São José do Rio Preto.

O acesso ao diagnóstico dos doentes não coinfectados e coinfectados pelo HIV foi classificado como regular (valor próximo a 3) na maioria das variáveis, o que mostra a necessidade de melhorar este acesso em todas as questões abordadas neste estudo.

Os escores médios obtidos no acesso ao tratamento mostraram que os doentes coinfectados pelo HIV apresentaram maiores dificuldades na obtenção deste acesso que os doentes não coinfectados pelo HIV. As questões relacionadas à locomoção do paciente ao serviço de saúde (transporte e gasto com transporte) foram as que apresentaram menor desempenho e desta forma merecem maior atenção de gestores e profissionais de saúde.

Ressalta-se a necessidade de integração e comunicação entre o PCT e o DST/Aids, fator este, considerado como facilitador tanto no acesso dos doentes ao diagnóstico quanto ao tratamento da doença. 
7. REFERÊNCIAS 


\section{REFERÊNCIAS}

ALVES, R.; SANTANA, C. C.; CUNHA, A. J. L. A. Epidemiologia da tuberculose infantil na cidade do Rio de Janeiro. Revista de Saúde Pública, São Paulo, v. 34, n. 4, p. 409-410, 2000 .

ARCÊNCIO, R. A. A acessibilidade do doente no tratamento de tuberculose no município de Ribeirão Preto (2007). 2008. 141 f. Tese (Doutorado)-Escola de Enfermagem de Ribeirão Preto. Universidade de São Paulo, Ribeirão Preto, 2008.

BERTAZONE, E. C.; GIR, E. Aspectos gerais da sexualidade dos portadores de tuberculose pulmonar atendidos em unidades básicas de saúde de Ribeirão Preto-SP. Revista LatinoAmericana de Enfermagem, Ribeirão Preto, v. 8, n. 1, p. 115-122, 2000.

BILLINGS, J.; ANDERSON, G. M.; NEWMAN, L. S. Recent findings on preventable hospitalizations. Health Affairs, Millwood, v. 15, n. 3, p. 239-249, 1996.

BODSTEIN, R. Atenção básica na agenda da saúde. Ciência \& Saúde Coletiva, Rio de Janeiro, v. 7, n. 3, p. 401-412, 2002.

BRASIL. Ministério da Saúde. Biblioteca Virtual em Saúde. Perfil da AIDS no Brasil. Brasília; 2007.2 Disponível em: $<\underline{\text { http://bvsms.saude.gov.br/php/level.php?lang=pt\&component }=51 \& i t e m=13}>$. Acesso em: 06 out. 2008.

BRASIL. Ministério da Saúde. Fundação Nacional de Saúde. Centro de Referência Professor Hélio Fraga, Sociedade Brasileira de Pneumologia e Tisiologia. Controle da tuberculose: uma proposta de integração ensino-serviço. 5. ed. Rio de Janeiro: FUNASA/CRPHF/SBPT, 2002.

BRASIL. Ministério da Saúde. Pacto dos indicadores da atenção básica: informe da atenção básica. Disponível em: <http://portal.saúde.gov.br/saúde>. Acesso em: 01 mar. 2005. 
BRASIL. Ministério da Saúde. Portaria no 648, de 28 de março de 2006. Aprova a Política Nacional de Atenção Básica, estabelecendo a revisão de diretrizes e normas para a organização da Atenção Básica para o Programa Saúde da Família (PSF) e o Programa Agentes Comunitários de Saúde (PACS). Diário Oficial [da] República Federativa do Brasil, Brasília, DF, n. 61, 29 mar. 2006. Seção 1.

BRASIL. Ministério da Saúde. Secretaria de Atenção Básica. Manual para organização da atenção básica. Brasília, 1999.

BRASIL. Ministério da Saúde. Secretaria de Vigilância em Saúde. Departamento de Vigilância Epidemiológica. Coordenação Geral Endêmicas. Área Técnica de Pneumologia Sanitária. Programa Nacional de Controle da Tuberculose. Brasília, DF, 2004. Disponível em: <http://bvsms.saude.gov.br/bvs/publicacoes/ProgramaTB.pdf $>$. Acesso em: 17 set. 2008. BRASIL. Ministério da Saúde. Sistema de Informação em Saúde. DATASUS. Disponível em: <http://dtr2004.saude.gov.br/sinanweb/novo>. Acesso em: 17 set. 2008.

CAMPOS, C. E. A. Estratégias de avaliação e melhoria contínua da qualidade no contexto da atenção primária à saúde. Revista Brasileira de Saúde Materno Infantil, Recife. v. 5, p. 563-569, 2005. Suplemento, 1.

CARVALHO, L.G.M. et al. Coinfecção por Mycobacterium tuberculosis e vírus da imunodeficiência humana: uma análise epidemiológica em Taubaté (SP). Jornal Brasileiro de Pneumologia, Brasília, v. 32, n. 5, p. 424-429. 2006.

CASTELO FILHO, A. II Consenso Brasileiro de Tuberculose: diretrizes brasileiras para tuberculose 2004. Jornal Brasileiro de Pneumologia, Brasília, v. 30, p. S2- S56, 2004. Suplemento 1.

CAVALCANTI, Z. R. et al. Características da tuberculose em idosos no Recife (PE): contribuição para o programa de controle. Jornal Brasileiro de Pneumologia, Brasília, v. 32, n. 6, p. 535-543, 2006.

CORTEZI, M. D.; SILVA, M. V. Abandono do tratamento da tuberculose em pacientes coinfectados com HIV, em Itajaí, Santa Catarina, 1999-2004. Boletim de Pneumologia Sanitária, Rio de Janeiro, v. 14, n. 3, p. 145-152, 2006.

CHEADE, M. F. M. et al. Caracterização da tuberculose em portadores de HIV/AIDS em um serviço de referência do Mato Grosso do Sul. Revista da Sociedade Brasileira de Medicina Tropical, Brasília, v. 42, n. 2, p. 119-125, 2009. 
DIMITROVA, B. et al. Health service provider's perceptions of barriers to tuberculosis care in Russia. Health Policy Planning, Oxford, v. 21, n. 4, p. 265-274, 2006.

DONABEDIAN, A. An introduction to quality assurance in helth care. New York: Oxford University Press, 2003.

DONABEDIAN, A. Aspects of medical care administration. Boston: Harvard University Press, 1973.

DOURADO, I. et al. Tendências da epidemia de AIDS no Brasil após terapia anti-retroviral. Revista de Saúde Pública, São Paulo, v. 40, p. 9-17, 2006. Suplemento.

DYE, C.; WATT, C. J.; BLEED, D. Low access to a highly effective therapy: a challenge for international tuberculosis control. Bulletin of the World Health Organization, Geneve, v. 80, n. 6, p. 437-444, 2002.

ELIAS, P. E. et al. Atenção básica em saúde: comparação entre PSF e UBS por estrato de exclusão social no município de São Paulo. Ciência \& Saúde Coletiva, Rio de Janeiro, v. 11, n. 3, p. 633-641, 2006.

FEKETE, M. C. Estudo da acessibilidade na avaliação dos serviços de saúde. In: SANTANA, J. P. et al. (Org.). Desenvolvimento gerencial de unidades básicas do sistema único de saúde (SUS). Brasília: OPAS/OMS, 1997. p. 114-120.

FEKETE, M. C. Planejamento e programação local em saúde. Bases conceituais e metodológicas do planejamento em saúde. In: BRASIL. Ministério da Saúde. Gestão Municipal de Saúde: textos básicos. Brasília (DF), 2001, p. 201-217. Disponível em: $<$ http://portal.saude.gov.br/portal/arquivos/pdf/gestao_municipal_de_saude.pdf $>$. Acesso em: 27 out. 2009.

FIGUEIREDO, T. M. R. M. Acesso ao tratamento de tuberculose: avaliação das características organizacionais e de desempenho dos serviços de saúde - Campina Grande/PB, Brasil (2007). 2008. 120 f. Tese (Doutorado)-Escola de Enfermagem de Ribeirão Preto, Universidade de São Paulo, Ribeirão Preto, 2008.

FIGUEIREDO, T. M. R. M. et al. Desempenho da atenção básica no controle da tuberculose. Revista de Saúde Pública, São Paulo, v. 43, n. 5, p. 825-831, 2009. 
FRANCO, C. Avaliação de exposição ocupacional como risco para infecção pelo mycobacterium tuberculosis no Hospital de Base de São José do Rio Preto, S.P. 2003. 117 f. Dissertação (Mestrado)-Faculdade de Medicina de São José do Rio Preto, São José do Rio Preto, 2003.

FREIRE, D. N.; BONAMETTI, A. M.; MATSUO, T. Diagnóstico precoce e progressão da tuberculose em contatos. Epidemiologia e Serviços de Saúde, Brasília, v. 16, n. 3, p. 155163, 2007.

GARCIA, G. F. et al. Prevalência da infecção pelo HIV em pacientes internados por tuberculose. Jornal de Pneumologia, Brasília, v. 26, n. 4, p. 189-193, 2000.

GAZETTA, C. E. et al. Estudo descritivo sobre a implantação da estratégia de tratamento de curta duração diretamente observado no controle da tuberculose em São José do Rio Preto e seus impactos (1998-2003). Jornal Brasileiro de Pneumologia, Brasília, v. 33, n. 2, p. 192198, 2007.

GAZETTA, C. E. et al. Aspectos epidemiológicos da tuberculose em São José do Rio Preto SP a partir de notificações da doença em um hospital escola (1993-1998). Pulmão RJ, Rio de Janeiro, v. 12, n. 3, p. 155-162, 2003.

GIR, E.; VAICHULONIS, C. G.; OLIVEIRA, M. D. Adesão à terapêutica anti-retroviral por indivíduos com HIV/AIDS assistidos em uma instituição do interior paulista. Revista LatinoAmericana Enfermagem, Ribeirão Preto, v. 13, n. 5, p. 634-641, 2005.

HANE, F. et al. Identifying barriers to effective tuberculosis control in Senegal: an anthropological approach. International Journal of Tuberculosis and Lung Disease, Paris, v. 11, n. 5, p. 539-543, 2007.

HOUAISS, A.; VILLAR, M. Minidicionário Houaiss da língua portuguesa. Rio de Janeiro: Objetiva, 2001.

IBAÑEZ, N. et al. Avaliação do desempenho da atenção básica no Estado de São Paulo. Ciência \& Saúde Coletiva, Rio de Janeiro, v. 11, n. 3, p. 683-703, 2006.

JAISWAL, A. et al. Adherence to tuberculosis treatment: lessons from the urban setting of Delhi, India. Tropical Medicine and International Health, Oxford, v. 8, n. 7, p. 625-633, 2003. 
JAMAL, L. F.; MOHERDAUI, F. Tuberculose e infecção pelo HIV no Brasil: magnitude do problema e estratégias para o controle. Revista de Saúde Pública, São Paulo, v. 41, p. 104110, 2007. Suplemento 1.

JARAMILLO, E. Encompassing treatment with prevention: the path for a lasting control of tuberculosis. Social Science and Medicine, Oxford, v. 49, n. 3, p. 393-404, 1999.

LEUNG, E. C.; LEUNG, C. C.; TAM, C. M. Delayed presentation and treatment of newly diagnosed pulmonary tuberculosis patients in Hong Kong. Hong Kong Medical Journal, Hong Kong, v. 13, n. 3, p. 221-227, 2007.

LIMA, M. M. et al. Coinfecção HIV/Tuberculose: necessidade de uma vigilância mais efetiva. Revista de Saúde Pública, São Paulo, v. 31, n. 3, p. 217-220, 1997.

LUCCA, M. E. S. Análise epidemiológica da tuberculose e co-infecção HIV/TB, em Ribeirão Preto-SP, de 1998-2006. 2008. 134 f. Dissertação (Mestrado)-Faculdade de Medicina de Ribeirão Preto, Universidade de São Paulo, Ribeirão Preto, 2008.

MACINKO, J.; ALMEIDA, C.; OLIVEIRA, E. Avaliação das características organizacionais dos serviços de atenção básica em Petrópolis: teste de uma metodologia. Saúde em Debate, Londrina, v. 27, n. 65, p. 243-256, 2003.

MAGUALHÃES, R.; BURLANDY, L.; SENNA, M. C. M. Desigualdades sociais, saúde e bem-estar: oportunidades e problemas no horizonte de políticas públicas transversais. Ciência \& Saúde Coletiva, Rio de Janeiro, v. 12, n. 6, p. 1415-1421, 2007.

MENDES, E. V. A atenção primária à saúde no SUS. Ceará: Escola de Saúde Pública, 2002. 92p.

MENDES, E. V. O SUS que temos e o SUS que queremos: uma agenda para a saúde. Revista Mineira de Saúde Pública, Belo Horizonte, v. 3, n. 4, p. 4-26, 2004.

MONROE, A. A. et al. Envolvimento de equipes da atenção básica à saúde no controle da tuberculose. Revista da Escola de Enfermagem da USP, São Paulo, v. 42, n. 2, p. 262-268, 2008.

MUNIZ, J. N. et al. A incorporação da busca ativa de sintomáticos respiratórios para o controle da tuberculose na prática do agente comunitário de saúde. Ciência \& Saúde Coletiva, Rio de Janeiro, v. 10, n. 2, p. 315-321, 2005. 
MUNIZ, J. N.; VILLA, T. C. S.; RUFFINO-NETO, A. Experiência de implantação do DOTS em Ribeirão Preto. In: RUFFINO-NETTO, A.; VILLA, T. C. S. (Org). Tuberculose: implantação do DOTS em algumas regiões do Brasil: histórico e peculiaridades regionais. Ribeirão Preto: Faculdade de Medicina de Ribeirão Preto/USP, 2006. p. 113-122.

NEVES, L. A. S.; GIR, E. Mães portadoras do HIV/Aids: percepções acerca da severidade da infecção. Revista da Escola de Enfermagem da USP, São Paulo, v. 41, n. 4, p. 613-618, 2007.

OLIVEIRA, A. R. Avaliando as condições de acessibilidade dos doentes de tuberculose ao diagnóstico e tratamento em serviços de saúde no município de Campina Grande/PB. 2008. 143 f. Dissertação (Mestrado)-Universidade Federal da Paraíba, Campina Grande, 2008.

OLIVEIRA, H. B.; MARIN-LEÓN, L.; CARDOSO, J. C. Perfil da mortalidade de pacientes com tuberculose relacionada à comorbidade tuberculose-AIDS. Revista de Saúde Pública, São Paulo, v. 38, n. 4, p. 503-510, 2004.

OLIVEIRA, M. F. et al. O acesso ao diagnóstico da tuberculose nos serviços de saúde do município de Ribeirão Preto - SP (2007). In: VILLA, T. C. S.; RUFFINO NETTO, A. (Org.). Tuberculose: pesquisas operacionais. Ribeirão Preto: FUNPEC Editora, 2009. p. 36-42.

ORGANIZAÇÃO MUNDIAL DE SAÚDE. Alma Ata 1978. Cuidados Primários de Saúde. Relatório de conferência internacional sobre cuidados primários de saúde. Brasília, DF: OMS/UNICEF, 1979.

ORGANIZAÇÃO PAN-AMERICANA DA SAÚDE. Validação de uma metodologia de avaliação rápida das características organizacionais e do desempenho dos serviços de atenção básica do Sistema Único de Saúde (SUS) em nível local. Brasília, DF: Organização Pan-Americana da $2006 . \quad 215 p . \quad$ Disponível em: $<$ http://iah.iec.pa.gov.br/iah/fulltext/pc/monografias/ms/pdsss/pdsss-v10.pdf $>$. Acesso em: 05 jul. 2008.

ORGANIZAÇÃO PANAMERICANA DE LA SAÚDE. Informação geral sobre a tuberculose e o HIV. Geneva, 2004. Disponível em: $<$ http://who.int/tb/who/htm/tb/2004.329/chap1.pdf > . Acesso em: 06 out. 2008.

PASSOS, A. D. C.; RUFFINO-NETTO, A. Estudos transversais. In: FRANCO, L. J.; PASSOS, A. D. C. (Org.). Fundamentos de epidemiologia. São Paulo: Manole, 2005. p. 262. 
PIRES, M. R. G. M.; GOTTEMS, L. B. D. Análise da gestão do cuidado no programa de saúde da família: referencial teórico-metodológico. Revista Brasileira de Enfermagem, Brasília, v. 62, n. 2, p. 294-299, 2009.

PONCE, M. A. Z. et al. A co-morbidade tuberculose e AIDS em São José do Rio Preto: aspectos epidemiológicos e sociais (1998-2006). In: VILLA, T. C. S.; RUFFINO NETTO, A. (Org.). Tuberculose: pesquisas operacionais. Ribeirão Preto: FUNPEC, 2009. p. 108-114.

REIS, R. K.; GIR, E. Caracterização da produção científica sobre doenças sexualmente transmissíveis e HIV/AIDS publicados em periódicos de enfermagem do Brasil. Revista da Escola de Enfermagem da USP, São Paulo, v. 36, n. 4, p. 376-385, 2002.

RUFFINO-NETTO, A. Tuberculose: a calamidade negligenciada. Revista da Sociedade Brasileira de Medicina Tropical, Brasília, v. 35, n. 1, p. 51-58, 2002.

RUFFINO-NETTO, A.; VILLA, T. C. S. Tuberculose: implantação do DOTS em algumas regiões do Brasil, histórico e peculiaridades regionais. Ribeirão Preto: Faculdade de Medicina de Ribeirão Preto/Rede TB-USP, 2006. 210p.

SA, L. D. et al. Tuberculosis treatment in family health units: stories of abandonment. Texto \& Contexto-Enfermagem, Florianópolis, v. 16, n. 4, p. 712-718, 2007.

SAGBAKKEN, M.; FRICH, J. C.; BJUNE, G. Barriers and enablers in the management of tuberculosis in Addis Ababa, Ethiopia: a qualitative study. BMC Public Health, 2008. Disponível em: < http://www.biomedcentral.com/content/pdf/1471-2458-8-11.pdf>. Acesso em: 10 mar. 2008.

SANCHEZ, A. I. M. O tratamento diretamente observado "DOTS" e a adesão ao tratamento da tuberculose: significados para os trabalhadores de unidades de saúde da região central do município de São Paulo - São Paulo - Brasil. 2007. 151 f. Tese (Doutorado)Escola de Enfermagem da Universidade de São Paulo, São Paulo, 2007.

SANTOS, M.L.S.G. et al. A estratégia DOTS em municípios prioritários para o controle da tuberculose no estado de São Paulo. In: VILLA, T.C.S.; RUFFINO-NETTO, A. (org.). Tuberculose: Pesquisas Operacionais. São Paulo: FUNPEC, 2009.p. 185-213.

SANTOS, M. L. S. G. et al. The epidemiological dimension of TB/HIV co-infection. Revista Latino-Americana de Enfermagem, Ribeirão Preto, v. 17, n. 5, p. 683-688, 2009. 
SÃO JOSÉ DO RIO PRETO (SP). Prefeitura Municipal de São José do Rio Preto. Secretaria Municipal de Saúde. Sistema Único de Saúde São José do Rio Preto: Experiências Bem Sucedidas. São José do Rio Preto: SUS, [2008?]. 152p.

SÃO JOSE DO RIO PRETO. Prefeitura Municipal. Secretaria Municipal de Planejamento e Gestão estratégica. Conjuntura Econômica 2008, São Jose do Rio Preto, 2008.

SECRETARIA DO ESTADO DE SÃO PAULO. Coordenadoria de Controle de Doenças. Tuberculose no Estado de São Paulo. Indicadores de morbimortalidade e indicadores de desempenho. Boletim Epidemiológico Paulista, São Paulo, v. 3, p. S7-37, 2006. Suplemento 4.

SELIG, L. et al. Óbitos atribuídos à tuberculose no Estado do Rio de Janeiro. Jornal Brasileiro de Pneumologia, Brasília, v. 30, n. 4, p. 417-424, 2004.

SOUZA, M. V. N. Tuberculose em pacientes HIV-positivos, um grave problema de saúde pública mundial. Revista Brasileira de Farmácia, Rio de Janeiro, v. 87, n. 2, p. 42-44, 2006.

STARFIELD, B. Atenção primária: equilíbrio entre necessidades de saúde, serviços e tecnologia. Brasília: UNESCO, Ministério da Saúde, 2002. 726 p.

THIEDE, M.; MCINTYRE, D. Information, comunication and equitable acess to helth care: a conceptual note. Cadernos de Saúde Pública, Rio de Janeiro, v. 24, n. 5, p. 1168-1173, 2008.

TRAVASSOS, C.; CASTRO, M. S. M. Determinantes e desigualdades sociais no acesso e na utilização de serviços de saúde. In: GIOVANELLA, L. et al. Políticas e sistemas de saúde no Brasil. Rio de Janeiro: FIOCRUZ, 2008. p. 215-243.

TRAVASSOS, C.; MARTINS, M. Uma revisão sobre os conceitos de acesso e utilização de serviços de saúde. Cadernos de Saúde Pública, Rio de Janeiro, v. 20, p. S190-S198, 2004. Suplemento, 2.

VENDRAMINI, S. H. F. et al. Current epidemiological aspects of. tuberculosis and the impacto of the DOTS strategy in disease control. Revista Latino-Americana Enfermagem, Ribeirão Preto, v. 15, n. 1, p. 171-173, 2007.

VENDRAMINI, S. H. F. et al. Experiência de implantação do DOTS em São José do Rio Preto. In: VILLA, T. C. S.; RUFFINO NETTO, A. (Org.). Tuberculose: implantação do 
DOTS em algumas regiões do Brasil; histórico e peculiaridades regionais. Ribeirão Preto: Faculdade de Medicina de Ribeirão Preto/USP, 2006. p. 122-135.

VENDRAMINI, S. H. F. O programa de controle da tuberculose em São José do Rio Preto-S. P 1985-2004: do contexto epidemiológico à dimensão social. 2005. 251 f. Tese (Doutorado)-Escola de Enfermagem de Ribeirão Preto, Universidade de São Paulo, Ribeirão Preto, 2005.

VILLA, T. C. S. et al. Experiência da implantação da estratégia DOTS no Estado de São Paulo (1998-2005). In: VILLA, T. C. S.; RUFFINO NETTO, A. (Org.). Tuberculose: implantação do DOTS em algumas regiões do Brasil: histórico e peculiariedades regionais. Ribeirão Preto: FMRP/USP, 2006. p. 75-139.

VILLA, T. C. S. et al. Fatores preditivos aos resultados desfavoráveis no tratamento da tuberculose: revisão integrativa da literatura (2001-2005). Online Brazilian Journal of Nursing, $2008 . \quad$ Disponível em: <http://www.uff.br/objnursing/index.php/nursing/article/view/j.1676-4285.2008.1098>.

Acesso em: 27 nov. 2008.

VILLA, T. C. S.; RUFFINO-NETTO, A. Questionário para avaliação de desempenho de serviços de atenção básica no controle da tuberculose no Brasil. Jornal Brasileiro de Pneumologia, Brasília, v. 35, n. 6, p. 610-612, 2009.

VITÓRIA, M. A. A. Concertos e recomendações básicas para melhorar a adesão ao tratamento anti-retroviral. Brasília: Ministério da Saúde, 2006. Disponível em: <http://www.aids.gov.br/assistencia/Adesaoarv.html>. Acesso em: 27 nov. 2008.

WORLD HEALTH ORGANIZATION, 1978 apud STARFIELD, B. Atenção primária: equilíbrio entre necessidades de saúde, serviços e tecnologia. Brasília: UNESCO, Ministério da Saúde, 2002.

WORLD HEALTH ORGANIZATION. Global tuberculosis control: Geneva: WHO, 2009.

WORLD HEALTH ORGANIZATION. Global tuberculosis control: surveillance, planning, financing. Geneva: WHO; 2005.

WORLD HELATH ORGANIZATION. Global Tuberculosis Control: surveillance, planning, financing. Geneva: WHO, 2008. 


\section{ANEXOS}

\section{ANEXO I: QUESTIONÁRIO}

\section{Doentes de Tuberculose}

Número do questionário:
Município:
Data da digitação dos dados:
Digitador:

Grupo de Estudos Operacionais em Tuberculose / CNPq

Rede Brasileira de Pesquisa em Tuberculose

\section{Questionário sobre Avaliação da organização e do desempenho dos serviços de atenção} básica no controle da TB em centros urbanos de diferentes regiões do Brasil

(Para ser aplicado aos doentes de TB)

\section{Apresentação:}

Bom dia!

Meu nome é...

Estou realizando uma pesquisa.

Posso conversar um pouco com o(a) Sr.(a)?

$\mathrm{O}(\mathrm{A})$ Sr.(a) aceita participar desta pesquisa?.

Observação: Ler o Termo de Consentimento Livre e Esclarecido e solicitar a assinatura ou impressão digital.

Só após a aceitação do sujeito poderá ser iniciada a aplicação do Questionário.

Atualizado em 01 de junho de 2007

Este instrumento é baseado num questionário elaborado por James Macincko (New York University) e Célia Almeida (ENPS-FIOCRUZ), norteado por Bárbara Starfield, MD, MPH, FRPCGP e James Macincko, PHD.D, Dept. of Health Policy \& Management, John Hopkins, Bloomberg School of Public Health, Baltimore, MD. USA.

Adaptado para a atenção à tuberculose por Tereza Cristina Scatena Villa (EERP-USP/ Área Operacional REDE-TB) e Antonio Ruffino Netto (FMRP/ REDE-TB).

Nome do Entrevistador:.

Data:

Município: Estado: 


\begin{tabular}{|c|c|c|c|}
\hline \multicolumn{4}{|c|}{ A. INFORMAÇÕES GERAIS. } \\
\hline 1 & \begin{tabular}{|l|} 
Código \\
identificador \\
(N ${ }^{0}$ SINAM ou \\
WEB-TB) do \\
entrevistado \\
\end{tabular} & & \\
\hline \multirow[t]{2}{*}{2} & Iniciais do & \multicolumn{2}{|l|}{ Iniciais: } \\
\hline & $\begin{array}{ll}\text { entrevistado } & \mathrm{e} \\
\mathrm{N}^{\mathrm{O}} & \text { do } \\
\text { Prontuário: } & \end{array}$ & Prontuário: & \\
\hline 3 & \begin{tabular}{|l|}
$\begin{array}{l}\text { Endereço } \\
\text { completo do } \\
\text { entrevistado }\end{array}$ \\
\end{tabular} & & \\
\hline 4 & $\begin{array}{|lr|}\text { Nome ra da } & \text { da } \\
\text { Unidade de } A B\end{array}$ & & \\
\hline 5 & $\begin{array}{|lr|}\text { Endereço ra } \\
\text { Unidade de } & \mathrm{AB} \\
\end{array}$ & & \\
\hline \multirow[t]{2}{*}{6} & $\begin{array}{|ll|}\text { Tipo } & \text { de } \\
\text { Unidade } & \\
\end{array}$ & & \\
\hline & UBS & $1(\mathrm{r})$ & \\
\hline & UBS/PACS & 2() & \\
\hline & USF/PACS & 3() & \\
\hline & $\begin{array}{l}\text { Ambulatório de } \\
\text { Referência }\end{array}$ & $4($ ) & \\
\hline \multirow[t]{2}{*}{7} & \multirow{2}{*}{$\begin{array}{lr}\text { Unidade } & \text { de } \\
\text { saúde } & \text { que } \\
\text { diagnosticou } & \\
\text { caso } & \end{array}$} & \multicolumn{2}{|l|}{ Nome: } \\
\hline & & End $: \quad$ & _ Bairro: \\
\hline 8 & Faz Tratamento & Sim & Não \\
\hline & Supervisionado & & \\
\hline 9 & \multicolumn{3}{|c|}{ Local de Atendimento } \\
\hline \multirow[t]{5}{*}{$9^{\mathrm{a}}$} & \multirow{5}{*}{\begin{tabular}{|ll} 
Consulta & \\
Médica de \\
Controle
\end{tabular}} & USF/PACS & $1(\mathrm{)}$ \\
\hline & & UBS & 2() \\
\hline & & UBS/PACS & 3() \\
\hline & & Ambulatório de Referência & 4() \\
\hline & & Domicílio & 5() \\
\hline \multirow[t]{5}{*}{$9 b$} & \multirow{5}{*}{\begin{tabular}{|l} 
Tratamento \\
Supervisionado
\end{tabular}} & USF/PACS & 1() \\
\hline & & UBS & 2() \\
\hline & & UBS/PACS & 3() \\
\hline & & Ambulatório de Referência & $4(\mathrm{r})$ \\
\hline & & Domicílio & 5() \\
\hline
\end{tabular}

\section{B. INFORMAÇÕES SÓCIO-DEMOGRÁFICAS SOBRE O DOENTE DE TB.}

\begin{tabular}{|l|l|l|l|}
\hline \multirow{2}{*}{$10 . \mathrm{a}$} & Sexo do usuário & Feminino & $0($ ) \\
\cline { 3 - 4 } & & Masculino & $1($ ) \\
\hline
\end{tabular}




\begin{tabular}{|c|c|c|c|}
\hline \multirow[t]{7}{*}{ 10.b } & \multirow{7}{*}{$\begin{array}{l}\text { Qual foi a última } \\
\text { série escolar que } \\
\text { o(a) Sr.(a) cursou? }\end{array}$} & Sem escolaridade & 0() \\
\hline & & $\begin{array}{l}\text { Ensino Fundamental }\left(1^{\circ} \text { grau }\right. \\
\text { incompleto) }\end{array}$ & $1($ ) \\
\hline & & $\begin{array}{l}\text { Ensino Fundamental }\left(1^{\circ} \text { grau }\right. \\
\text { completo) }\end{array}$ & $2($ ) \\
\hline & & Ensino Médio ( $2^{\circ}$ grau incompleto) & 3() \\
\hline & & Ensino médio ( $2^{\circ}$ grau completo $)$ & $4(\mathrm{r})$ \\
\hline & & $\begin{array}{l}\text { Ensino superior (universitário) } \\
\text { incompleto }\end{array}$ & $5($ ) \\
\hline & & $\begin{array}{l}\text { Ensino superior (universitário) } \\
\text { completo }\end{array}$ & $6($ ( ) \\
\hline \multirow[t]{6}{*}{$10 . c$} & \multicolumn{3}{|c|}{ O local onde o(a) Sr.(a) vive é: } \\
\hline & \begin{tabular}{|l|} 
Própria \\
\end{tabular} & \multicolumn{2}{|l|}{$1(\mathrm{)})$} \\
\hline & Alugada & \multicolumn{2}{|l|}{$2($ ) } \\
\hline & Empréstimo & \multicolumn{2}{|l|}{$3($ ) } \\
\hline & $\begin{array}{l}\text { Instituição (asilar/ } \\
\text { abrigo/outros) }\end{array}$ & \multicolumn{2}{|l|}{4()} \\
\hline & Não tem moradia & \multicolumn{2}{|l|}{$5($ ) } \\
\hline
\end{tabular}

\begin{tabular}{|c|c|c|c|c|}
\hline \multirow[t]{5}{*}{ 10.d } & \multicolumn{4}{|c|}{ Tipo de Moradia } \\
\hline & Alvenaria & \multicolumn{3}{|l|}{$1(\mathrm{r})$} \\
\hline & Madeira & \multicolumn{3}{|l|}{2()} \\
\hline & \begin{tabular}{|l|} 
Material \\
Reciclável
\end{tabular} & \multicolumn{3}{|l|}{$3($ ) } \\
\hline & Outros & \multicolumn{3}{|l|}{$\begin{array}{l}\text { ( ) ) } \\
\text { Especifique: }\end{array}$} \\
\hline \multirow[t]{10}{*}{ 10.e } & \multicolumn{4}{|c|}{ O(A) Sr.(a) têm em sua moradia? } \\
\hline & & \multicolumn{3}{|r|}{ Não } \\
\hline & \multicolumn{4}{|l|}{ Água } \\
\hline & \multicolumn{4}{|l|}{ Geladeira } \\
\hline & \multicolumn{4}{|l|}{\begin{tabular}{|l} 
Telefone \\
(Cel. Ou \\
Fixo)
\end{tabular}} \\
\hline & \multicolumn{4}{|l|}{ Carro } \\
\hline & \multicolumn{4}{|l|}{ Luz Elétrica } \\
\hline & \multicolumn{4}{|l|}{\begin{tabular}{|l|} 
Banheiro \\
dentro casa
\end{tabular}} \\
\hline & \multicolumn{4}{|l|}{ Rádio } \\
\hline & \multicolumn{4}{|l|}{ Televisão } \\
\hline \multirow[t]{6}{*}{$10 . \mathrm{f}$} & \multicolumn{4}{|c|}{ Número de cômodos da sua casa INCLUINDO o banheiro: } \\
\hline & 1 Cômodo & \multicolumn{3}{|l|}{$1(\mathrm{r})$} \\
\hline & 2 Cômodos & \multicolumn{3}{|l|}{$2(\mathrm{l})$} \\
\hline & 3 Cômodos & \multicolumn{3}{|l|}{$3(\mathrm{r})$} \\
\hline & 4 Cômodos & \multicolumn{3}{|l|}{$4(\mathrm{)}$} \\
\hline & $\begin{array}{l}5 \text { ou mais } \\
\text { Cômodos }\end{array}$ & \multicolumn{3}{|l|}{$5($ ) } \\
\hline & & 4 ou mais pessoas & $2-3$ pessoas & 1 pessoa \\
\hline & & 1 & 2 & 3 \\
\hline
\end{tabular}




\begin{tabular}{|l|l|l|l|l|}
\hline $10 . g$ & $\begin{array}{l}\text { Número de } \\
\text { pessoas } \\
\text { residentes } \\
\text { em sua casa? }\end{array}$ & & \\
\hline $10 . h$ & $\begin{array}{l}\text { Número de } \\
\text { adultos } \\
\text { maiores de } \\
60 \text { anos? }\end{array}$ & & \\
\hline $10 . i$ & $\begin{array}{l}\text { Número de } \\
\text { crianças de } \\
\text { (menores de } \\
12 \text { anos)? }\end{array}$ & & \\
\hline
\end{tabular}

OBS: MOSTRAR E EXPLICAR AO ENTREVISTADO O CARTÃO DE RESPOSTAS: A-BC

C. SAÚDE DO CASO CONFIRMADO DE TB.

\begin{tabular}{|c|c|c|c|c|c|c|}
\hline \multirow{2}{*}{\multicolumn{2}{|c|}{ CARTÃO A }} & Muito Ruim & Ruim & Regular & Bom & Muito Bom \\
\hline & & 1 & 2 & 3 & 4 & 5 \\
\hline 11.a & $\begin{array}{l}\text { De um modo geral, } \\
\text { nos últimos } 30 \text { dias, } \\
\text { como o(a) Sr.(a) } \\
\text { considera seu estado } \\
\text { de saúde? }\end{array}$ & & & & & \\
\hline \multirow{2}{*}{\multicolumn{2}{|c|}{ CARTÃO B }} & Sempre & $\begin{array}{c}\text { Quase } \\
\text { Sempre }\end{array}$ & Às vezes & Quase Nunca & Nunca \\
\hline & & 1 & 2 & 3 & 4 & 5 \\
\hline 11.b & $\begin{array}{l}\text { Com que freqüência } \\
\text { o(a) Sr.(a) deixa de } \\
\text { realizar qualquer } \\
\text { atividade habitual } \\
\text { (trabalhar, estudar, } \\
\text { lazer), por conta do } \\
\text { tratamento de TB? }\end{array}$ & & & & & \\
\hline
\end{tabular}

OBS: AGORA VAMOS FALAR DE QUANDO O(A) Sr.(A) COMEÇOU A FICAR DOENTE (TOSSE, FEBRE, PERDA DE PESO, FRAQUEZA...)

D. PORTA DE ENTRADA.

\begin{tabular}{|l|l|c|c|c|c|c|}
\hline \multicolumn{2}{|c|}{ CARTÃo C } & Nunca & Quase Nunca & Às vezes & $\begin{array}{c}\text { Quase } \\
\text { Sempre }\end{array}$ & Sempre \\
\cline { 3 - 6 } & 12 & 2 & 3 & 4 & 5 \\
\hline & $\begin{array}{l}\text { Quando o(a) Sr.(a) } \\
\text { precisa de algum } \\
\text { controle de saúde } \\
\text { preventivo (vacinar } \\
\text { BCG, exames de } \\
\text { escarro), vai ao } \\
\text { posto/centro/unidad } \\
\text { e de saúde? }\end{array}$ & & & & & \\
\hline
\end{tabular}


Anexos

\begin{tabular}{|l|l|l|l|c|c|c|}
\hline \multicolumn{2}{|c|}{ CARTÃo C } & Nunca & Quase Nunca & Às vezes & $\begin{array}{c}\text { Quase } \\
\text { Sempre }\end{array}$ & Sempre \\
\cline { 2 - 6 } & 1 & 2 & 3 & 4 & 5 \\
\hline 13 & $\begin{array}{l}\text { Quando o(a) Sr.(a) } \\
\text { começou a ficar } \\
\text { doente de TB foi ao } \\
\text { posto/centro/unidad } \\
\text { e de saúde? }\end{array}$ & $\begin{array}{l}\text { Quando o(a) Sr.(a) } \\
\text { começou a ficar } \\
\text { doente de TB foi ao } \\
\text { pronto } \\
\text { socorro/hospital? }\end{array}$ & $\begin{array}{l} \\
\text { Quando o(a) Sr.(a) } \\
\text { começou a ficar } \\
\text { doente de TB e } \\
\text { precisou de algum } \\
\text { especialista, } \\
\text { consultou antes no } \\
\text { posto/centro/unidad } \\
\text { e de saúde? }\end{array}$ & & & \\
\hline
\end{tabular}

OBS: CONTINUAMOS A FALAR DE QUANDO O(A) Sr.(A) COMEÇOU A FICAR DOENTE (TOSSE, FEBRE, PERDA DE PESO, FRAQUEZA...)

E. ACESSO.

E.1. ACESSO AO DIAGNÓSTICO.

\begin{tabular}{|c|c|c|c|c|c|c|}
\hline \multirow{2}{*}{\multicolumn{2}{|c|}{ 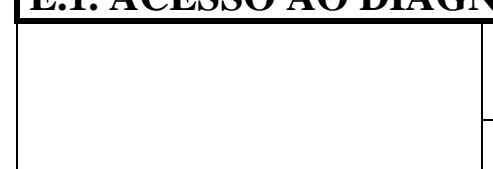 }} & $\begin{array}{c}5 \text { ou mais } \\
\text { vezes }\end{array}$ & 4 vezes & 3 vezes & 2 vezes & $1 \mathrm{vez}$ \\
\hline & & 1 & 2 & 3 & 4 & 5 \\
\hline 16 & \begin{tabular}{|lrr} 
Quando & o(a) & Sr.(a) \\
começou & a & ficar \\
doente, & quantas \\
vezes & precisou \\
procurar & o \\
posto/centro/unidad \\
e de saúde & para \\
conseguir & \\
atendimento? & \\
\end{tabular} & & & & & \\
\hline & CARTÃO B & Sempre & $\begin{array}{l}\text { Quase } \\
\text { Sempre }\end{array}$ & Às vezes & Quase Nunca & Nunca \\
\hline & & 1 & 2 & 3 & 4 & 5 \\
\hline 17 & \begin{tabular}{|lrr} 
Quando o(a) & Sr.(a) \\
começou a & ficar \\
doente, & teve \\
dificuldade para & se \\
deslocar até & o \\
posto/centro/unidad \\
e de saúde?
\end{tabular} & & & & & \\
\hline
\end{tabular}




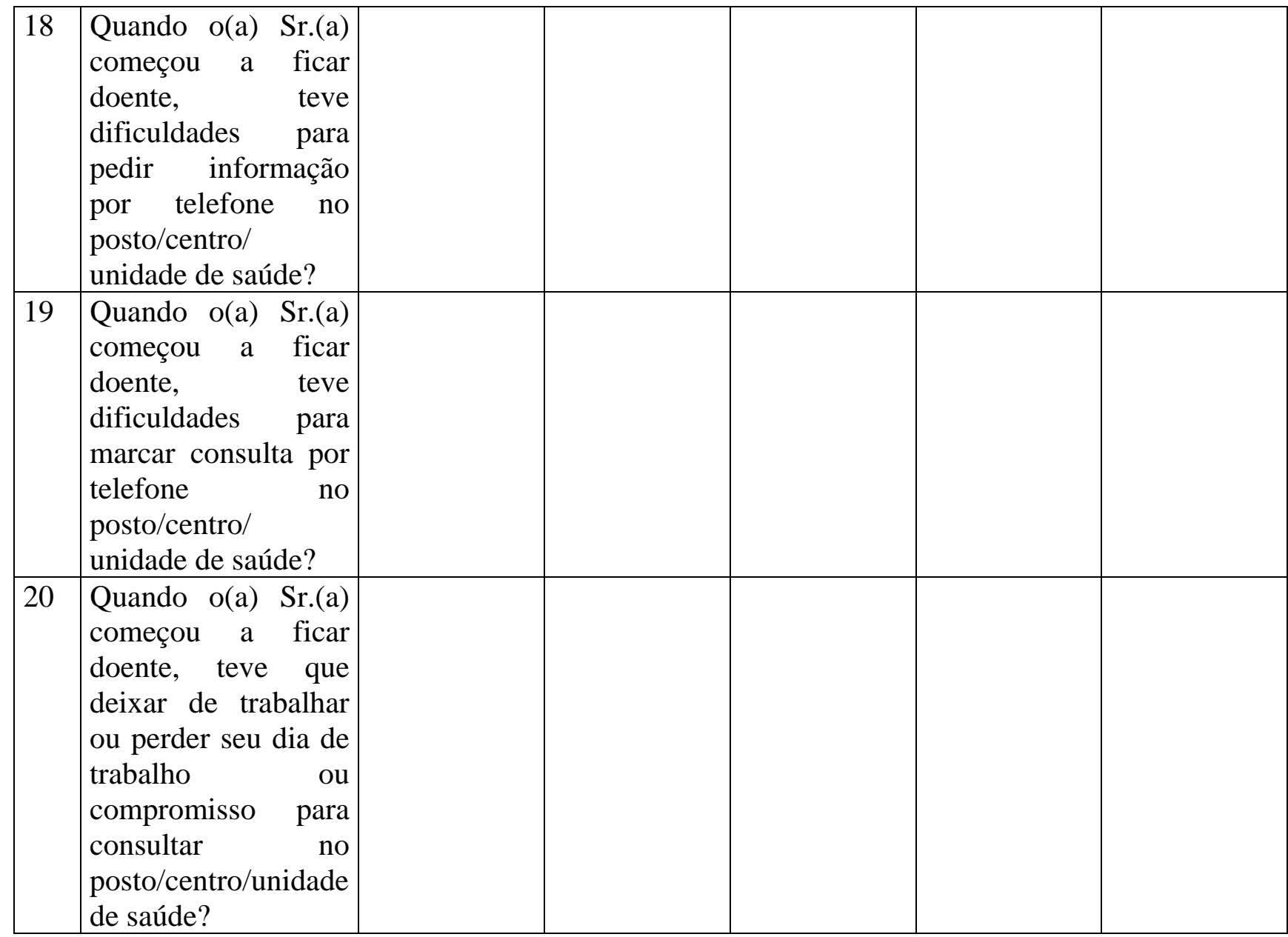

\begin{tabular}{|c|c|c|c|c|c|c|}
\hline \multirow{2}{*}{\multicolumn{2}{|c|}{ CARTÃO B }} & Sempre & $\begin{array}{c}\text { Quase } \\
\text { Sempre }\end{array}$ & Às vezes & Quase Nunca & Nunca \\
\hline & & 1 & 2 & 3 & 4 & 5 \\
\hline 21 & \begin{tabular}{|lrr} 
Quando & o(a) & Sr.(a) \\
começou & a & ficar \\
doente & de & TB, \\
precisou & utilizar \\
algum & tipo & de \\
transporte & & \\
motorizado & para & ir \\
até ao & posto/centro/ \\
unidade de saúde?
\end{tabular} & & & & & \\
\hline 22 & $\begin{array}{lrr}\text { Quando o(a) } & \text { Sr.(a) } \\
\text { começou a } & \text { ficar } \\
\text { doente de } & \text { TB, } \\
\text { gastou dinheiro com } \\
\text { o transporte } & \text { para ir } \\
\text { até } & \text { o } \\
\text { posto/centro/unidade } \\
\text { de saúde? }\end{array}$ & & & & & \\
\hline
\end{tabular}


Anexos

\begin{tabular}{|c|c|c|c|c|c|c|}
\hline \multirow{2}{*}{\multicolumn{2}{|c|}{ CARTÃO C }} & Nunca & Quase Nunca & Às vezes & $\begin{array}{c}\text { Quase } \\
\text { Sempre }\end{array}$ & Sempre \\
\hline & & 1 & 2 & 3 & 4 & 5 \\
\hline 23 & \begin{tabular}{|lrr} 
Quando & o & Sr.(a) \\
começou & a & ficar \\
doente & de & TB \\
conseguiu & consulta \\
no & & \\
posto/centro/unidade \\
de saúde & para \\
descobrir a & doença \\
no prazo & de & 24 \\
horas? & &
\end{tabular} & & & & & \\
\hline 24 & \begin{tabular}{|lrr} 
Quando o(a) & rr.(a) \\
começou a & ficar \\
doente & de & TB, \\
procurou & 0 \\
posto/centro/unidade \\
de saúde mais & perto \\
\multicolumn{2}{l}{ da sua casa? }
\end{tabular} & & & & & \\
\hline
\end{tabular}

\begin{tabular}{|c|c|c|c|c|c|c|}
\hline \multirow{2}{*}{\multicolumn{7}{|c|}{\begin{tabular}{|l} 
OBS: AGORA VAMOS FALAR DO \\
TRATA A TB \\
E 2. ACESSO AO TRATAMENTO. \\
\end{tabular}}} \\
\hline & & & & & & \\
\hline \multirow{2}{*}{\multicolumn{2}{|c|}{ CARTÃO C }} & Nunca & Quase Nunca & Às vezes & $\begin{array}{l}\text { Quase } \\
\text { Sempre }\end{array}$ & Sempre \\
\hline & & 1 & 2 & 3 & 4 & 5 \\
\hline \multicolumn{7}{|c|}{\begin{tabular}{|l|l|}
25 & Se o Sr.(a) passar \\
& mal por causa da \\
& medicação ou da \\
& TB, consegue uma \\
& consulta médica no \\
prazo de 24 horas?
\end{tabular}} \\
\hline 26 & $\begin{array}{lr}\text { O rr.(a) } & \text { consegue } \\
\text { pedir informações } \\
\text { por telefone no no } \\
\text { posto/centro/unidade } \\
\text { de saúde? }\end{array}$ & & & & & \\
\hline 27 & \begin{tabular}{|lr|} 
O Sr.(a) r consegue \\
marcar consultas por \\
telefone r no \\
posto/centro/unidade \\
\multicolumn{2}{|c|}{ de saúde? }
\end{tabular} & & & & & \\
\hline
\end{tabular}




\begin{tabular}{|c|c|c|c|c|c|c|}
\hline \multirow{2}{*}{\multicolumn{2}{|c|}{ CARTÃO B }} & Sempre & $\begin{array}{c}\text { Quase } \\
\text { Sempre }\end{array}$ & Às vezes & Quase Nunca & Nunca \\
\hline & & 1 & 2 & 3 & 4 & 5 \\
\hline 28 & $\begin{array}{lr}\text { Quando o(a) } & \text { Sr.(a) } \\
\text { vai } & \text { ao } \\
\text { posto/centro/unidade } \\
\text { de saúde para } \\
\text { consultar r seu } \\
\text { problema de TB, } \\
\text { tem que deixar de } \\
\text { trabalhar ou perder } \\
\text { seu dia de trabalho } \\
\text { ou compromisso? }\end{array}$ & & & & & \\
\hline 29 & $\begin{array}{lrr}\text { Quando o(a) } & \text { Sr.(a) } \\
\text { vai } & \text { ao } \\
\text { posto/centro/unidade } \\
\text { de saúde } & \text { para } \\
\text { consultar } & \text { seu } \\
\text { problema de } & \text { TB } \\
\text { precisa } & \text { utilizar } \\
\text { algum tipo } & \text { de } \\
\text { transporte } & \\
\text { motorizado? } & \end{array}$ & & & & & \\
\hline 30 & $\begin{array}{lr}\text { Quando o(a) } & \text { Sr.(a) } \\
\text { vai } & \text { ao } \\
\text { posto/centro/unidade } \\
\text { de saúde r para } \\
\text { consultar, paga pelo } \\
\text { transporte? }\end{array}$ & & & & & \\
\hline 31 & $\begin{array}{lr}\begin{array}{l}\text { Durante o } \\
\text { tratamento }\end{array} & \text { seu } \\
\text { faltou } \\
\text { medicamentos para } \\
\text { TB? }\end{array}$ & & & & & \\
\hline 32 & $\begin{array}{lr}\text { Quando o(a) } & \text { Sr.(a) } \\
\text { vai } & \text { ao } \\
\text { posto/centro/unidade } \\
\text { de saúder para } \\
\text { consultar, demora } \\
\text { mais de } 60 \text { minutos } \\
\text { para ser atendido? }\end{array}$ & & & & & \\
\hline & CARTÃO C & Nunca & Quase Nunca & Às vezes & $\begin{array}{l}\text { Quase } \\
\text { Sempre }\end{array}$ & Sempre \\
\hline & & 1 & 2 & 3 & 4 & 5 \\
\hline 33 & \begin{tabular}{lr} 
O profissional do & do \\
posto/centro/unidade \\
de saúde que \\
acompanha seu \\
tratamento de $\mathrm{TB}$, \\
costuma visitá-lo em \\
\multicolumn{2}{l}{ sua moradia? }
\end{tabular} & & & & & \\
\hline
\end{tabular}




\begin{tabular}{|l|l|l|l|l|l|}
\hline 34 & $\begin{array}{l}\text { O(A) Sr.(a) faz o } \\
\text { tratamento de TB no } \\
\text { posto/centro/unidade } \\
\text { de saúde mais perto } \\
\text { da sua casa? }\end{array}$ & & & & \\
\hline
\end{tabular}
AGORA VAMOS FALAR SOBRE A FORMA DE COMO O(A) SR.(A) É ATENDIDO
PELOS PROFISSIONAIS DO POSTO/CENTRO/UNIDADE DE SAÚDE.

\section{F. VÍNCULO.}

\begin{tabular}{|c|c|c|c|c|c|c|}
\hline \multirow{2}{*}{\multicolumn{2}{|c|}{ CARTÃO C }} & Nunca & Quase Nunca & Às vezes & $\begin{array}{c}\text { Quase } \\
\text { Sempre }\end{array}$ & Sempre \\
\hline & & 1 & 2 & 3 & 4 & 5 \\
\hline 35 & 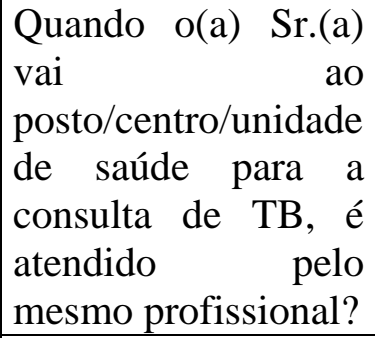 & & & & & \\
\hline 36 & $\begin{array}{l}\text { Se o(a) } \text { Sr.(a) tem } \\
\text { alguma dúvida sobre } \\
\text { o seu tratamento, } \\
\text { consegue falar com } \\
\text { o r mesmo } \\
\text { profissional r do } \\
\text { posto/centro/unidade } \\
\text { de saúde que o } \\
\text { atende? }\end{array}$ & & & & & \\
\hline \multirow{2}{*}{\multicolumn{2}{|c|}{ CARTÃO C }} & Nunca & Quase Nunca & Às vezes & $\begin{array}{l}\text { Quase } \\
\text { Sempre }\end{array}$ & Sempre \\
\hline & & 1 & 2 & 3 & 4 & 5 \\
\hline 37 & $\begin{array}{l}\text { Quando o(a) Sr.(a) } \\
\text { faz alguma pergunta } \\
\text { ao profissional do } \\
\text { posto/centro/unidade } \\
\text { de saúde sente que } \\
\text { ele entende? }\end{array}$ & & & & & \\
\hline 38 & \begin{tabular}{|lrr} 
Quando o(a) & Sr.(a) \\
consulta & o \\
profissional & do \\
posto/centro/unidade \\
de saúde & conversa \\
sobre & outros \\
problemas de saúde?
\end{tabular} & & & & & \\
\hline 39 & $\begin{array}{l}\text { O profissional do } \\
\text { posto/centro/unidade } \\
\text { de saúde dá tempo } \\
\text { suficiente para que } \\
\text { o(a) Sr.(a) fale suas } \\
\text { dúvidas }\end{array}$ & & & & & \\
\hline
\end{tabular}




\begin{tabular}{|c|c|c|c|c|c|c|}
\hline & preocupações? & & & & & \\
\hline 40 & $\begin{array}{l}\text { O profissional do } \\
\text { posto/centro/unidade } \\
\text { de saúde que o(a) } \\
\text { Sr.(a) está fazendo o } \\
\text { tratamento responde } \\
\text { às suas perguntas de } \\
\text { maneira clara? }\end{array}$ & & & & & \\
\hline 41 & \begin{tabular}{|lr} 
Durante & seu \\
atendimento & o \\
profissional ro do & posto/centro/unidade \\
de saúde anota as \\
suas queixas no seu \\
prontuário?
\end{tabular} & & & & & \\
\hline 42 & $\begin{array}{l}\text { O profissional do } \\
\text { posto/centro/unidade } \\
\text { de saúde explica } \\
\text { sobre } \\
\text { medicamentos } \\
\text { utilizados para o } \\
\text { tratamento de TB? }\end{array}$ & & & & & \\
\hline 43 & $\begin{array}{|lr|}\text { O profissional do } \\
\text { posto/centro/unidade } \\
\text { de saúde pergunta } \\
\text { sobre todos res } \\
\text { medicamentos que } \\
\text { o(a) Sr.(a) está } \\
\text { utilizando? }\end{array}$ & & & & & \\
\hline 44 & \multicolumn{6}{|c|}{$\begin{array}{l}\text { Quando o(a) Sr.(a) tem algum problema de saúde ou outras necessidades (cesta básica, vale } \\
\text { transporte...), com que freqüência procura os seguintes profissionais do posto/centro/unidade de } \\
\text { saúde? }\end{array}$} \\
\hline & \multirow[t]{2}{*}{ CARTÃO C } & Nunca & Quase Nunca & Às vezes & $\begin{array}{l}\text { Quase } \\
\text { Sempre }\end{array}$ & Sempre \\
\hline & & 1 & 2 & 3 & 4 & 5 \\
\hline $\begin{array}{l}44 \\
\mathrm{a}\end{array}$ & Médico & & & & & \\
\hline $\begin{array}{l}44 \\
\mathrm{~b}\end{array}$ & Enfermeiro & & & & & \\
\hline $\begin{array}{l}44 \\
c\end{array}$ & \begin{tabular}{|l} 
Auxiliar \\
Enfermagem
\end{tabular} & & & & & \\
\hline $\begin{array}{l}44 \\
d\end{array}$ & $\begin{array}{l}\text { Agente Comunitário } \\
\text { de Saúde/ACS }\end{array}$ & & & & & \\
\hline $\begin{array}{l}44 \\
\mathrm{e}\end{array}$ & Outros Profissionais & & & & & \\
\hline \multirow{2}{*}{\multicolumn{2}{|c|}{ CARTÃO A }} & Muito Ruim & Ruim & Regular & Bom & Muito Bom \\
\hline & & 1 & 2 & 3 & 4 & 5 \\
\hline 45 & $\begin{array}{l}\text { Qual é sua opinião } \\
\text { sobre a equipe de } \\
\text { saúde que o atende? }\end{array}$ & & & & & \\
\hline
\end{tabular}




\section{G. ELENCO DE SERVIÇOS.}

COM QUE FREQÜÊNCIA AS AÇÕES A SEGUIR SÃO OFERECIDAS PELA EQUIPE QUE ACOMPANHA O PROBLEMA DA TB NO POSTO/CENTRO/UNIDADE DE SAÚDE?

\begin{tabular}{|c|c|c|c|c|c|c|}
\hline & CARTÃO C & Nunca & Quase Nunca & Às vezes & $\begin{array}{l}\text { Quase } \\
\text { Sempre }\end{array}$ & Sempre \\
\hline & & 1 & 2 & 3 & 4 & 5 \\
\hline 46 & $\begin{array}{l}\text { Pote para exame de } \\
\text { escarro? }\end{array}$ & & & & & \\
\hline 47 & $\begin{array}{l}\text { Teste da pele (prova } \\
\text { tuberculínica)? }\end{array}$ & & & & & \\
\hline 48 & $\begin{array}{|ll|}\text { Exame } & \text { para } \\
\text { HIV/AIDS? } & \\
\end{array}$ & & & & & \\
\hline 49 & $\begin{array}{l}\text { Pote para exame de } \\
\text { escarro } \\
\text { mensalmente para } \\
\text { controle da TB? }\end{array}$ & & & & & \\
\hline 50 & \begin{tabular}{|l} 
Consulta mensal de \\
controle para o \\
tratamento da TB?
\end{tabular} & & & & & \\
\hline 51 & \begin{tabular}{|l|} 
Cestas básicas ou \\
vale alimentação?
\end{tabular} & & & & & \\
\hline 52 & Vale transporte? & & & & & \\
\hline 53 & \begin{tabular}{|lrr} 
Informação & sobre a \\
TB & e & seu \\
tratamento? & \\
\end{tabular} & & & & & \\
\hline 54 & $\begin{array}{|lr|}\text { Educação em saúde } \\
\text { (informação sobre } \\
\text { outros temas de } \\
\text { saúde)? }\end{array}$ & & & & & \\
\hline 55 & \begin{tabular}{|l} 
Visitas domiciliares \\
durante \\
tratamento?
\end{tabular} & & & & & \\
\hline 56 & $\begin{array}{l}\text { Visitas domiciliares } \\
\text { por outros motivos } \\
\text { além da TB? }\end{array}$ & & & & & \\
\hline 57 & \begin{tabular}{|l|} 
Participação em \\
grupos de doentes \\
de TB no posto / \\
centro / unidade de \\
saúde? \\
\end{tabular} & & & & & \\
\hline 58 & $\begin{array}{l}\text { Tratamento } \\
\text { Supervisionado? * }\end{array}$ & & & & & \\
\hline
\end{tabular}

\section{H. COORDENAÇÃO.}

CARTÃO C

\begin{tabular}{|c|c|c|c|c|}
\hline Nunca & Quase Nunca & Às vezes & $\begin{array}{c}\text { Quase } \\
\text { Sempre }\end{array}$ & Sempre \\
\hline 1 & 2 & 3 & 4 & 5 \\
\hline
\end{tabular}




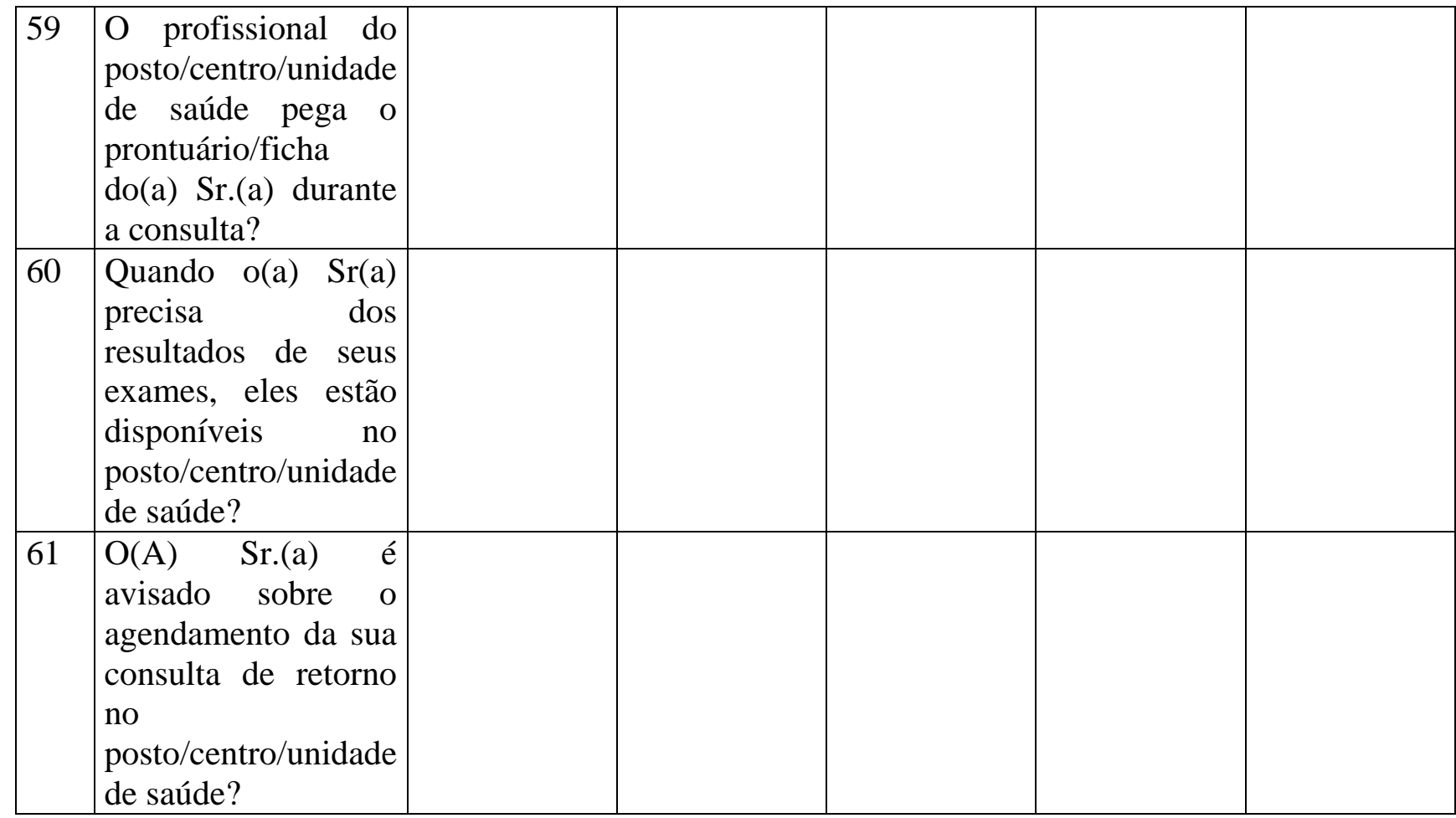

OBS: AGORA VAMOS FALAR SOBRE O ENCAMINHAMENTO DO (A) SR.(A) PARA OUTROS SERVIÇOS DE SAÚDE OU ESPECIALIDADES (serviço social, odontologia, fisioterapia, psicologia, médico especialista)

\begin{tabular}{|c|c|c|c|c|c|c|}
\hline \multirow{2}{*}{\multicolumn{2}{|c|}{ CARTÃO C }} & Nunca & Quase Nunca & Às vezes & $\begin{array}{c}\text { Quase } \\
\text { Sempre }\end{array}$ & Sempre \\
\hline & & 1 & 2 & 3 & 4 & 5 \\
\hline 62 & $\begin{array}{lrr}\text { Quando } & \text { o(a) } & \text { Sr.(a) } \\
\text { precisa } & \text { consultar } \\
\text { com } & & \text { algum } \\
\text { especialista, } & \text { é } \\
\text { encaminhado } & \text { por } \\
\text { um profissional } & \text { do } \\
\text { posto/centro/unidade } \\
\text { de saúde? } & & \end{array}$ & & & & & \\
\hline 63 & \begin{tabular}{|lr} 
Quando & o \\
profissional & do \\
posto/centro/unidade \\
encaminha & o(a) \\
Sr(a) para & outros \\
serviços de & saúde, \\
ele discute ou indica \\
os possíveis lugares \\
de atendimento? \\
\end{tabular} & & & & & \\
\hline 64 & \begin{tabular}{|lr} 
Quando o(a) & Sr.(a) é \\
encaminhado & ao \\
especialista, & o \\
profissional & do \\
posto/centro/unidade \\
de saúde ajuda
\end{tabular} & & & & & \\
\hline
\end{tabular}




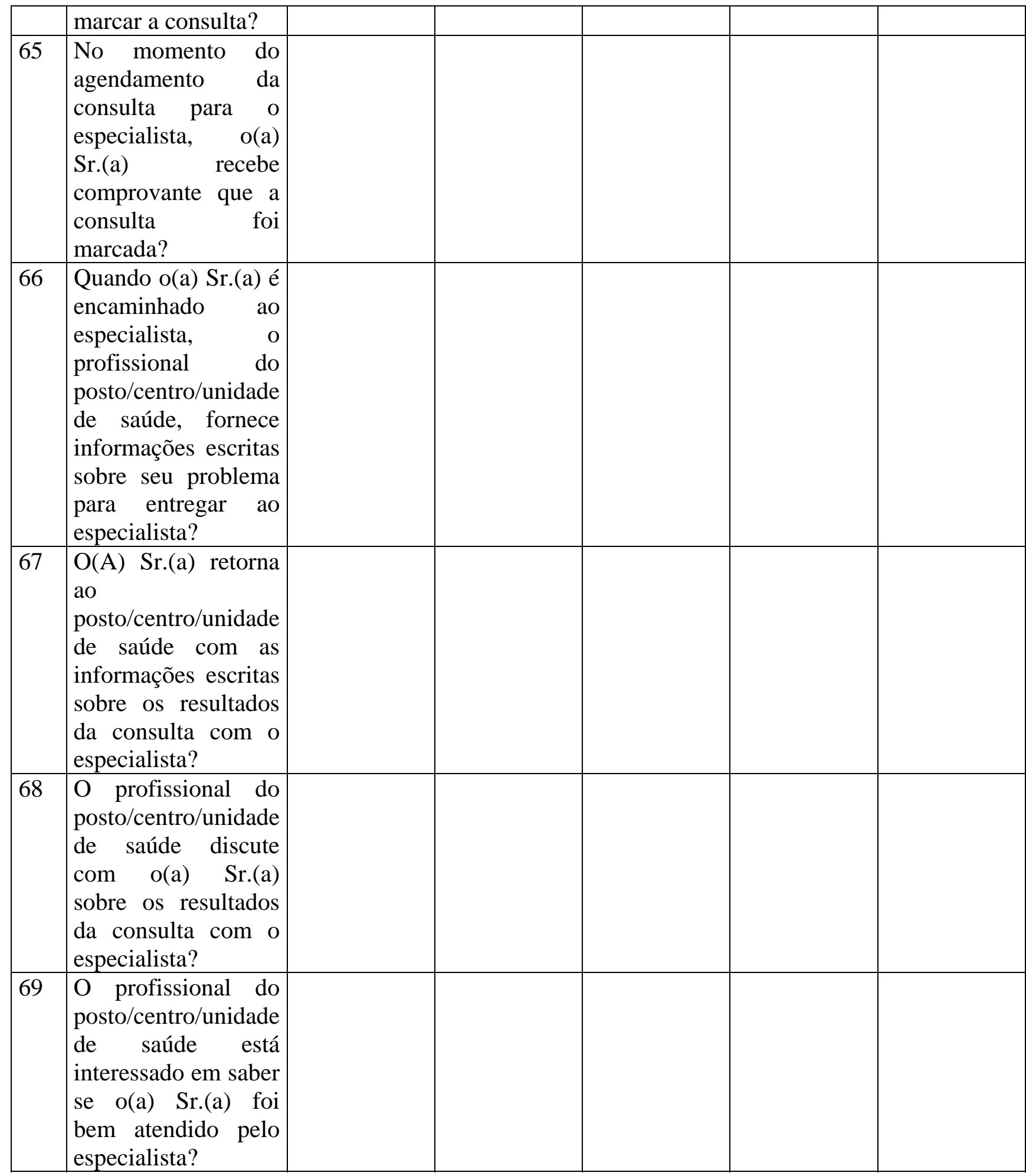

AGORA VAMOS FALAR UM POUCO SOBRE A PARTICIPAÇÃO DA SUA FAMÍLIA DURANTE SEU TRATAMENTO DE TB.

\section{ENFOQUE NA FAMÍLIA.}

CARTÃo C

\begin{tabular}{|c|c|c|c|c|}
\hline Nunca & Quase Nunca & Às vezes & $\begin{array}{c}\text { Quase } \\
\text { Sempre }\end{array}$ & Sempre \\
\hline 1 & 2 & 3 & 4 & 5 \\
\hline
\end{tabular}




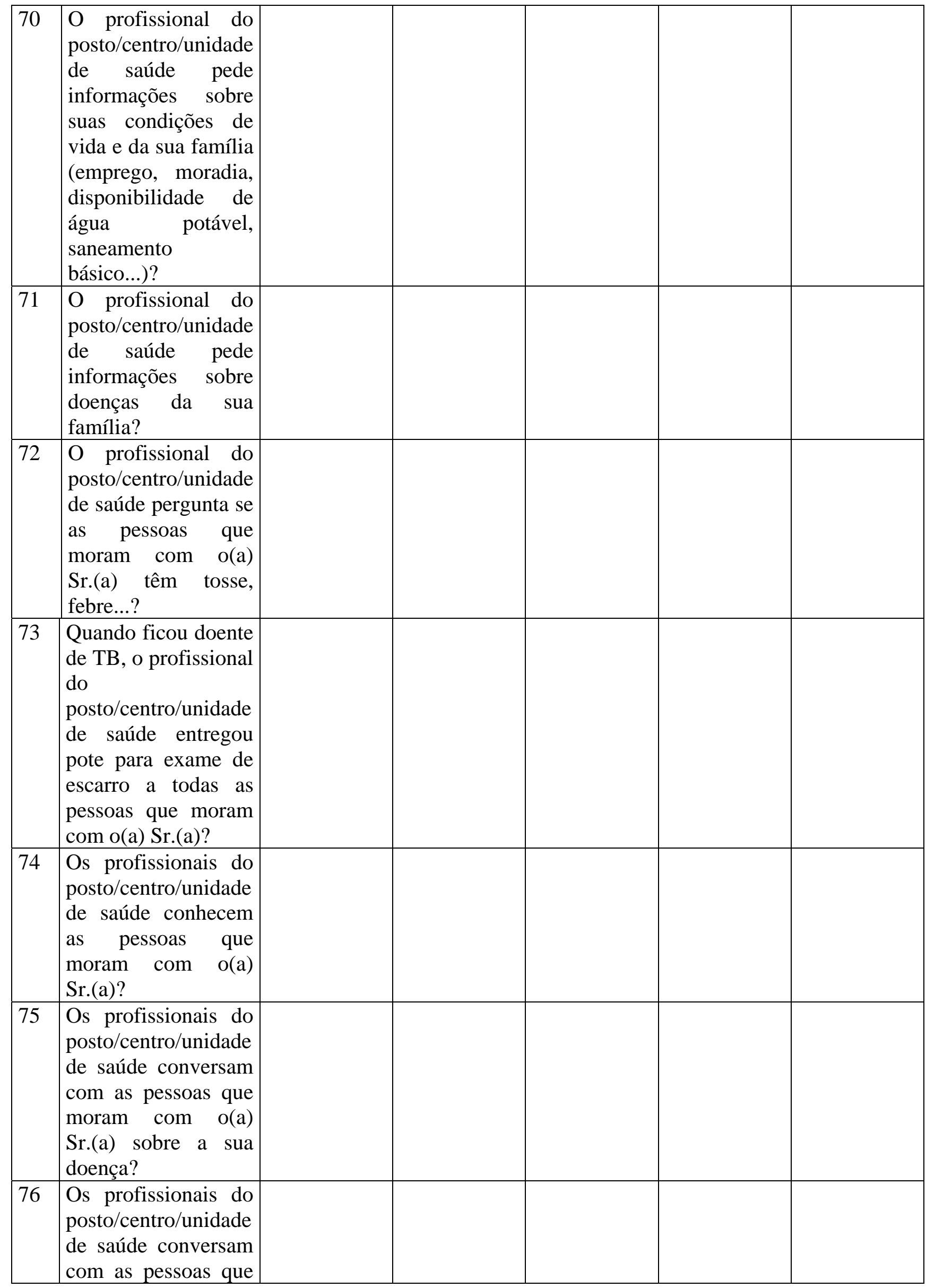




\begin{tabular}{|l|l|l|l|l|l|}
\hline & $\begin{array}{l}\text { moram com o(a) } \\
\text { Sr.(a) sobre seu } \\
\text { tratamento? }\end{array}$ & & & & \\
\hline 77 & $\begin{array}{l}\text { Os profissionais do } \\
\text { posto/centro/unidade } \\
\text { de saúde conversam } \\
\text { com as pessoas que } \\
\text { moram com o(a) } \\
\text { Sr.(a) sobre outros } \\
\text { problemas de sua } \\
\text { saúde? }\end{array}$ & & & & \\
\hline
\end{tabular}

AGORA VAMOS FALAR COM O (A) Sr. (a) SOBRE O TRABALHO DESENVOLVIDO PELOS PROFISSIONAIS DO POSTO/CENTRO/UNIDADE DE SAÚDE NA COMUNIDADE.

\section{J. ORIENTAÇÃO PARA A COMUNIDADE}

\begin{tabular}{|c|c|c|c|c|c|c|}
\hline \multicolumn{2}{|r|}{ CARTÃO C } & Nunca & $\begin{array}{l}\text { Quase } \\
\text { Nunca }\end{array}$ & Às vezes & $\begin{array}{c}\text { Quase } \\
\text { Sempre }\end{array}$ & Sempre \\
\hline 78 & 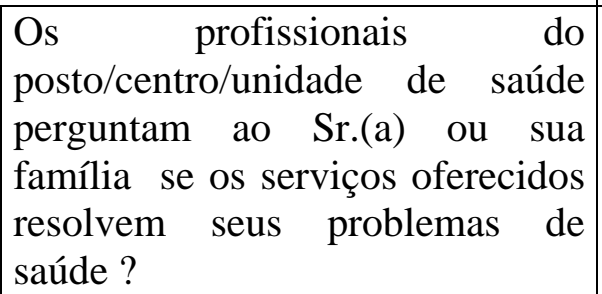 & & & & & \\
\hline 79 & \begin{tabular}{|lrr} 
O(A) & Sr.(a) & observa \\
propagandas/campanhas/trabalhos \\
educativos & realizados & pelos \\
profissionais & & do \\
posto/centro/unidade & de & saúde \\
para informar a comunidade sobre \\
a TB?
\end{tabular} & & & & & \\
\hline 80 & $\begin{array}{l}\text { O(A) Sr.(a) observa que os } \\
\text { profissionais } \\
\text { posto/centro/unidade de saúde } \\
\text { desenvolvem ações de saúde com } \\
\text { as Igrejas, Associações de Bairro, } \\
\text { etc, para entrega do pote para } \\
\text { coleta de escarro? }\end{array}$ & & & & & \\
\hline 81 & $\begin{array}{l}\text { O(A) Sr.(a) observa visitas dos } \\
\text { profissionais do } \\
\text { posto/centro/unidade de saúde na } \\
\text { sua vizinhança, para a entrega do } \\
\text { pote para coleta de escarro? }\end{array}$ & & & & & \\
\hline 82 & $\begin{array}{l}\text { O(A) Sr.(a) observa que os } \\
\text { profissionais } \\
\text { posto/centro/unidade de } \\
\text { solicitam aúde } \\
\text { alguém da comunidade para } \\
\text { discutir o problema da TB? }\end{array}$ & & & & & \\
\hline
\end{tabular}




\begin{tabular}{|c|c|c|c|c|c|c|}
\hline \multicolumn{7}{|c|}{$\begin{array}{l}\text { AGORA VAMOS FALAR UM POUCO SOBRE OUTROS ASSUNTOS RELACIONADOS } \\
\text { AOS PROFISSIONAIS QUE ATENDEM O (A) SR. (A) NO POSTO/CENTRO/UNIDADE DE } \\
\text { SAÚDE. }\end{array}$} \\
\hline \multicolumn{7}{|c|}{ K. FORMAÇÃO PROFISSIONAL } \\
\hline \multirow{2}{*}{\multicolumn{2}{|c|}{ CARTÃO C }} & Nunca & Quase Nunca & Às vezes & $\begin{array}{l}\text { Quase } \\
\text { Sempre }\end{array}$ & Sempre \\
\hline & & 1 & 2 & 3 & 4 & 5 \\
\hline 83 & $\begin{array}{l}\text { O(A) Sr.(a) encontra } \\
\text { um profissional no } \\
\text { posto/centro/unidade } \\
\text { de saúde r para } \\
\text { atende-lo em dias } \\
\text { úteis da semana? }\end{array}$ & & & & & \\
\hline 84 & 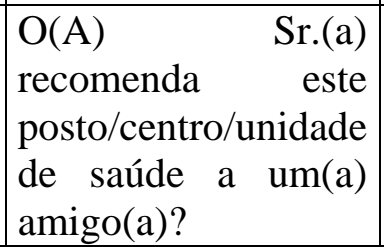 & & & & & \\
\hline 85 & \begin{tabular}{|lr} 
Os profissionais do \\
posto/centro/unidade \\
de saúde conseguem \\
resolver r reus \\
problemas de saúde?
\end{tabular} & & & & & \\
\hline 86 & 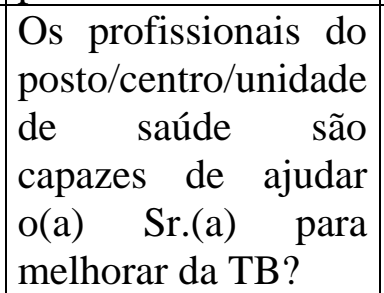 & & & & & \\
\hline
\end{tabular}

\begin{tabular}{|c|c|c|c|c|c|c|}
\hline \multirow{2}{*}{\multicolumn{2}{|c|}{ CARTÃO C }} & Nunca & Quase Nunca & Às vezes & $\begin{array}{c}\text { Quase } \\
\text { Sempre }\end{array}$ & Sempre \\
\hline & & 1 & 2 & 3 & 4 & 5 \\
\hline 87 & $\begin{array}{l}\text { Os profissionais do } \\
\text { posto/centro/unidade } \\
\text { de saúde } \\
\text { relacionam-se bem } \\
\text { com as pessoas da } \\
\text { comunidade? }\end{array}$ & & & & & \\
\hline \multirow{2}{*}{\multicolumn{2}{|c|}{ CARTÃO B }} & Sempre & $\begin{array}{c}\text { Quase } \\
\text { Sempre }\end{array}$ & Às Vezes & Quase Nunca & Nunca \\
\hline & & 1 & 2 & 3 & 4 & 5 \\
\hline 88 & $\begin{array}{lr}\text { O(A) } & \text { Sr.(a) já se } \\
\text { sentiu } & \text { rejeitado } \\
\text { pelos } & \text { profissionais } \\
\text { do } & \\
\text { posto/centro/unidade } \\
\text { de saúde por ter TB? }\end{array}$ & & & & & \\
\hline
\end{tabular}




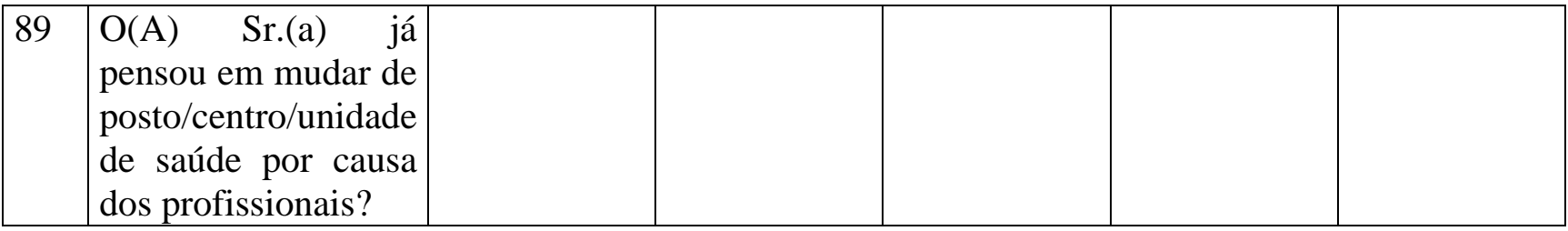

O(A) Sr.(a) tem alguma pergunta, sugestão, comentário ou dúvida?

Observações do entrevistador. 


\section{ANEXO II: COMITÊ DE ÉTICA}
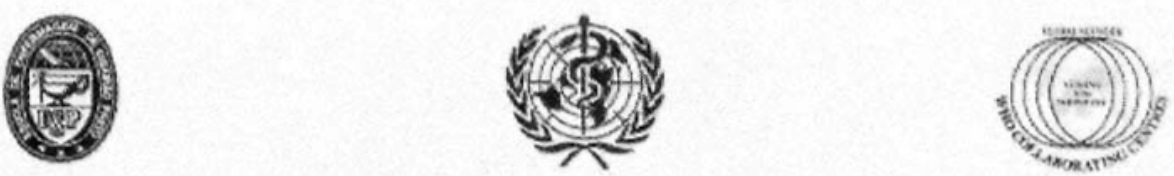

ESCOLA DE ENFERMAGEM DE RIBEIRÃO PRETO - UNIVERSIDADE DE SÃO PAULO CENTRO COLABORADOR DA ORGANIZAÇĀO MUNDIAL DA SAÚDE PARA O DESENVOLVIMENTO DA PESQUISA EM ENFERMAGEM

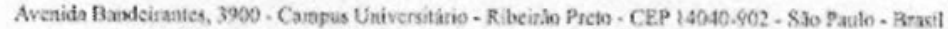
FAX: (55) - 16-3633-3271/3602-4419; TEL,EFONE, (55) - 16-3602-3352

\section{COMITÉ DE ÉTICA EM PESQUISA DA EERPIUSP}

Of CEP-EERPIUSP - 054/2007

Ribeirâo Preto, 22 de março de 2007

Prezada Senhora,

Comunicamos que o projeto de pesquisa, abaixo especificado, foi analisado e considerado APROVADO, pelo Comitê de Ética em Pesquisa da Escola de Enfermagem de Ribeiråo Preto da Universidade de Sáo Paulo, em sua $93^{*}$ Reuniâo Ordinária, realizada em 21 de março de 2007.

Protocolo: $n^{\circ} 0762 / 2007$

Projeto: AVALIACCAOO DAS DIMENSOES ORGANIZACIONAIS E DE DESEMPENHO DOS SERVICOOS DE ATENCCAOO BASICA NO CONTROLE DA TB EM CENTROS URBANOS DE DIFERENTES REGIOES DO BRASIL.

Pesquisador: Tereza Cristina Scatena Villa

Em atendimento à Resoluçāo 196/96, deverá ser encaminhado ao CEP o relatório final da pesquisa e a publicaçáo de seus resultados, para acompanhamento, bem como comunicada qualquer intercorrência ou a sua interrupção.

Atenciosamente.

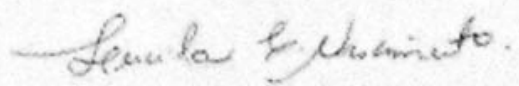

Profa Dra Lucila Castanheira Nascimento

Coordenadora do CEP.EERPIUSP

IIma. Sra.

Profe Dr Tereza Cristina Scatena Villa

Dept $^{\circ}$ de Enfermagem Materno-Infantil e Saúde Pública

Escola de Enfermagem de Ribeirao Preto - USP 
9. APÊNDICE 


\section{APÊNDICE}

\section{APÊNDICE I: TERMO DE CONSENTIMENTO LIVRE E ESCLARECIDO}

Prezado(a) senhor(a),

Gostaria de convidá-lo (a) para participar de uma pesquisa sobre “Avaliação das dimensões organizacionais e de desempenho dos serviços de atenção básica no controle da tuberculose em centros urbanos de diferentes regiões do Brasil”.

Esta pesquisa está sendo realizada por uma equipe de pesquisadores da instituição: . Ela tem como objetivo avaliar o atendimento

de tuberculose nos serviços de saúde do Estado de São Paulo.

Sua participação consistirá em responder a um questionário, que dura em média 30 minutos, e as informações fornecidas contribuirão com a melhoria dos serviços de saúde na atenção a tuberculose.

$\mathrm{Eu}$, tendo recebido as informações acima e ciente de meus direitos abaixo relacionados, concordo em participar.

A garantia de receber todos os esclarecimentos sobre as perguntas do questionário antes e durante a entrevista, podendo afastar-me em qualquer momento se assim o desejar, vem como esta me assegurado o segredo das informações por mim reveladas;

A segurança de que não serei identificado, assim como está assegurado que a pesquisa não trará prejuízo Amim e a outras pessoas;

A segurança de que não terei nenhuma despesa financeira durante o desenvolvimento da pesquisa,

A garantia de que todas as informações por mim fornecidas serão utilizadas apenas na construção da pesquisa e ficará sob a guarda dos pesquisadores, podendo ser requisitada por mim a todo o momento.

Uma cópia desta declaração deve ficar com o (a) Sr . (a).

$$
\text { Ribeirão Preto, }
$$
, de de 2009

\section{Assinatura do entrevistado}

Telefone:

Certo de estar contribuindo com o conhecimento em Tuberculose para a melhoria da saúde da população contamos com a sua preciosa colaboração.

Atenciosamente

$$
\text { Prof }^{\mathrm{a}} \mathrm{Dr}^{\mathrm{a}} \text { Tereza Cristina Scatena Villa }
$$

CONTATO: Escola de Enfermagem de Ribeirão Preto da Universidade de São Paulo. Endereço: Avenida Bandeirantes, 3900 Campus Universitário - Ribeirão Preto - SP; CEP 14049-900 - SP , Telefone (0XX16)36023228, e.mail: tite@eerp.usp.br 